\title{
THE HISTORY AND BIOLOGICAL BASIS OF OCCUPATIONAL EXPOSURE LIMITS FOR CHEMICAL AGENTS
}

Dennis J. Paustenbach, Ph.D., CIH, DABT, Dallas M. Cowan, Ph.D., AND JENNIFER SAHMEL, CIH

\section{HISTORY}

Over the past 60 years, many organizations in numerous countries have proposed occupational exposure limits (OELs) for airborne contaminants (1). The limits or guidelines that have been the most widely accepted both in the United States and in most other countries are those issued annually by the American Conference of Governmental Industrial Hygienists (ACGIH) and are termed Threshold Limit Values $^{\circledR}$ (TLVs) (1-10).

The usefulness of establishing OELs for potentially harmful agents in the working environment has been demonstrated repeatedly since their inception $(3,5,6)$. It has been claimed that whenever these limits have been implemented in a particular industry, no worker has been shown to have sustained serious adverse effects on his health as a result of exposure to these concentrations of an industrial chemical (7). Although this statement is arguable with respect to the acceptability of OELs for those chemicals established before 1980, and later found to be carcinogenic, there is little doubt that millions of persons have avoided serious effects of workplace exposure due to their existence.

Patty's Industrial Hygiene, Sixth Edition, Edited by Vernon E. Rose and Barbara Cohrssen Copyright (C) 2011 John Wiley \& Sons, Inc. 
It was, of course, well understood as long ago as the fifteenth century, that airborne dusts and chemicals could bring about illness and injury, but the concentrations and durations of exposure at which this might be expected to occur were unclear (8). Between 1700 and 1920, the lack of chemical sampling and analytical methods did not allow for much progress regarding how to quantitatively evaluate the workplace environment. Even after these methods were developed, and even after various guidelines were developed by various regulatory agencies in the United States, they were often not observed $(2,3,7,9,10)$.

As noted by Anna Baetjer, one of the pioneers of occupational health (11), “. . .early in this century when Dr. Alice Hamilton began her distinguished career in occupational medicine, no air samples and no standards were available to her, nor indeed were they necessary. Simple observation of the working conditions and the illness and deaths of the workers readily proved that harmful exposures existed. Soon, however, the need for determining standards for safe exposure became obvious." Interestingly, the work of Alice Hamilton continues to be a source of valuable information (12).

Cook has reported that the earliest efforts to set an OEL were directed at carbon monoxide (CO), the toxic gas to which more persons are occupationally exposed than any other. Interestingly, the work of Max Gruber at the Hygienic Institute of Munich related to $\mathrm{CO}$ was published in 1883. The paper described exposing two hens and 12 rabbits to known concentrations of carbon monoxide up to $47 \mathrm{~h}$ over 3 days, he stated that "the boundary of injurious action of carbon monoxide lies at a concentration on all probability of 500 parts per million, but certainly (not less than) 200 parts per million." In spite of this conclusion, however, he reported no symptoms or uncomfortable sensations after $3 \mathrm{~h}$ on each of two consecutive days at concentrations of $210 \mathrm{ppm}$ and $240 \mathrm{ppm}$ (3).

According to Cook, the earliest and most extensive series of animal experiments to understand exposure limits were those conducted by K.B. Lehmann and others under his direction at the same Hygienic Institute where Gruber had done his work with carbon monoxide. The first publication in the series, entitled Experimental Studies on the Effect of Technically and Hygienically Important Gases and Vapors on the Organism, was a report on ammonia and hydrogen chloride gas that was 126 pages in length within Volume 5 of Archiv für Hygiene (13). This series of reports on animal experimentation with a large number of chemical substances by Lehmann and associates continued through Part 35 in Volume 83 (1914), followed by a final comprehensive paper of 137 pages on chlorinated hydrocarbons in Ref. 14. These reprints became the standard against which others would be compared for nearly 30 years.

Kobert (15) published one of the earlier tables of acute exposure limits. Concentrations for 20 substances were listed under the headings: (1) Rapidly fatal to man and animals, (2) Dangerous in $0.51 \mathrm{~h}$, (3) $0.51 \mathrm{~h}$ without serious disturbances, and (4) Only minimal symptoms observed (3). In his paper on Interpretations of Permissible Limits, Schrenk (16) notes that the "values for hydrochloric acid, hydrogen cyanide, ammonia, chlorine and bromine as given under the heading "only minimal symptoms after several hours' in the foregoing Kobert paper agree with values as usually accepted in present-day tables of MACs for reported exposures." 
However, values for some of the more toxic organic solvents, such as benzene, carbon tetrachloride and carbon disulfide, far exceeded those currently in use (3).

One of the first tables of exposure limits to originate in the United States was that published by the U.S. Bureau of Mines (17). Although its title does not reflect the content, the 33 substances listed are those encountered in workplaces. Cook (3) also noted that most of the exposure limits through the 1930s, except for dusts, were based on rather short animal experimentation. A notable exception was the study of chronic benzene exposure by Greenburg of the U.S. Public Health Service conducted under the direction of a committee of the National Safety Council (18). From this, an OEL was derived based on long-term animal experimentation.

According to Cook (3) for dust exposures, permissible limits established before 1920 were based on exposures of workers in the South African gold mines where the dust from drilling operations was high in crystalline free silica. The effects of the dust exposure were followed by periodic chest X-ray examination and the dust concentrations were monitored with an instrument known as a konimeter that collected a nearly instantaneous sample. In 1916, based on a correlation of these two sets of findings, an exposure limit of 8.5 million particles per cubic foot of air (mppcf) for the dust with an 80-90\% quartz content was set (19). Later, the level was lowered to 5 mppcf. Cook (3) also reported that, in the United States, standards for dust, also based on exposure of workers, were recommended by Higgins et al. following a study at the southwestern Missouri zinc and lead mines in 1917. The initial level established for high quartz dusts was 10 mppcf, appreciably higher than was established by later dust studies conducted by the U.S. Public Health Service (USPHS).

The most comprehensive list of OELs up to 1926 was that for 27 substances published in Volume 2 of International Critical Tables (20). Sayers and Dalle Valle (21) published a table giving physiological response to 5 different concentrations of 37 substances. The first four refer to acute effects but the fifth is for the maximum allowable concentration (MAC) for prolonged exposure. In 1930, the USSR Ministry of Labor issued a decree that included the first actual approval of workplace maximum allowable concentrations for the former USSR with a list of 12 industrial toxic substances. About this time, Lehmann and Flury (22) and Bowditch et al. (23) published papers that presented tables with a single value for repeated exposures to each substance.

As noted by Cook (3), many of the exposure limits developed by Lehmann were included in the Henderson and Haggard monograph (24) initially published in 1927 and a little later in (25). According to Cook (3), this book acted as the bible on effects of injurious gases, vapors and dusts in industrial exposures until Volume II of Patty's Industrial Hygiene and Toxicology was published in 1949 (228).

Baetjer (11) has reported that the first list of standards for chemical exposures in industry in the United States were called MAC and these were prepared in 1939 and 1940. They represented a consensus opinion of the American Standards Association (ASA) and a number of industrial hygienists who had formed the ACGIH in 1938. These "suggested standards" were published in 1943 by James Sterner (3).

A committee of the ACGIH met in early 1940 to begin the task of identifying safe levels of exposure to workplace chemicals. They first assembled all the data they could 
locate that would relate the degree of exposure to a toxicant to the likelihood of producing an adverse effect $(2,3)$. This task, as might be expected, was a formidable one. After much painstaking research and labor intensive documentation, the first values issued by the ACGIH were released in 1941 by this committee, which was composed of Warren Cook, Manfred Boditch (reportedly America's first hygienist employed by industry), William Fredrick, Philip Drinker, Lawrence Fairhall, and Alan Dooley $(6,9)$.

In 1941, a committee, designated as Z-37, of the American National Standards Institute (ANSI), then known as the ASA, developed its first Standard-carbon monoxide, with an acceptable concentration of 100 parts per million (ppm). The committee issued separate bulletins through 1974 including exposure standards for 33 toxic dusts and gases.

At the Fifth Annual Meeting of the ACGIH in 1942, the newly appointed Subcommittee on Threshold Limits presented in its report a table of 63 toxic substances with the "maximum allowable concentrations of atmospheric contaminants" from lists furnished by the various state industrial hygiene units. The report contains the statement, "The table is not to be construed as recommended safe concentrations. The material is presented without comment" (3).

In 1945, a list of 132 industrial atmospheric contaminants with MACs was published by Cook. This is considered a landmark publication since it was thorough, included references on the original investigations, and provided the rationale leading to the values. The table included the then current values for the six states-California, Connecticut, Massachusetts, New York, Oregon, and Utah-values presented as a guide for occupational disease control by the U.S. Public Health Service, and 11 other standards. In addition, Cook included a list of MACs that appeared best supported by the references to original investigations (3).

At the 1946 Eighth Annual Meeting of ACGIH, the Subcommittee on Threshold Limits presented their second report with the values of 131 gases, vapors, dusts, fumes, mists, and 13 mineral dusts. As stated in the report, the values were "compiled from the list reported by the subcommittee in 1942, from the list published by Warren Cook in Industrial Medicine (9), and from published values of the Z-37 Committee of the American National Standards Association (ANSI)." The committee emphasized that the "list of MAC values is presented ... with the definite understanding that it be subject to annual revision."

The overall impact of these efforts to develop quantitative limits to protect humans from the adverse effects of workplace air contaminants and physical agents could not have been anticipated by the early TLV committees. To their credit, even though toxicology was then only a fledgling science, their approach to setting limits has generally been shown to be yield reasonable and generally protective guidelines even by today's standards. For this reason, most of the techniques for setting limits established by this committee are still in use today $(1,2,5,6,9,10,26-28)$. The principles they used to set OELs were similar to those originally used to identify safe doses of food additives and pharmaceuticals (29).

From the perspective of the hygienist, engineer, and businessperson, there have been a multitude of benefits associated with the setting of OELs. The establishment 
of limits, by their very nature, implies that at some concentration or dose, exposure to a toxicant can be expected to be safe and pose no significant risk of harm to exposed persons. In the European Union (EU), the term "tolerable or acceptable dose" is sometimes used to describe what has been termed insignificant risk in the United States. The key to the success of limits has not been only that they were established on solid scientific principles; rather, the setting of any goal gives a sense of purpose and direction to industrial, occupational, or medical programs that, prior to the TLVs, had been difficult to evaluate.

The setting of a goals, vis a vis, maintain workplace concentrations below an OEL, establishes an objective that can then be mutually pursued by the occupational health team, engineers, and management. History has shown that by introducing the concept of "safe level of exposure" and by establishing a type of "management by objectives," occupational health professionals will establish and pursue a systematic program for reducing exposure (30). Indeed, it has been shown in many studies that airborne concentration in major corporations in the United States were usually lowered to mirror the anticipated changes in either the ACGIH TLVs or the OSHA Permissible Exposure Limits (PELs) $(222,223,240)$.

\subsection{Intended Use of OELs}

The ACGIH TLVs and most other OELs used in the United States, as well as most other countries, are limits that refer to airborne concentrations of substances and represent conditions under which "it is believed that nearly all workers may be repeatedly exposed day-after-day without adverse health effects." (ACGIH, 2009). In some countries, which will be discussed later, the OEL is set at a concentration that attempts to protect virtually everyone. It is important to recognize that unlike some exposure limits for ambient air pollutants, contaminated water, or food additives set by other professional groups or regulatory agencies, exposure to the TLV will not necessarily prevent discomfort or injury for everyone who is exposed $(1,31)$.

The ACGIH recognized long ago that because of the wide range in individual susceptibility, a small percentage of workers may experience discomfort from some substances at concentrations at or below the threshold limit and that a smaller percentage may be affected more seriously by aggravation of a preexisting condition or by development of an occupational illness (32). This is clearly stated in the introduction to the ACGIH's annual booklet "Threshold Limit Values for Chemical Substances and Physical Agents and Biological Exposure Indices" (4), as it has stated for at least 50 years.

This limitation, although perhaps less than ideal, has been considered a practical one since airborne concentrations so low as to protect highly susceptible persons have traditionally been judged infeasible due to either engineering or economic limitations. This shortcoming in the TLVs has, until about 1990, not been considered a serious one. However, in light of the dramatic improvements of the past 20 years in our analytical capabilities, personal monitoring/sampling devices, biological monitoring techniques, and the use of robots as a plausible engineering control, we are now technologically able to consider more stringent OELs. Indeed, as recently as 2009, 
there has been a continuing dialogue about whether OELs should be set independent of economic or engineering feasibility.

The background information and rationale for each of the ACGIH TLVs are published periodically in the Documentation of the Threshold Limit Values (34). Some type of documentation is usually available for OELs set in other countries; such as the MAKs in Germany and the guidelines of the HSE in the United Kingdom. The rationale or documentation for a particular OEL, as well as the specific data considered in establishing it, should always be consulted before interpreting or adjusting an exposure limit (35).

TLVs, like OELs used in most other countries, are intended to be based on the best available information from industrial experience, experimental human and animal studies and, when possible, a combination of the three (33). The rationale for each of the values differs from substance to substance. For example, protection against impairment of health may be a guiding factor for some, whereas reasonable freedom from irritation, narcosis, nuisance or other forms of stress may form the basis for others. The age and completeness of the information available for establishing most OELs varies from substance to substance; therefore, it is wise to compare the various OELs set by different organizations and the date when they were set. The most recent TLV and its documentation should always be consulted in order to evaluate the quality of the data upon which that value was set.

Even though all of the publications that contain OELs emphasize that they were intended for use only in establishing safe levels of exposure for persons in the workplace, they have been used at times to establish acceptable levels of exposure in other situations. It is for this reason that all exposure limits should be interpreted and applied only by someone knowledgeable of industrial hygiene and toxicology. The TLV Committee did not intend that they be used, or modified for use

1. in the evaluation or control of community air pollution nuisances;

2. estimating the toxic potential of continuous, uninterrupted exposures or other extended work periods;

3. as proof or disproof of an existing disease or physical condition; and

4. by countries whose working conditions or cultures differ from those of the United States and where substances and processes differ.

It is noteworthy to remember that the ACGIH TLV Committee has repeatedly stated in the introduction to the TLV booklet that "these limits are not fine lines between safe and dangerous contaminations" (4). In short, without knowing the toxic endpoint to be avoided, they cannot be used as relative indices of toxicity.

The TLV Committee and other groups that set OELs warn that these values should not be "directly used" or extrapolated to predict safe levels of exposure for other exposure settings. However, if one understands the scientific rationale for the guideline and the appropriate approaches for extrapolating data, considers the pharmacokinetics and mechanism of action of the chemical, they can be adjusted to identify acceptable 
levels of exposure for many different kinds of exposure scenarios and work schedules $(35,224)$.

The reason that the ACGIH has stated that the TLVs should not be used for other purposes and that they should be used only by professionals trained in the field is because of the history of misuse. For example, there are dozens of examples where lawyers, physicians, and others have erroneously concluded that if a worker was exposed above a TLV concentration then the person was at "real" danger, or worse, that they may have been harmed. Often, such interpretations were self-serving and persons were adversely affected by such unfounded opinions. In addition, the TLVs have often been inappropriately used by regulatory agencies as a basis for establishing "temporary standards" for everything from ambient air guidelines to emergency evacuation criteria. Often, the group issuing the draft criteria knew that this was not a proper use of the TLVs but such action was considered justifiable because it was "science forcing." That is, it made professionals in the regulated community go about the task of doing the more detailed work necessary to develop proper standards since the regulatory agency was simply understaffed to handle such a large task.

Because no one has been able to anticipate all of the various ways these values could be misused, the ACGIH decided to issue a "blanket disclaimer" many years ago. The Documentation of the TLVs (34) provides a good deal of important information to the health scientist and, from this, a professional should be able to derive other criteria if all of the appropriate factors are considered.

\subsection{Philosophical Underpinnings of TLVs and Other OELs}

TLVs were originally intended for the use of industrial hygienists who could exercise their own judgment in their application. They were not to be used for legal or enforcement purposes (11). However, in 1968 the Walsh-Healey Public Contract Act incorporated the 1968 TLV list, which covered about 400 chemicals. In the United States, when the Occupational Safety and Health Administration (OSHA) was formed, Congress allowed OSHA, for a period of two years, to adopt national consensus standards or established federal standards.

Exposure limits for workplace air contaminants are based on the premise that, although all chemical substances are toxic at some concentration when experienced for a period of time, a concentration (e.g., dose) does exist for all substances at which no injurious effect should result no matter how often the exposure is repeated. This premise applies to substances whose effects are limited to irritation, narcosis, nuisance, or other forms of stress $(5,7)$.

This philosophy thus differs from that applied to physical agents such as ionizing radiation, and for some chemical carcinogens, specifically, the clearly genotoxic carcinogens, since it is possible that there may be no threshold clear dose at which zero increased risk would be expected $(7,36)$. Even though many would say that this position is too conservative in light of our current understanding of the mechanisms for developing cancer, there are some data for some highly genotoxic chemicals that support this theory (37). On the other hand, a large number of toxicologists who believe that a threshold dose exists for those chemicals that are carcinogenic in animals but that 
act through a nongenotoxic (sometimes called epigenetic) mechanism (38-40). Generally, in toxicology, it is believed that a practical threshold exists for even genotoxic chemicals, although they agree that the threshold dose for these chemicals (like BCME or NDMA) may be at an extremely low dose (41-44).

With this in mind, some OELs for carcinogens proposed by regulatory agencies in the early 1980s were set at levels that, although not completely without risk, posed risks no greater than classic occupational hazards such as electrocution, falls, etc. (about one in one thousand) (45). Although a clear description of this risk level or the rationale for the criteria has rarely been presented or discussed, it is now apparent that it was used, in part, to justify the various OSHA PELs for carcinogens set over the past 20 years $(45-48)$.

\subsection{Occupational Exposure Limits in the United States}

A comprehensive listing of the various OELs used throughout the world can be found in one of three references. One is the Occupational Exposure Limits For Airborne Toxic Substances, 4th Edition, published by International Labour Office of the World Health Organization (27), another is Occupational Exposure Limits-Worldwide published by the American Industrial Hygiene Association (AIHA) (3) and recently, global occupational exposure limit for 6,000 specific chemicals (229).

The philosophical underpinnings for the various OELs vary between the organizations and countries that develop them $(3,49-51)$. For example, in the United States at least six groups recommend exposure limits for the workplace. These include the ACGIH TLVs, the Recommended Exposure Limits (RELs) suggested by the National Institute for Occupational Safety and Health (NIOSH) of the U.S. Department of Health and Human Services, the Workplace Environment Exposure Limits (WEEL) developed by the American Industrial Hygiene Association standards for workplace air contaminants suggested by the Z-37 Committee of ANSI, the proposed workplace guides of the American Public Health Association (52) and lastly, recommendations that have been made by local, state or regional government. In addition to these recommendations or guidelines, PELs, which are regulations that must be met in the workplace in the United States because they are law, have been promulgated by the Department of Labor and are enforced by OSHA (53).

$\mathrm{n}$ addition to the OELs established by professional societies and regulatory bodies, guidance has also been provided by many corporations who handle or manufacture specific chemicals $(1,54)$. For example, beginning in the 1960s, Dow Chemical, DuPont, Celanese, Kodak, Union Carbide, and some other large firms began to establish internal OELs intended to protect their workers, as well as their customers who purchased the chemicals. Later, due to the fact that only their workers would be exposed to the chemicals that they manufactured (without a prescription), the pharmaceutical industry began to set limits for some of their intermediate and final products (55). Workers in the drug industry needed these guidelines because the doses to which they could be exposed each day had the potential to be several fold greater than the therapeutic dose. Over the years, perhaps more than 40 firms in the United States set internal OELS. 
Outside the United States, as many as 50 other countries or groups of countries have established OELs (1, 3, 6, 49, 51, 229). Historically, many, if not most, of these limits are nearly or exactly the same as the ACGIH TLVs developed in the United States $(1,3$, $49,56,57)$. Since about 1995, the limits set by countries in the European Union (EU) have diverged from those set by the $\operatorname{ACGIH}(50,167)$. In some cases, such as in the East European countries, including former Soviet bloc countries, and in Japan, the limits can be dramatically different than those used in the United States and the European Union. Differences among various limits recommended by other countries can be due to a number of factors:

1. Difference in the philosophical objective of the limit and the untoward effects they are meant to minimize or eliminate.

2. Difference in the predominant age and sex of the workers.

3. The duration of the average workweek.

4. The economic state of affairs in that country.

5. A lack of enforcement (therefore the OEL serves only as a guide).

For example, limits established in what is now Russia were often based on a premise that they will protect "everyone rather than nearly everyone, from any (rather than most) toxic or undesirable effects of exposure" (2, 6, 49, 51, 56, 58, 59).

For about the past 15 years, the ACGIH has worked closely with the European community (in particular, the German MAK Committee) in an attempt to harmonize the various approaches used to set OELs. For example, in 1997 a joint meeting between the TLV and the MAK committees was held in Germany to move this initiative forward. The meeting went well and differences of opinion were shared freely. Due to a number of differences in their views of various scientific and social considerations, it is unlikely that a single method for dealing with each category of adverse effects will be adopted in the foreseeable future by these two organizations. In recent years, there has been an annual joint meeting of these two groups to promote a more frequent dialogue (60).

\section{APPROACHES USED TO SET OEL}

OELs established both in the United States and elsewhere are based on data from a wide number of studies and sources. As shown in Table 20.1, the 1968 TLVs (those adopted by OSHA in 1972 as federal regulations) were based largely on human experience (53). This may come as a surprise to many hygienists who have recently entered the profession since it indicates that, in most cases, the setting of an exposure limit was often after a chemical had been found to produce toxicity, irritation or other undesirable effects on humans. As might be anticipated, many of the more recent exposure limits for systemic toxins, especially those internal limits set by manufacturers, have been based primarily on toxicology tests conducted on animals, which is in contrast with waiting for observations of adverse effects in exposed workers $(54,61)$.

However, even as far back as 1945, animal tests were acknowledged by the TLV Committee to be very valuable and they do, in fact, constitute the second most common 
TABLE 20.1 Distribution of Procedures Used to Develop ACGIH TLVs for 414 Substances Through $1968^{a, b}$

\begin{tabular}{lcc}
\hline Procedure & Number & Percent Total \\
\hline Industrial (human) experience & 157 & 38 \\
Human volunteer experiments & 45 & 11 \\
Animal, inhalation—chronic & 83 & 20 \\
Animal, inhalation-acute & 8 & 2 \\
Animal, oral—chronic & 18 & 4.5 \\
Animal, oral-acute & 2 & 0.5 \\
Analogy & 101 & 24 \\
\hline
\end{tabular}

${ }^{a}$ From Ref. 4 .

${ }^{b}$ Exclusive of inert particulates and vapors.

source of information upon which these guidelines have been established even in $2010(62,63)$.

Several approaches for deriving OELs from animal data have been proposed and put into use over the past 40 years. The approach used by the TLV Committee and others is not markedly different from that which has been used by the U.S. Food and Drug Administration (FDA) in establishing acceptable daily intake (ADI) for food additives as far back as the early 1950s $(29,62)$. An understanding of the FDA approach to setting exposure limits for food additives and contaminants can provide insight to industrial hygienists who are involved in interpreting OELs $(1,28,45,64)$.

Discussions of methodological approaches that can be used to establish workplace exposure limits based exclusively on animal data have been presented $((28,62$, $65-68,1)$ ). A review of the general procedures used by groups setting OELs has been published and it warrants evaluation (73). Numerous reviews have been published other in recent years $(76,156,157,162,167)$. The OELs derived from the various approaches will yield different results, and while a particular OEL may also prevent illness or irritation at two to three times the selected OEL; conversely, in some cases, symptoms of overexposure may be seen in a few persons exposed at the recommended OEL.

Most scientists believe that much of the uncertainty in identifying proper OELs could be reduced by the availability of better epidemiological information and through the use of physiologically based pharmacokinetic (PB-PK) models (a much better approach than the traditional qualitative extrapolation of animal test results to humans). These models are discussed in another chapter in this text.

As noted, in 1968, approximately 50\% of the TLVs were derived from the human data, and approximately $30 \%$ were based on animal data. By 2009 , about $50 \%$ of the 800 or so TLVs were still derived primarily from animal data. The criteria used to develop the TLVs have, in the past, been classified into four groups: morphologic, functional, biochemical, and miscellaneous (nuisance, cosmetic) (6). In recent years, these categories have been subdivided according to adverse effect (4).

The rationale upon which most of the historical TLVs have been established is presented in Table 20.2. It is noteworthy that in 1968 only about $50 \%$ of the TLVs were intended primarily to prevent systemic toxic effects. Roughly $40 \%$ were based on 
TABLE 20.2 Distribution of Criteria Used to Develop ACGIH TLVs for 414 Substances Through $1968^{a, b}$

\begin{tabular}{lrrlcc}
\hline Criteria & Number & Percent & Criteria & Number & Percent $^{c}$ \\
\hline $\begin{array}{l}\text { Organ or organ system } \\
\quad\end{array}$ & 201 & 49 & Biochemical changes & 8 & 2 \\
Irritation & 165 & 40 & Fever & 2 & 0.5 \\
Narcosis & 21 & 5 & Visual changes (halo) & 2 & 0.5 \\
Odor & 9 & 2 & Visibility & 2 & 0.5 \\
Organ function changes & 8 & 2 & Taste & 1 & 0.25 \\
Allergic sensitivity & 6 & 1.5 & $\begin{array}{l}\text { Roentgenographic } \\
\text { changes }\end{array}$ & 1 & 0.25 \\
Cancer & 6 & 1.5 & Cosmetic effect & 1 & 0.25 \\
\hline
\end{tabular}

${ }^{a}$ Ref. 6.

${ }^{b}$ Exclusive of inert particulates and vapors.

${ }^{c}$ Number of times a criterion was used of total number of substances examined $\times 100$, rounded to nearest $0.25 \%$. Total percentages exceed 100 because more than one criterion formed the basis of the TLV of some substances.

irritation and about $2 \%$ were intended to prevent cancer. By 2010 , about $50 \%$ of the TLVs were meant to prevent systemic effects, $30 \%$ to prevent irritation, $5 \%$ to prevent cancer, and the remainder to prevent other adverse effects.

In the early years of the modern era of industrial hygiene, that is the post-OSHA era defined here as the, very little information was available to the public regarding the precise methodology by which TLVs, MAKs, and other OELs were derived. To Warren Cook's credit, as eraly as 1946 he wisely shared his rationale for selecting specific values in his documentation for the various limits (9) but it is clear from his writings that no set of uncertainty factors (UFs) or criteria were universally adopted in setting these limits of exposure. Furthermore, over the ensuing 50 years, the TLV Committee never adopted a standard approach and this has been troublesome to critics of the committee. For example, many professionals believed that a fairly generic approach to setting OELs could be applied to the various classes of chemicals. On only a few occasions has a prescribed approach to setting OELs been suggested in a published paper $(67,69,61,71,74,72)$. Most professional believe it is not possible to standardize the methodology.

One reason that neither occupational nor environmental limits can be derived in a "cookbook" manner is because of the relatively "soft" nature of the data upon which these limits are based. For example, no animal bioassay can ever be large enough to conclusively assure us that we can identify a precise dose that will not pose some theoretical risk to some individual, and no human epidemiology study can be so strong as to show that a chemical may not produce some type of adverse effect in some person. Nonetheless, in spite of our inability to prove the absence of risk, there is clear evidence that virtually safe doses for humans can be identified for all substances. The primary question that is difficult to answer with respect to any specific OEL is "What is the margin of safety between what we label as a 'safe' dose and the dose that might have some probability of producing some type of adverse effect in some individual?" $(75,76)$. 
The following sections describe, in a general way, some of the various approaches that could be or have been used to establish OELs. In the main, the UF approach can be used to establish OELs for nearly all adverse effects (except perhaps genotoxic carcinogens). The primary variable in setting these limits is the size of the UF, which will vary with the adverse effect to be avoided, as well as the amount of available data. It is noteworthy that in most cases, the use of uncertainty or safety factors that have been used to establish the TLVs, for example, has rarely been explicitly described in the Documentation of the TLVs (34). This is a shortcoming in the process that deserves to be addressed.

In recent years, the AIHA and other organizations have promoted the use of control banding as a method for setting occupational exposure limits. This approach has recently been formalized in a document entitled Qualitative Risk Characterization and Management of Occupational Hazards: Control Banding $(78,79)$. The history of control banding has recently been reviewed (79). These are discussed at the end of this chapter.

\subsection{Uncertainty Factors}

Uncertainty factors, UFs, or safety factors (as they were called from 1950 to 1980), are used in health risk assessment to account for a lack of complete knowledge or uncertainties about the dose delivered, human variations in sensitivity, and other factors associated with extrapolating animal data to estimate human health effects (28). They are applied to animal or human data in an attempt to identify safe levels of exposure for most persons. The UF approach has been and continues to be used by FDA, EPA, OSHA, and virtually all agencies and scientific bodies who set acceptable levels of exposure to toxic substances.

Within the United States Environmental Protection Agency (EPA), for example, UFs are factors used to operationally derive environmental regulatory criteria. Specifically, the Reference Concentrations (RfCs) or Reference Doses (RfDs) are derived from experimental or epidemiological data $(80,81)$ involving animals or humans. The critical dose is usually defined as the No Observed Effect Level (NOEL) for the most sensitive adverse effect from the best animal study. The RfC or RfD is calculated by dividing the critical dose by one or more UFs and sometimes a modifying factor (MF). Although the application of this number of UFs is not consistent with the history of setting occupational exposure limits, it is prudent for setting environmental limits if properly conducted.

UFs are intended to account for

1. the variation in sensitivity among the members of the human population,

2. the uncertainty in extrapolating animal data to estimate human health effects. 3 . The uncertainty in extrapolating from data obtained in a study that is of less than lifetime exposure,

3. the uncertainty in using lowest observable adverse effect level (LOAEL) data rather than the no observed adverse effect level (NOAEL) data, and 
4. an incomplete database, generally with regards to reproductive or developmental toxicity.

Usually, each of these factors is set at 3 or 10 but a value as low as 1 may sometimes be appropriate (65). MFs are used the same way as UFs are used. However, MFs are applied when additional uncertainty exists after accounting for the uncertainty within the five listed categories. MFs would not generally be applied when setting an OEL because some human data are almost always available, thus avoiding the need for additional conservatism.

Additional information on EPA's justification and rationale for the use of UFs and MFs is presented in several documents, including Interim Methods for Development of Inhalation Reference Doses, Methods for Derivation of Inhalation Reference Concentrations and Application of Inhalation Dosimetry, IRIS Supportive Documentation-Volume 1 (82), Dourson and Stara (28) and Barnes and Dourson (80). These documents are worth consulting because when occupational exposure limits are set, the same factors are considered. The primary differences in setting an RfC versus an OEL are the number and size of the UFs, the difference in the length of exposure (continuous versus $40 \mathrm{~h}$ workweek), the lack of a recovery period, the difference in the type of exposed population (old, young, women, and those with illness versus healthy workers) and differences in the definition of "acceptable risk" for the worker population and the public. In short, OELs do not attempt to protect everyone in the general population who could be exposed continually for a lifetime, while this is the intent of an RfD and an RfC.

2.1.1 Specific UFs Used to Set an RfC As mentioned previously, the EPA issues guidance regarding safe airborne concentrations of various chemicals. This guidance is known as a reference concentration, or RfC. The formula for deriving the RfC is generally as follows:

$$
\mathrm{RfC}=\frac{\text { Critical dose }}{\mathrm{UF} \times \mathrm{MF}}
$$

where critical dose is the best estimate of the NOEL from the studies that have evaluated the most sensitive relative toxic effect, MF is the modifying factor, and UF is the uncertainty factor.

When the EPA sets an RfC, documentation is presented in their database, IRIS, for each chemical specifying the UFs applied and their rationale. This documentation is available to anyone via the World Wide Web. The EPA's application of UFs has evolved over time. Until recently they relied only on UFs representing an "order of magnitude" (factor of 10). Where appropriate, the EPA now uses an intermediate UF of 3 , rather than 10 . On a logarithmic scale or multiplicative scale, 3 is midway between 1 and 10. Since 3 is the approximate midpoint between 1 and 10 on a logarithmic scale, when 2 successive applications of UF 3 are performed, the combined UF is rounded to 10. Over the years, when setting OELs (rather than RfDs) the TLV Committee frequently applied an uncertainty or safety factor of 3 rather 
than 10 (although this was rarely explicitly stated in the documentation) and only one or two, rather than three to five, UFs were applied to human or animal data to form the overall or aggregate UF.

UFs have often been applied by the EPA in the following manner when setting ambient air limits. It is noteworthy that only the EPA's conceptual approach, but not the specific size and number of UFs, is applicable to setting an OEL because a smaller population of healthy persons is the focus of workplace standards, they are exposed only $40 \mathrm{~h}$ a week, and the levels of risk considered acceptable are much different for these two populations:

- When setting limits to protect the general population, a 10-fold UF is used to protect the sensitive individuals. However, as when they derived the RfC for carbon disulfide, the EPA used a threefold UF because the critical dose was measured directly as an internal measure of dose.

- Where necessary, either a 10-fold or a 3-fold UF is used to account for uncertainties in the extrapolation of data from animal studies to estimating effects on humans. When dosimetric adjustments are used, the smaller (threefold) UF is used.

- The EPA uses a 10-fold or 3-fold UF to extrapolate from subchronic studies to predict the hazard due to exposure that may last a lifetime. The size of the UF depends on whether progression of the adverse condition is expected.

- In addition, EPA uses a 10-fold or 3-fold UF to extrapolate from a LOAEL to a NOAEL (in those studies where no clear NOAEL was observed). The smaller UF is used when the adverse effect is judged to be sufficiently mild.

- Where indicated, a 10-fold or 3-fold UF for database deficiencies can be applied. The most common deficiencies are lack of developmental or reproductive toxicity studies. This additional UF is most often used where there is reason to suspect the effect, but the necessary studies are lacking.

Finally, the MF is used by EPA only when there may be indications from previous studies or from supporting biological data that other effects may occur. The following example illustrates how this approach was used to derive a chronic RfC for methyl ethyl ketone for the general population.

2.1.1.1 Example 1: Setting an RfC for Methyl Ethyl Ketone Recently, the EPA recommended a chronic RfC for methyl ethyl ketone (MEK). It was based on decreased fetal birth weight in animals. They reported that the NOAEL adjusted to a human equivalent concentration (critical dose) from the best study was $2978 \mathrm{mg} / \mathrm{m}^{3}$. From this beginning, they established an RfC in the following manner:

$$
\mathrm{RfC}=\frac{\text { Critical dose }}{\mathrm{UF} \times \mathrm{MF}}=\frac{2978 \mathrm{mg} / \mathrm{m}^{3}}{1000 \times 3} \approx 1 \mathrm{mg} / \mathrm{m}^{3}
$$

A total UF of 1000 was derived by multiplying the following factors: 
- 10 to account for interspecies extrapolation.

- 10 to account for sensitive individuals.

- 10 to account for an incomplete database including the lack of chronic and reproductive toxicity studies.

An MF of 3 was used to address the lack of unequivocal data for respiratory tract (portal of entry) effects.

$$
\text { Critical dose }=2978 \mathrm{mg} / \mathrm{m}^{3} \quad[\text { the NOAEL }(\text { HEC })]
$$

Note: This RfC was intended to protect virtually anyone in the population including the very young, the very old and those with one of a number of illnesses. The approach is unnecessarily conservative for establishing an occupational exposure limit intended to protect a much smaller and less diverse population that would not be continuously exposed to this concentration in ambient air. In the author's view, EPA should not have added an MF factor of three to account for possible respiratory effects since developmental effects were the most sensitive endpoint. Further, an aggregate 3000-fold safety factor appears excessive for an RfC for this chemical given the large amount of toxicity data and the available information from worker studies.

2.1.2 UFs and OELs The method by which one chooses the size of each of the specific UF has been debated for many years $(28,70,83,84)$. Not surprisingly, no single method has been embraced by all scientific bodies. For example, from about 1950 to 1985 , the FDA often applied a UF of 10 to account of the possible increased susceptibility of humans versus the animal tested and another factor of 10 to account for the differences in susceptibility across the human population (e.g., a total UF of 100) when establishing limits of exposure for food additives and pesticide residues. Often, if chronic animal data were available, this factor of 100 was considered adequate (83). On the other extreme, Weil (70) once suggested that if only acute toxicity information was available, such as an $\mathrm{LD}_{50}$, then an aggregate UF of 5000 was reasonable if one is trying to prevent a chronic risk. Later research conducted at Harvard University generally supported his opinion (Wilson and Crouch, 2001).

When evaluating the various views about UFs, it is worthwhile to note that the size of the UF used to account for various "unknowns" has changed over the years. For example, it would not be fair to compare the views of Warren Cook in 1945 to those of the current Chair of the TLV Committee. For example, one reason that the magnitude of the overall UF has changed over time is because the margin of safety thought to be necessary to protect "most workers" in 1945 is different than in 2010. In part, this is because society has begun to encourage scientists to prevent toxicological effects that are more subtle or less severe than the traditional endpoints. In addition, the margin of safety thought to be necessary to ensure protection of the diverse number of persons in the population has changed over the past 10-20 years $(64,75)$. Third, our knowledge of the degree of interindividual variability in response to xenobiotics within the 
population has improved and toxicology has identified a number of polymorphisms (230).

The same four extrapolation factors used to adjust animal data to set an ambient air limit (RfC) can be used to derive an OEL although their magnitude will often be much smaller. A number of papers that have been published over the years discuss the rationale for selecting the various values $(54,81,84,85)$. The use of UFs to set OELs has been discussed by Zielhuis and VanDer Kreck $(71,72)$ and others. Unlike the approach used to set RfCs, aggregate or overall UFs much less than 100 have often been applied to lifetime animal studies to predict safe exposures for humans exposed in the workplace. This is because workers are only exposed as adults, they are generally healthier than the general population, and the exposure is only for $40 \mathrm{~h}$ per week and only for 30-40 years. Consequently, it is not unusual to see an overall UF as small as 10-100 being applied to chronic animal NOELs to establish an OEL for workers. This is not to say that larger safety factors are not often warranted. When the slope of the dose-response curve is known, it should influence the size of the uncertainty factors.

Regrettably, the ACGIH TLV Committee has not explicitly presented the quantitative basis for identifying the rationale the vast majority of the TLVs. Thus, one must look at the value suggested for a specific chemical and the information from the specific study or studies that they seemed to rely upon in order to derive the size of "safety factor" that was used. Nevertheless, if one analyzes the historic TLVs for many of the systemic toxicants, a few generalizations can be offered. First, if a solid NOEL from a 6-month to 2-year animal study was available; it appears that a UF of 10-100 was usually applied to the NOEL to establish an OEL for a chronic toxicant that was not carcinogenic. Assuming there was no evidence of mutagenicity or carcinogenic potential, this margin of safety was considered adequate. Second, if there was a reasonable amount of human experience with the chemical and no adverse effects had been observed in carefully monitored workers, then UFs as small as 10 have often been used to establish TLVs when chronic animal data were available. Third, in recent years, there has been some interest by those involved in setting OELs to increase the margin of safety inherent in most OELs to accommodate the differences in susceptibility among workers. An interesting analysis of the various implied UFs in the TLVs has been published (86). The following section discusses various approaches that have been adopted or could be adopted to set OELs based on the toxic effect of the agent. Although Nielsen and Ovrebo have noted that some agencies have divided the types of adverse effects into as many as 32 different categories, in our view, this is overly complicated so the following categories were identified.

\subsection{Setting Limits for Systemic Toxicants}

By far, the majority of chemicals for which OELs have been established are systemic toxicants. By definition, this class of chemicals brings about their adverse effects at a site or target organ distant from the site of contact (86). An example of a systemic toxicant is ethanol, which is usually ingested. Although the ethanol is absorbed in the GI, the adverse effects are on the central nervous system and the liver; thus, it is a systemic toxicant. 
Before proceeding to interpret toxicity studies, it is important to evaluate the chemical structure of the substance in an attempt to see whether it has characteristics suggesting that it may act like another chemical for which the toxicology is well understood. This is called a structure-activity relationship (SAR) evaluation. For example, toxicity data on phenol are useful for understanding benzene (phenol is a major metabolite of benzene). Likewise, information about trichloroethylene is useful for understanding some aspects of perchloroethylene. Conversely, although one might expect 1,1,2-trichloroethane to be similar in toxicity to 1,1,1-trichloroethane, the two chemicals have markedly different potency with respect to liver toxicity. Understanding why there are differences or similarities among chemicals can be helpful to setting proper OELs.

Beyond evaluating the SAR, it is also useful to assess the available mutagenicity data. For those systemic toxicants that are slightly positive in the Ames test or other tests for genotoxicity, it is often useful to provide a slightly greater margin of safety than might otherwise be indicated if a lifetime bioassay has not been conducted.

The process used to set either an OEL for an industrial chemical or an ADI for a food additive is quite similar. After evaluating the SAR, the genotoxicity battery, the human experience, and all of the applicable toxicity studies, one attempts to identify the dose that is unlikely to pose any significant risk to humans. Generally, an emphasis is placed on those studies of the longest duration for which an adequate number of animals were used.

Because inhalation is generally the primary route of exposure to industrial chemicals, tests that use inhalation data are favored over those in which the animal was exposed via ingestion or gavage. If test results for both ingestion (dietary) and inhalation studies are available, then the results should be compared on a $\mathrm{mg} / \mathrm{kg}$ basis (or other relevant dose metric) so that "first-pass" effects can be evaluated. "First-pass" effects are those produced prior to having the chemical metabolized by the liver.

Conceptually, the various groups that set OELs use the same approach as that used by EPA to set an RfC for a systemic toxicant. First, all relevant animal studies are evaluated and are placed in order of strength or quality. Second, the best study involving the most relevant species is selected. Third, the NOEL from this study is identified. One caution is that a NOEL should be identified for an endpoint with genuine biological significance. For example, it is widely held that transient changes in liver enzymes or slight liver hypertrophy due to the challenge of dealing with a xenobiotic are not usually considered a significant adverse effect so, in these cases, they should not be used as the basis for deriving an OEL. Fourth, the results of the study should be compared with those from other studies to determine if there is a consistent and clear message from all data sets. Fifth, if little else is known, the most simplistic approach to setting an OEL for a systemic chemical is to divide the NOEL from a high quality chronic animal study by a factor of 100 . If a different route of exposure than inhalation is used, route-to-route conversions can be made. In all cases, the size of the safety factor should be influenced by the steepness of the doseresponse curve. 
2.2.1 Example 2: One Approach to Setting a Chronic OEL Assuming that the NOEL for rats exposed for 2 years to 1,1,1-trichloroethane is $1000 \mathrm{ppm}$ (vapor) and that for mice the NOEL was 1500 ppm; what is a reasonable OEL? Assume that the primary adverse effect observed in animals is liver toxicity (a systemic effect). Lastly, epidemiology data suggest that human exposure in the workplace to $100 \mathrm{ppm}$ for $8 \mathrm{~h}$ /day for a lifetime poses no adverse effects.

$$
\mathrm{OEL}=\frac{\mathrm{NOEL}}{\left(\mathrm{UF}_{1}\right)\left(\mathrm{UF}_{2}\right)}
$$

where NOEL is the no observed effect level in animals (most sensitive species), $\mathrm{UF}_{1}=5-10$ (to account for animal to human differences), and $\mathrm{UF}_{2}=3-10$ (to account for differences in sensitivity among humans).

Therefore,

$$
\begin{gathered}
\mathrm{OEL}=\frac{\mathrm{NOEL}}{\left(\mathrm{UF}_{1}\right)\left(\mathrm{UF}_{2}\right)} \\
\mathrm{OEL}=\frac{1000 \mathrm{ppm}}{(5)(4)} \\
\mathrm{OEL}=50 \mathrm{ppm}
\end{gathered}
$$

If the epidemiology data suggested that human experience at $100 \mathrm{ppm}$ had been favorable, one would have even greater confidence in the validity of the OEL.

\subsection{Setting OELs for Sensory Irritants}

Sensory irritants are those chemicals that produce temporary and undesirable effects on the eyes, nose, or throat. These include such chemicals as ammonia, hydrogen sulfide, formaldehyde, sulfuric acid mist, and dozens of others. The general TLV policy on irritants can be found in the Introduction to the Chemical Substances in the TLV booklet, "The basis on which the values are established may differ from substance to substance; protection against impairment of health may be a guiding factor for some, whereas reasonable freedom from irritation, narcosis, nuisance, or other forms of stress may form the basis for others (4)." About 30-50\% of the published TLVs are based on avoidance of objectionable eye and upper respiratory tract irritation (Table 20.2).

The approach typically used by the TLV Committee has been to assign ceiling values $(\mathrm{CV})$ to rapidly-acting irritants and to assign short-term exposure limits (STELs) where the weight of evidence from irritation, bioaccumulation, and other endpoints (e.g., central nervous system depression, increased respiratory tract illness, decreased pulmonary function, impaired clearance) combine to warrant such a limit. It is likely that the MAK will assign a 15 min STEL when necessary and feasible and where the underlying data are sufficiently developed to justify a compound-specific excursion factor to control body burden (e.g., carbon monoxide) $(87,226)$. These changes lead, among other things, to modification of $8 \mathrm{~h}$ time-weighted averages 
(TWAs) and STELs to accommodate unusual work schedules, where compliance often rests with availability of Biological Exposure Indices (BEI). In each instance, simplicity and practical application are considered along with the relationship between absorbed dose (e.g., area under the curve) and the biological/medical endpoint of concern.

A significant debate among health professionals has taken place in recent years because some believe that transient irritation does not constitute material impairment of health while others contend that the TLVs should protect against any irritation $(87,226)$. It is noteworthy that in 1989, as part of OSHA's effort to promulgate PELs, 79 materials were proposed for regulation based on avoidance of sensory irritation:

The recognition of sensory irritation as potentially being "material impairment of health" is consistent with the current scientific consensus related to health effects of environmental agents. Mucous membrane irritants can cause increased blink frequency and tearing, nasal discharge, congestion, and sneezing and cough, sputum production, chest discomfort, sneezing, chest tightness and dyspnea. Work environments often require levels of physical and mental performance considerably greater than encountered in daily living. Even in the absence of any permanent impairment, the symptoms listed can interfere with job performance and safety. Mucous membrane irritation is associated with respiratory illness, depending on the composition of specific exposure and on the dose, duration and frequency of exposure. No universally applicable conclusion can be drawn at this time regarding the association between irritative symptoms and permanent injury or dysfunction. Where certain individuals show no measurable impairment after an exposure, even when experiencing irritative symptoms, others may develop identifiable dysfunction (88).

OSHA concluded that exposure to sensory irritants can cause inflammation and increase susceptibility to other irritants and infectious agents, lead to permanent injury or dysfunction and permit greater absorption of hazardous substances (88). OSHA (88) also concluded that "Exposing workers repeatedly to irritants at levels that cause subjective irritant effects may cause workers to become inured to the irritant warning properties of these substances and thus increase the risk of overexposure." TLV treatment and interpretation of dose-response relationships for irritants are consistent with the OSHA description. While the TLV Committee assumes a sigmoid concentration-response relationship for common irritants and believes a NOEL (below which the risk of experiencing irritation is trivial) can be identified for "nearly all workers," the Committee seldom has a data set sufficiently robust so as to assign a specific level of risk. Even though correlations have been drawn, there is no widely accepted method for extrapolation of animal irritation data to human beings $(87,89$, 90, 91, 92, 94, 95, 96).

Historically, OELs for irritants were based on observations of the response of workers to various airborne concentrations measured by industrial hygienists. Basically, concentrations that did not produce irritation were recorded and this information was sent to the TLV Committee so they could recommend an appropriate OEL. Armed with whatever information the committee was sent over the next two 
years following the "notice of intended change," individual hygienists were expected to submit information regarding whether workers were experiencing some irritation at the proposed TLV. Following receipt of comments, the committee could then choose to make adjustments to the value. It is because of the importance of the subjective information gathered in the workplace that the TLV Committee has placed such reliance on the advice offered by the "consulting members" of the committee; for example, those toxicologists and industrial hygienists who work in industry.

More recently, methodologies for setting OELs for sensory irritants have been proposed which would be based on the results of eye and skin irritation tests conducted in rabbit or rodent studies. Since sensory irritation is generally considered an acute response, animal tests involving limited durations of exposure should be adequate to identify "interim" safe levels of exposure. However, unless the animals are exposed via inhalation, toxicologists and physicians have had to make rough estimates about the likely airborne concentration that might prevent irritation based on anology to the chemicals tested using "liquid in the eye" testing. Generally, if a number of persons might be exposed to the chemistry, animal studies need to be conducted with vapors to identify the airborne concentration when adverse effects are observed.

Historically, UFs applied to NOELs obtained in studies when animals are exposed to vapors to set an OEL for humans to prevent sensory irritation have been rather small. Often, the overall UF has been as low as 2-5. There are a number of reasons why this has been the case. First, rabbits have been considered more susceptible to eye irritants than humans, so if only animal data were available, these tests have been considered "worst case." Second, mild eye irritation due to vapors, if it occurs in humans, is generally transient. Third, mild or slight irritation is often accommodated and the effects are reversible. Another reason the margins of safety have been small is that, until recent years, most TLVs and other OELs were established after, rather than before, workers were exposed to the chemical. Thus, when these committees met to establish OELs there was generally a significant amount of information about the airborne concentrations known to produce eye, nose, throat, or lung irritation in workers. Thus, having some information about human response and some animal data, the TLV Committee apparently believed that they could set TLVs at values that did not require large UFs.

Today, there is a greater expectation that nearly everyone should be protected against even minor sensory irritation. Therefore, in recent years, committees establishing OELs tend to apply UFs of 5-10 or more to an animal NOEL to set an OEL if human data are not available. The UF should vary depending on the slope of the doseresponse curve. Of course, for the period during which a new OEL (such as a TLV) is "out for comment," it is expected that those who use the chemical will collect industrial hygiene data and that they will submit comments regarding the reasonableness of the proposed guideline. In some cases, such as for chlorine, formaldehyde, and other widely used chemicals, data from controlled human studies have been available (74). In those situations where human studies have been conducted, it has not been uncommon for an OEL setting group to apply a UF as low as 1-2 to a well-understood human NOEL. Whenever possible, it is recommended that expert panels identify 


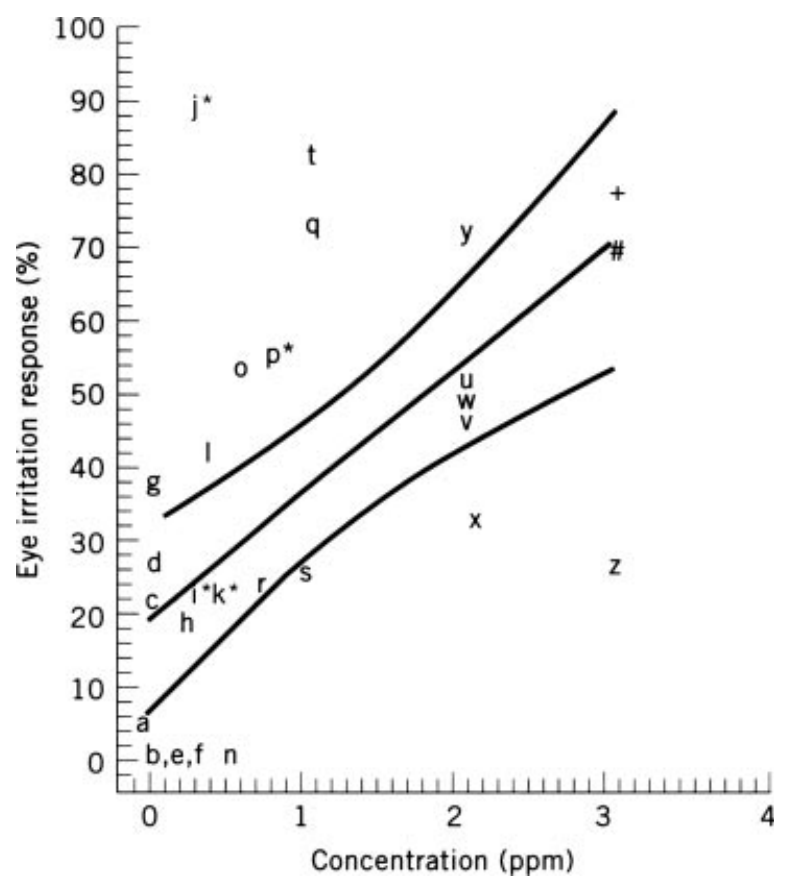

FIGURE 20.1 Linear concentration-response curve based on the data from various human studies regarding eye irration due to formaldehyde. Linear least squares regression analysis of the data presented in Paustenbach et al. Ref. 74, omitting the data for mobile home studies (points $\mathrm{i}^{*}, \mathrm{j}^{*}, \mathrm{k}^{*}$, and $\mathrm{p}^{*}$ ). The regression equation is response (in $\left.\%\right)=19.6+(17.4 \times$ concentration in ppm): $n=24, r^{2}=0.45$. The regression, that is positive slope, is significant $(p=0.001)$ and the $95 \%$ confidence interval for the regression lines are shown. The data points $\mathrm{b}, \mathrm{e}$, and f represent studies with zero response at zero concentration. The fit of the line does not vary appreciably if one fits the line with only the controlled human studies or all of the studies. From Ref. 74.

all the studies considered to be of good quality and to build a comprehensive dose-response curve (74). As shown in Figure 20.1 these can be very informative and they represent a weight of evidence approach to setting an OEL.

Fairly recently, a generic approach to setting occupational exposure limits for irritants was proposed by Gaffney and Paustenbach (89). The authors indicated that the OEL identified for a chemical odorant or irritant depends on the type of chemosensory effect that the chemical is likely to exhibit and that in order to establish the appropriate OEL, organizations need to agree upon the percentage of the workforce that they are attempting to protect and the types of toxicological end points that are sufficiently important to protect against (e.g., transient eye irritation, throat irritation, or other reversible effects). The authors proposed a flow chart for categorizing chemicals, based on their chemosensory effects, which would allow toxicologists and industrial hygienists to more rapidly identify the appropriate OEL. Nearly 50 different references 
were provided. These authors (89) recommended that this method could be extended to setting limits for ambient air contaminants where risk perception plays a dominant role in whether the public views the exposure as being reasonable or safe.

2.3.1 Setting OELs for Irritants Using Models Unlike the period 1940-1975, when OELs for irritants were based primarily on the human experience or simple tests with rabbits, we now have a reasonably reliable capability for predicting safe levels of exposure using models. Two kinds of models are available. One is based on tests that consider the response of rats and/or mice (90-95) to irritants. The second is based on chemical properties (68). Going forward, it is recommended that these be used to identify OELs that can be used until experience has been gained with workers.

The first approach was developed at the University of Pittsburgh (93). It involves exposing rodents to various concentrations of contaminants and then measuring respiratory parameters. In this bioassay, mice are exposed to an airborne chemical and changes in their respiratory pattern are determined. For each chemical tested, the concentration capable of producing a $50 \%$ decrease in respiratory rate $\left(\mathrm{RD}_{50}\right)$ is obtained and its relative potency estimated. It is known that as the degree of irritation increases, the respiration rate decreases in rodents. Rodents, unlike other species, will decrease their metabolism to near death in order to avoid lung damage due to serious irritation.

In one of the more comprehensive papers, Schaper (95) described the success of their methodology, the $\mathrm{RD}_{50}$ approach, to accurately predict safe levels of human exposure for 89 chemicals. In this study, 295 such airborne materials, including single chemicals and mixtures, were found in the literature. A total of $154 \mathrm{RD}_{50}$ values were obtained in male mice of various strains for the 89 chemicals in the database for which there were also TLVs. An examination of the TLVs and $\mathrm{RD}_{50}$ values demonstrated, as previously with the smaller data set $(n=40)$, a high correlation $\left(r^{2}=0.78\right)$ of the TLVs with $0.03 \times \mathrm{RD}_{50}$. The authors concluded that these results supported the continued use of the animal bioassay for establishing exposure limits to prevent sensory irritation.

A second modeling approach, one based on chemical properties, has been used to set OELs for organic acids and bases, a class of chemicals that are well-known irritants (68). A generic method for understanding these chemicals was needed since only a few of the more than 40 chemicals in this class used in industry had OELs when the approach was developed. Although a great structural diversity exists among these chemicals, the primary biological effect produced by exposure to these materials is irritation. These researchers proposed that irritation should be related to their acidity or alkalinity. Since the strength of an organic acid or base is measured by its $\mathrm{p} K_{a}$, it was shown that this term could be used to identify preliminary acceptable levels of human exposure.

As shown in Figures 20.2 and 20.3, the OELs for organic acids and bases correlate well $\left(r^{2} \geq 0.80\right)$ with $\mathrm{p} K$. For organic acids and bases for which no OEL has been established, the following equations can be used to set a preliminary limit: 


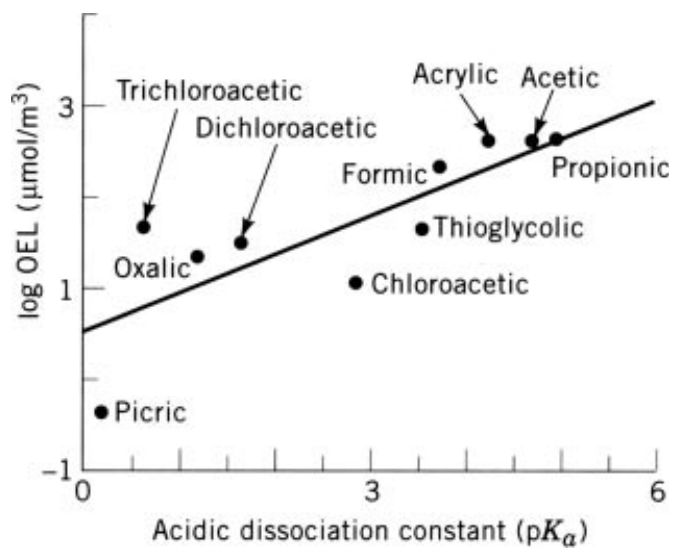

FIGURE 20.2 Correlation of OELs with equilibrium dissociation constants of organic acids. The correlation coefficient, $r=0.80$. The regression equation is $\log$ OEL $\left(\mu \mathrm{mol} / \mathrm{m}^{3}\right)=0.43$ $\mathrm{p} K_{a}+0.53$. See Ref. 68 .

For organic acids : $\log \mathrm{OEL}\left(\mu \mathrm{mol} / \mathrm{m}^{3}\right)=0.43 \mathrm{p} K_{a}+0.53$

For organic bases : OEL $\left(\mu \mathrm{mol} / \mathrm{m}^{3}\right)=-200 \mathrm{p} K_{a}+2453$

Table 20.3 presents the OELs calculated with these formulas for a variety of organic acids and bases. A large number of corporate OELs have been adopted based on this approach.

In the coming years, it is quite likely that committees who set the TLVs and other OELs for the sensory irritants will recommend lower limits as society attempts to prevent even transient irritation from occurring in exposed workers (96).

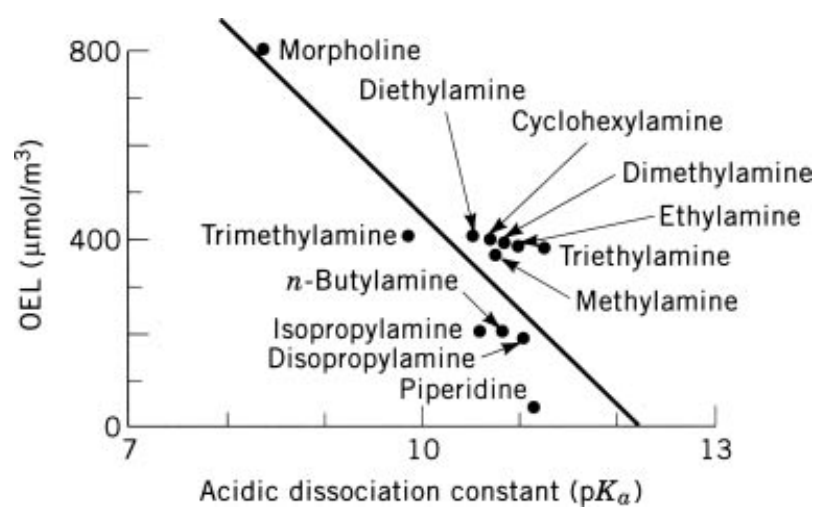

FIGURE 20.3 Correlation of OELs with equilibrium dissociation constants of organic bases. The correlation coefficient, $r=0.81$. The regression equation is: OEL $\left(\mu \mathrm{mol} / \mathrm{m}^{3}\right)=-200$ $\mathrm{p} K_{a}+2453$. See Ref. 68 . 
TABLE 20.3 Occupational Exposure Limits for Selected High Volume Organic Acids and Bases Recommended by a Mathematical Formula Based on the Disassociation Constant ${ }^{a, b}$

\begin{tabular}{lcclcr}
\hline Acid & $\mathrm{mg} / \mathrm{m}^{3}$ & $\mathrm{ppm}$ & \multicolumn{1}{c}{ Base } & $\mathrm{mg} / \mathrm{m}^{3}$ & $\mathrm{ppm}$ \\
\hline Acrylic & 16 & 5 & Allylamine & 29 & 12 \\
Butyric & 35 & 10 & Dialylamine & 58 & 15 \\
Caproic & 49 & 10 & Dibutylamine & 43 & 8 \\
Crotonic & 30 & 8.5 & Isobutylamine & 21 & 7 \\
Hepatanoic & 55 & 10 & Propylamine & 21 & 7 \\
Isobutyric & 35 & 10 & Trialylamine & 109 & 20 \\
Isocaproic & 49 & 10 & & & \\
Isovaleric & 42 & 10 & & & \\
Methacrylic & 30 & 8.5 & & & \\
Pentenoic & 32 & 7.8 & & & \\
Propiolic & 1.5 & 0.5 & & & \\
Valeric & 42 & 10 & & & \\
\hline
\end{tabular}

${ }^{a}$ From Ref. 66.

${ }^{b}$ Exposure limits were calculated by using the equations: acid: $\log \mathrm{OEL}\left(\mu \mathrm{mol} / \mathrm{m}^{3}\right)=0.43 \mathrm{pK}_{\mathrm{a}}+0.53$; base: $\operatorname{OEL}\left(\mu \mathrm{mol} / \mathrm{m}^{3}\right)=-200 \mathrm{pK}_{\mathrm{a}}+2453$.

\subsection{Setting Limits for Developmental Toxicants}

Very few of the current OELs have been set by the ACGIH TLV Committee, the MAK, or the AIHA WEEL committee with the primary objective of preventing developmental effects. One reason is that relatively few of the 1200 or so chemicals that have OELs have been tested in the standard Segment II test battery for assessing developmental toxicity and, of those chemicals tested, only a fraction have been found to be selectively toxic to the developing fetus $(57,97,98)$. However, in recent years it has been recognized that OELs that specifically protect against developmental toxicity need to be established, and there has been a discussion within the toxicology community about the appropriate approach for estimating safe levels of human exposure based on animal data (99-101).

For many years, due to the technical difficulties involved in the safety evaluation/ extrapolation process used to set OELs for developmental toxicants, toxicologists in industry typically recommended that women of child-bearing age not be placed in locations where exposure to these agents could occur. However, during the 1970s, in an attempt to satisfy federal labor laws in the United States and to give women greater access to higher paying jobs, it was no longer considered acceptable to restrict women from jobs where exposure to the truly significant developmental toxicants was possible. As a result, OELs should consider this hazard. The methodologies for setting OELs for these agents continues to evolve, as much due to changes in societal values about the required size of the margin of safety as to the changes in our scientific understanding of the developmental hazard (100-102).

By definition, a developmental toxicant is a chemical that can produce an adverse effect on the developing fetus (99). The range of possible adverse effects on 
development covers a very broad spectrum spanning small changes in birth weight to gross teratologic effects. The decision to classify a chemical as a developmental toxicant is clouded by the fact that at some dose, virtually all chemicals will produce an adverse effect on developing offspring (103). To complicate matters further, there are very significant differences in the susceptibility to various developmental effects among the various animal species and humans. There are also differences in the percentage of naturally occurring defects among rodent and nonrodent species, and humans (97). For these and other reasons, it is not surprising that a great deal of deliberation needs to occur when attempting to identify safe levels of exposure to developmental toxicants (104).

In general, the current approach to setting an OEL for these agents is much like that used by FDA to identify acceptable exposure to certain drugs that might pose a developmental hazard. First, the critical NOEL observed in a well conducted Segment II developmental toxicity study is identified. A Segment II test involves exposing a rabbit and a relevant species to three or four doses of a toxicant. About two weeks prior to pregnancy, females are first exposed. Exposures continue throughout the pregnancy. About three days before delivery, the pups are removed via C-section and then examined for detrimental effects (57). Two species are always evaluated in these tests so two NOELs are produced. If both are similar, the lower of the two is used in the safety evaluation. If they are not similar, then a careful review of the specific adverse effects and the differences in metabolism between the species and human needs to be conducted. If known, the species thought to provide information most relevant to humans should be used. Second, one or more UFs should be applied to the animal NOEL. Historically, when setting tolerances for food additives and pesticide residues, an UC of 100 has been applied to the NOEL observed in the most sensitive species exposed in a Segment II test to identify the ADI. The size of the UF applied to developmental studies (like Segment II) used to set most OELs appears to have varied over the years from 10-50 (104). For some chemicals, the apparent UC incorporated into some TLVs has been smaller, depending upon the strength of the animal data, the mechanistic data, the warning properties of the chemical, and other factors.

Because developmental effects have a threshold, it is anticipated that the UF or benchmark dose approach will continue to be used to identify safe levels of exposure. The benchmark dose approach is a hybrid method (i.e., relies on both low-dose modeling and the safety factor approach) that has certain benefits over either the modeling or the UF approaches $(1,42)$. Thus far, the authors are not aware of an OEL which has been based on the benchmark dose approach but it should be one of the methods considered by groups who set limits in the coming years. As different techniques for identifying more sensitive developmental effects evolve, and as societal values change, it is likely that the OELs for these chemicals will become smaller.

\subsection{Setting Limits for Reproductive Toxicants}

"Reproductive dysfunction" can be broadly defined to include all effects resulting from paternal or maternal exposure that interfere with the conception, development, 
birth, and maturation of offspring to healthy adult life (57). For purposes of this discussion, reproductive effects are those that impair the ability of a male or female to produce offspring (105). The relation between exposure and reproductive dysfunction is highly complex because exposure of the mother, the father, or both may influence reproductive outcome. In addition, exposures may have occurred at some time in the past, immediately prior to conception, or during gestation. For some specific dysfunctions, the relevant period of exposure can be identified, and for others it cannot. For example, chromosomal abnormalities detected in the embryo can arise from mutations in the germ cells of either parent prior to conception or at fertilization, or from direct exposure of embryonic tissues during gestation. Major malformations, however, usually occur with exposure during a discrete period of pregnancy, extending from the third to the eighth week of human development (57).

While historically the bulk of interest has been on female reproductive function, the precise male contribution to reproductive failure and adverse pregnancy outcomes, although often unknown, is considered to be significant (105). When evaluating males, attention is focused primarily on toxic effects that involve testicular and postspermatogenic processes that are essential for reproductive success. Male reproductive failure resulting from germ cell mutation (i.e., genotoxicity), the role of the endocrine system in the support of reproductive function, and female reproductive toxicity are all important variables. Like the developmental toxicants, there have been few OELs established for chemicals whose primary adverse effect is reproductive toxicity. These are at least two reasons. First, not a great many industrial chemicals have been tested in the classic male or female reproductive toxicity batteries $(57,105)$. Second, of those chemicals tested, few have been shown to produce adverse effects selectively on reproduction at concentrations or doses lower than those known to produce significant adverse effects on other organs; thus, this is infrequently the "driving" health effect.

Similar to the historical approaches used to identify OELs that protect against other adverse effects, it appears that UFs in the range of 10-100 applied to a NOEL from well-conducted animal studies have been considered adequate to protect humans from reproductive effects. For example, the OSHA PEL for dibromochloropropane is $1 \mathrm{ppb}$ and this appears to be based on applying an UF of less than 100 to the NOEL for adverse effects observed in rodents. Because there are a limited number of reproductive toxicants for which OELs have been set and there have been few long-term follow-up studies of workers exposed to these agents, it is unclear whether UFs closer to 10, 30, 100 , or slightly higher are the "best ones" for this class of chemicals. As with other adverse effects, the magnitude of the various UFs used to identify an OEL should be directly related to the strength of the animal and human data, the severity of the adverse effects, the reversibility of the effect, as well as the relationship to doses that cause other toxic effects.

\subsection{Setting Limits for Neurotoxic Agents}

Chemicals that can produce permanent neurological damage present significant concern to toxicologists and physicians. This is because some neurotoxins can produce 
permanent damage at doses that produce no other adverse effects (106). For this reason, the FDA has traditionally regulated in a fairly aggressive manner neurotoxic agents that can enter the food chain. Many agencies, including the EPA and OSHA, often regulate neurotoxicants as stringently as the carcinogens. That is, they tend to apply large UFs to animal data.

It appears that UFs in the region of 5-100 have been typically applied to animal NOELs from high quality tests to set OELs. As in the setting of other OELs, a large degree of professional judgement is needed to identify the appropriate value. It is noteworthy that at times FDA has applied UFs as great as 2000 to animal data to set acceptable levels of exposure to residues in foods of certain pesticides that cause permanent neurotoxicity, like dying-back neuropathies. Because most of the OELs for the neurotoxins are based on human experience and because of the fairly large database on these chemicals (like parathion), it appears that this is the justification for the relatively low UFs that have historically been used to set OELs.

\subsection{Setting Limits for Esthetically Displeasing Agents and Odors}

The process or approach to setting an OEL for a chemical that tends to have a low odor threshold or for those chemicals that are esthetically displeasing has been fairly simple. One of two approaches is used. In the first, if the agent has an airborne odor threshold much lower than the concentration that produces even subtle toxic effects, the agent is categorized as one that has "self limiting" exposure characteristics. That is, because the odor is so objectionable, workers are not going to allow themselves to be placed at risk of injury due to exposure (unless they are exposed in a confined space without easy egress). These chemicals generally do not pose much of a concern to toxicologists or industrial hygienists as long as the agent does not cause rapid olfactory fatigue.

In the second approach, one usually identifies the airborne concentration at which most persons find the odor of the chemical objectionable and then divides that concentration by a factor of 2 or 3 to establish a preliminary OEL. As with other "preliminary OELs," during the 2-year period for receiving comments, the value can be raised or lowered based on the feedback from workers and industrial hygienists.

Historically, human experience in the workplace has been used to identify the concentration at which most persons recognized an odor (generally, one only focuses on the concentration that is found objectionable rather than simply detectable) and then the OEL was established. In recent times, some firms have used odor or irritation panels to identify the concentration at which detection occurs, as well as those concentrations where the odor is considered objectionable. Such panels include men and women of various ages since both sex and age are known to affect the threshold of smell. From the results of the odor panel, a concentration that is likely to be acceptable to most persons can be identified (175).

One aspect of setting an OEL for this class of chemicals that requires attention is the phenomenon of "accommodation." Accommodation is usually differentiated from olfactory fatigue in that accommodation means that with continuing exposure 
throughout the day, the objectionable nature of the odor diminishes. For example, many persons who work in factories that use chemicals like amyl alcohol initially find the odor objectionable but within 5-10 min, and for the remainder of the workday, the workers do not even recognize that it is present. Some have claimed that the fatigue provides an opportunity for chronic cellular irritation; thus, in their view accommodation is not a beneficial response. Although there is no commonly accepted approach for dealing with chemicals with this property, it is important that the concentration selected as the OEL is a fraction of that known to produce toxic effects (even if the odor is tolerable).

\subsection{Setting Limits for Persistent Chemicals}

In general, those groups involved in setting OELs have not attempted to quantitatively account for the pharmacokinetics of chemicals. That is, it has usually been assumed that chemicals with very long half-lives in animals will also have long half-lives in humans and that this is accounted for in the results of chronic animal studies. Thus, the NOEL incorporates the possible hazard associated with these chemicals.

In recent years, more attention has been focused on chemicals with very long halflives and toxicologists now know that differences in the elimination between animals and humans can be substantial (even when relative life expectancies are considered). For example, the difference in the biologic half-life for dioxin between rodents and humans is sufficiently great that the steady-state blood concentrations at a given dose are quite different (107). For the so-called "long-lived or persistent" chemicals, which in the late 1990s were called persistent organic pollutants (POPs), it is prudent to rely upon PB-PK models to account for interspecies differences when deriving OELs (especially those based on animal data). The basis for and the benefits of the PB-PK approach are discussed in the chapter on Pharmacokinetics and Unusual Work Schedules, Chapter 21, of this book.

An approach to setting OELs for persistent chemicals has been described by Leung et al. (107) and it is worthy of evaluation. Basically, the methodology incorporates information on the biological half-life of the chemical in humans (the pharmacokinetics), as well as the background concentration of the chemical in humans due to contamination of the food chain. The approach assumes that the biological half-life of a chemical in humans can be predicted based on animal data using a PB-PK model when human data are not available. These researchers reasoned that if the amount of chemical absorbed due to workplace exposure is about the amount every American ingests every day, or if the total uptake (occupational or dietary) is much lower than the NOEL, then the occupational contribution is unlikely to pose significant increased health risks.

This approach was applied to setting an OEL for tetrachlorodibenzo- $p$-dioxin $[2,3,7,8$-TCDD (dioxin)] because a good deal of toxicology information was available. Since TCDD is highly lipophilic and has a long biologic half-life in humans, it is expected to accumulate in adipose tissue with repeated daily exposure. TCDD levels in the adipose tissue of nonoccupationally exposed adults in the United States have been about 7 ppt. 
The steady-state level of TCDD in adipose tissue resulting from exposure to an OEL of $200 \mathrm{pg} / \mathrm{m}^{3}$ (the value proposed in Ref. 107), for example, can be estimated by

$$
\text { Steady-state concentration }=\frac{1.44\left(D_{t}\right)\left(t_{1 / 2}\right)}{10.5+(59.5 / 10)}
$$

where $D_{t}$ is the daily intake and $t_{1 / 2}$ is the biologic half-life (years).

This calculation assumes that the TCDD concentration in the liver and other tissues is about one-tenth that in adipose tissue, and the average human weighs $70 \mathrm{~kg}$ with $10.5 \mathrm{~kg}(15 \%)$ body fat. If the half-life is assumed to be about 8 years, the steady-state TCDD concentration in adipose tissue resulting from occupational exposure at an airborne concentration of $200 \mathrm{pg} / \mathrm{m}^{3}$ will be $89-179 \mathrm{ppt}$. Thus, exposure to this OEL for 40 years could raise the steady-state body burden well above the $7 \mathrm{ppt}$ background concentration (107).

Even though the increase in body burden for TCDD for an OEL of $200 \mathrm{pg} / \mathrm{m}^{3}$ is much greater than due to diet, the dose not immediately be considered excessive. The authors to evaluate other factors and they presented the following rationale for concluding that the OEL was reasonable. First, the concentration of TCDD measured in the adipose tissue of rats exposed for 2 years to the NOEL of $0.001 \mu \mathrm{g} / \mathrm{kg}$-day was 540 ppt. Since humans sequester more TCDD in adipose tissue than lower species, which has been speculated by some scientists to lessen the toxic hazard, a comparable level in human fat should yield a lesser risk than that suggested in rodent studies. Second, humans exposed to $16 \mathrm{mg}$ TCDD had a theoretical peak adipose tissue level of about $1300 \mathrm{ppb}(16 \mathrm{mg} / 12.25 \mathrm{~kg})$, yet they only developed chloracne, which resolved within 6 months. None of those who received $8 \mu \mathrm{g}$ TCDD developed chloracne, yet their peak adipose tissue levels were about $650 \mathrm{ppt}(8 \mu \mathrm{g} / 12.25 \mathrm{~kg})$.

The third factor these authors (107) considered was the relationship between the adipose tissue concentration for other persistent chemicals in the diet that also had OELs. Table 20.4 shows that the 26-fold increase over background (179 ppt/7 ppt) for TCDD, when compared with other industrial chemicals following workplace exposure at their corresponding TLVs, appears to be comparable. Fourth, and most importantly, the risk associated with the proposed OEL was 100-fold below the animal NOEL for carcinogenicity (i.e., $10 \mathrm{pg} / \mathrm{kg}$-day) and this was thought to pose no significant human health hazard (107). Thus, from these data in 1988, the risk to humans appeared rather small (especially following a comparison with OELs for other persistent chemicals). Whether their conclusion about what constituted a safe dose of dioxin remains accurate today is irrelevant. The key point is that the methodology is a useful one for evaluating the hazard posed by persistent chemicals.

\subsection{Setting Limits for Respiratory Sensitizers}

Respiratory sensitization is an immune status whereas respiratory allergy is the clinical manifestation. Respiratory sensitization results from an immune response 
TABLE 20.4 Estimated Steady-State Adipose Tissue Concentration of Chemicals Following Chronic Exposure at the OEL Compared with the Levels Due to Background Exposure Alone ${ }^{a}$

\begin{tabular}{|c|c|c|c|c|c|}
\hline \multirow[b]{2}{*}{ Chemical } & \multirow[b]{2}{*}{ OEL } & \multirow[b]{2}{*}{$t_{1 / 2}(\mathrm{yr})$} & \multicolumn{2}{|c|}{ Adipose Tissue Level } & \multirow[b]{2}{*}{$E / B^{c}$} \\
\hline & & & Background $^{b}$ & Exposed $^{c}$ & \\
\hline DDT & $1 \mathrm{mg} / \mathrm{m}^{3}$ & 1.5 & $6 \mathrm{ppm}$ & $480 \mathrm{ppm}$ & 80 \\
\hline Dieldrin & $0.25 \mathrm{mg} / \mathrm{m}^{3}$ & 1 & $0.29 \mathrm{ppm}$ & $80 \mathrm{ppm}$ & 276 \\
\hline PCB & $1 \mathrm{mg} / \mathrm{m}^{3}$ & 2.5 & $1 \mathrm{ppm}$ & $800 \mathrm{ppm}$ & 800 \\
\hline TCDD & $0.2 \mathrm{ng} / \mathrm{m}$ & 8 & $7 \mathrm{ppt}$ & $180 \mathrm{ppt}$ & 26 \\
\hline
\end{tabular}

${ }^{a}$ From Ref. 103.

${ }^{b}$ Background levels refer to those in nonoccupationally exposed general population.

${ }^{c}$ The levels in persons occupationally exposed to the OEL are calculated with the equation presented in Calabrese (65).

${ }^{d} E / B=$ ratio of predicted steady-state adipose tissue level in persons occupationally exposed at the current TLV versus that measured in persons exposed to background levels.

DDT, dichlorodiphenyl triohloroethane; PCB, polychlorinated biphenyl; TCDD, 2,3,7,8tetrachlorodibenzo- $p$-dioxin.

${ }^{e} \mathrm{OEL}$ is the value suggested by Leung et al. (103).

to antigen (usually, but not exclusively, exogenous antigen), which may result in clinical hypersensitivity upon subsequent inhalation exposure to the same or similar antigen. An allergic or sensitization response characteristically requires at least two encounters with antigen. Following first exposure, the susceptible individual mounts a primary immune response, which results in sensitization (the induction or sensitization phase). If the sensitized individual subsequently comes into contact with the same antigen, a clinical allergic reaction may be provoked (the elicitation phase). Allergic reactions may be attributable to either antibody or cell-mediated immune responses. Acute allergic reactions in the respiratory tract induced by exposure to exogenous antigens (e.g., some industrial chemicals) are almost invariably associated with specific antibody responses, frequently, but not always, of the $\operatorname{IgE}$ class (108).

Certain chemicals can produce an allergic response as a result of either dermal or inhalation exposure (109). The reason for the interest is that this class of chemicals can, after a sensitizing exposure (called induction) occurs, produce an adverse effect with subsequent exposures to very small quantities. Respiratory sensitizers can produce asthma in select persons and so-called "attacks or incidents" can be fatal if untreated.

In the late 1990s, respiratory sensitizers received perhaps the most attention of all categories of toxicants with respect to setting OELs. The concern about inhalation sensitizers or allergens came about because researchers reported that the incidence of asthma in children and adults appeared to be increasing dramatically in the United States and other Western countries. A few years ago, the German MAK began to identify with notation those chemicals that were known or suspected inhalation sensitizers. In 1996, the ACGIH TLV ${ }^{\circledR}$ committee chose to pursue the same approach 
and has recently attached a similar notation to chemicals for which they believe a sensitization hazard exists.

The setting of occupational limits for sensitization became much more complex as more was learned about occupational exposure to beryllium came to be better understood in recent years. Since about 1995, the OEL has received considerable scrutiny and as more information was collected, the TLV and other OELs have been dramatically reduced $(231,232)$.

The experience with beryllium and some pharmaceutical agents alerted hygienists that some persons can become sensitized following extremely low exposures due to their genetic susceptibility. For beryllium, the interindividual differences regarding susceptibility, for becoming sensitized, as defined by the blood lymphocyte proliferation test (BLPT), could easily vary by a factor of 100 fold or greater (233). There is clear evidence for this polymorphism and the capacity to identify those persons prior to exposure has been studied for almost 20 years (231, 234-235). Hygienists would do well to study this history of this chemical to alert themselves to the difficulties of setting OELs for sensitizers. The history is described in the Documentation for the Threshold Limits its Value for beryllium.

The toxicology community has made significant headway in developing methods for identifying likely dermal and respiratory sensitizers over the past 10 years. Since exposure to most dermal sensitizers is prevented by gloves and other personal protective equipment, the focus of the TLV and MAK committees has been on respiratory sensitizers. Fortunately, a model that relies on SAR has been developed for screening groups of chemicals to identify sensitizers (110) thus making the task a manageable one. The SAR model relies upon identifying chemical moiety in a substance that is known to increase the probability that it will be a respiratory sensitizer, like an aldehyde or cyano group. This model has been applied to nearly 100 different chemicals.

In addition to SAR models, there are in vitro and in vivo test methods to identify sensitizers. The most common approach includes an in vitro assessment of protein binding potential, followed by in vivo evaluation using an animal model (110). Diverse species have been used including mice, rats, and guinea pigs, each possessing distinct advantages and disadvantages in representing human disease (110). The guinea pig model (110) assesses several hypersensitivity responses such as early and late airway reactions, airway hyperreactivity, production of allergen-specific $\operatorname{IgE}$ and $\operatorname{IgG}_{1}$ antibodies, and eosinophilic inflammation. However, the model is costly and requires a high degree of technical skill (109). Mouse models have been described that associate an increase in total IgE with respiratory sensitizers or characterize the cytokines produced following exposure to chemical allergens. Each of the animal models has been tested with only a limited number of chemicals and requires further validation. An excellent paper that reviews current views on toxicology testing of respiratory sensitizers has been published (108).

Of all the tests, the guinea pig sensitization test has been used most frequently and refinements in the procedure have made it a much more powerful and reliable tool for identifying likely human sensitizers (108). Although a related test relies upon administration of an agent via dermal contact, the most reliable way to identify a likely 
occupational allergen is through inhalation testing. Using the results of the testing, it has been shown that "safe" levels of exposure can be identified by comparing the test results on a new chemical versus the results obtained with a known occupational sensitizer that has a TLV. Using a simple ratio approach, an OEL for the "new" chemical can be calculated directly from the animal data. This approach has been discussed by Graham et al. (110).

\subsection{Setting Limits for Chemical Carcinogens}

Carcinogen is the term applied to a chemical that has been shown to produce a significant increase in the occurrence of tumors (above background) in an appropriately designed and executed animal study or has been shown to produce an increase in the incidence of cancer in a human population. Chemical carcinogens have been the focus of many, if not most, environmental and occupational regulations for the past 25 years.

In the United States, the impetus to have the TLV Committee develop a classification scheme for occupational carcinogens began in 1970. At that time, lists were routinely published by numerous agencies and different groups who claimed that a large number of substances were likely to be occupational carcinogens. As noted by Stokinger (63), substances of purely laboratory curiosity, such as acetylaminofluorene (AAF) and dimethylaminobenzene, which were found to be tumorigenic in animals, were classed along with known human carcinogens of high potency and individual significance, such as bischloromethyl ether (BCME). Often, no distinction was made between an animal tumorigen and a likely human carcinogen. Union leaders, workers and the public would often become worried equally about the positive results of animal bioassays of different chemicals even though for a given dose the carcinogenic or mutagenic potency could vary by $1,000,000$-fold (63).

During the 1970s and 1980s, the TLV Committee believed that the finding of a substance to be tumorigenic, often in a half-dead mouse or rat administered intolerable doses, as was the case for chloroform and trichloroethylene, was not suggestive evidence that it was likely to be carcinogenic in humans under controlled working conditions. It is for this reason that the ACGIH Chemical Substance TLV Committee, as early as 1972, made a clear distinction between animal and human carcinogens. As time has passed, the TLV Committee has stood firm that not all carcinogens pose an equal hazard, even when the potency of two chemicals may be equally great. One reason, among others, was that some chemicals are mutagenic or genotoxic while others produce tumors through epigenetic mechanisms $(111,112)$. By setting exposure limits, the ACGIH, adopted the view that all chemical carcinogens should at least have a "practical threshold." This term simply means that some dose of these agents would not be expected to pose a significant cancer risk. The basic concept behind the term "practical threshold" is that humans, as they evolved mechanisms for handling naturally occurring carcinogens in the diet, these same mechanisms will detoxify small amounts of industrial chemicals (111). 
In 1977, Herbert Stokinger, then chairman of the ACGIH TLV Committee, summarized the historical philosophy of the ACGIH with respect to TLVs for carcinogens:

Experience and research findings still support the contention that TLVs make sense for carcinogens. First and foremost, the TLV Committee recognizes practical thresholds for chemical carcinogens in the workplace, and secondly, for those substances with a designated threshold, that the risk of cancer from a worker's occupation is negligible, provided exposure is below the stipulated limit. There is no evidence to date that cancer will develop from exposure during a working lifetime below the limit for any of those substances.

Where did the TLV Committee get the idea that thresholds exist for carcinogens? We have been asked 'Where is the evidence?' ... Well, the Committee thinks it has such evidence, and here it is.

It takes following three forms:

1. Evidence from epidemiologic studies of industrial plant experience, and from well-designed carcinogenic studies in animals,

2. Indisputable biochemical, pharmacokinetic, and toxicologic evidence demonstrating inherent, built-in anticarcinogenic processes in our bodies,

3. Accumulated biochemical knowledge makes the threshold concept the only plausible concept (63).

Although these comments were written about more than 30 years ago, a large fraction of industrial hygienists, industrial toxicologists, and occupational physicians generally continue to agree with Dr. Stokinger's position. This has been due, in part, to the work of Ames et al. (111) who have shown that man's diet is abundant with chemical carcinogens and that humans have clearly developed adequate mechanisms and this is generally validated by the continuing decrease in the incidence of cancer in the twentieth century in spite of the tremendous increase in the amount of xenobiotics in our environment.

In recent times, the TLV and MAK Committees have attempted to keep pace with the increased understanding of the hazards posed by chemical carcinogens. For example, beginning in about 1985, they considered not only the results of mathematical models used to estimate response at low doses but also in vitro data, information on the mechanisms of action, case-reports, genotoxicity data, and other information on chemical carcinogens before setting a particular TLV. Evidence that such discussions occurred is presented in the documentation for the TLV for trichloroethylene, methylene chloride, 1,1,1-trichloroethane, and others that were revised between 1985 and 2010. Due to the variability in risk estimates between the various statistical or low-dose models (e.g., Weibull, multistage) and their inability to incorporate biological repair mechanisms, the TLV Committee has been reluctant to place much 
emphasis on their results, and thus far, has not set a TLV based on the results of lowdose models. Often, the spoken or unstated objective was to keep the theoritical increased cancer risk rise to less than in 1,000.

As noted in the current TLV booklet (4), when deciding on values for chemical carcinogens, the Chemical Substance Group within the TLV Committee gives greatest weight to epidemiologic studies based on good quantitative exposure data. When the weight of evidence is convincing, certain chemicals will receive an A1 categorization and these are called Confirmed Human Carcinogens. Next in importance, and more typically available, are positive bioassays involving rats or mice (but lacking human data). Such substances are given an A2 designation and are called "suspected human carcinogens." In reviewing the key experimental toxicology studies, the Committee considers route of entry (greatest weight given to inhalation studies), dose-response gradient, potency, mechanism of action, cancer site, time to tumor, length of exposure, and underlying incidence rate for the type of cancer and species under study. Replication of results is important to the committee, especially if comparable results are obtained in different species. Other types of information, such as batteries of genetic toxicity studies, are useful in confirming that a substance is a carcinogen but are not usually helpful in setting a TLV.

Appendix A of the annual TLV booklet contains a description of categories into which chemical carcinogens have been placed (4). The goal of the Chemical Substances TLV Committee has been to synthesize the available information in a manner that will be useful to practicing industrial hygienists without overburdening them with needless details. The Committee reviewed current methods of classification used by other groups and in 1991 developed a new procedure for classification (113). This was generally accepted in 1992 and these are regularly updated. The following categories for occupational carcinogens are currently used by the TLV Committee in 2010 (4):

- Al-Confirmed Human Carcinogen. The agent is carcinogenic to humans based on the weight of evidence from epidemiologic studies.

- A2-Suspected Human Carcinogen. Human data are accepted as adequate in quality but are conflicting or insufficient to classify the agent as a confirmed human carcinogen; OR, the agent is carcinogenic in experimental animals at dose(s), by route(s) of exposure, at site(s), of histologic type(s), or by mechanism (s) considered relevant to worker exposure. The A2 is used primarily when there is limited evidence of carcinogenicity in humans and sufficient evidence of carcinogenicity in experimental animals with relevance to humans.

- A3-Confirmed Animal Carcinogen with Unknown Relevance to Humans. The agent is carcinogenic in experimental animals at a relatively high dose, by route (s) of administration, at site(s), of histologic type(s), or by mechanism(s) that may not be relevant to worker exposure. Available epidemiologic studies do not confirm an increased risk of cancer in exposed humans. Available evidence does not suggest that the agent is likely to cause cancer in humans except under uncommon or unlikely routes or levels of exposure. 
- A4-Not Classifiable as a Human Carcinogen. Agents about which there is concern that they could be carcinogenic for humans, but that cannot be assessed conclusively because of a lack of data. In vitro or animal studies do not provide indications of carcinogenicity sufficient to classify the agent into one of the other categories.

- A5-Not Suspected as a Human Carcinogen. The agent is not suspected to be a human carcinogen on the basis of properly conducted epidemiologic studies in humans. These studies have sufficiently long follow-up, reliable exposure histories, sufficiently high dose, and adequate statistical power to conclude that exposure to the agent does not convey a significant risk of cancer to humans; $\mathrm{OR}$, the evidence suggesting a lack of carcinogenicity in experimental animals is supported by mechanistic data.

Substances for which no human or experimental animal carcinogenic data have been reported are assigned no carcinogenicity designation.

Exposures to carcinogens must be kept to a minimum. Workers exposed to A1 carcinogens without a TLV should be properly equipped to eliminate to the fullest extent possible all exposure to the carcinogen. For A1 carcinogens with a TLV and for A2 and A3 carcinogens, worker exposure by all routes should be carefully controlled to levels as low as possible below the TLV. Refer to the "Guidelines for the Classification of Occupational Carcinogens" in the Introduction to the Documentation of the Threshold Limit Values and Biological Exposure Indices for a more complete description and derivation of these designations.

The TLV Committee continues to evaluate the mechanisms through which various chemical carcinogens act and they are seeking improved methods for identifying more accurate guidelines $(4,5)$. In the future, for example, it is possible that the TLV Committee may place more emphasis on model derived cancer risk estimates for certain genotoxic agents $(113,114)$ rather than on the UF approach. As evidenced in their deliberations on benzene, formaldehyde, and vinyl chloride, the committee has tried to consider PB-PK models, controlled human studies, mechanisms of action data, pharmacokinetic data, and other relevant information when attempting to identify the appropriate TLV.

\subsection{Two Approaches for Identifying OELs for Carcinogens}

Even though the ACGIH TLV Committee, as well as many other groups that recommend OELs, may believe that there is likely to be a threshold for carcinogens at very low doses, another school of thought is that there is little or no evidence for the existence of thresholds for chemicals that are genotoxic (26, 113-116). In an attempt to take into account the philosophical postulate that chemical carcinogens do not have a threshold even though a NOEL can be identified in an animal experiment and because a test involving several hundred animals cannot describe the large differences among humans in the general population, modeling approaches to estimate the possible cancer risk to humans exposed to very low doses have been developed $(30,114,116,117)$. 
The rationale for a modeling approach to identify safe levels of exposure is that it is impossible to conduct toxicity studies at doses near those measured in the environment because the number of animals necessary to elicit a response at such low doses would be too great (116). Consequently, results of animal studies conducted at high doses are extrapolated by these statistical models to those levels (e.g., doses) found in the workplace or the environment. By the early 1980s, mathematical modeling approaches for evaluating the risks of exposure to carcinogens were relied upon by various regulatory agencies who were attempting to protect the public; these models rapidly identified doses that almost certainly posed no health hazard. Interestingly, the limits derived by these models have rarely been the sole factor by which environmental regulatory limits have been established $(45,48,115,116,118)$.

The most popular models for low-dose extrapolation are the one-hit, multistage, Weibull, multihit, logit, and probit. The pros and cons of these models have been discussed in many papers. Since it is usually presumed in these models that at any dose, no matter how small, a response could occur in a sufficiently large population, an arbitrary increased lifetime cancer risk level is usually selected (i.e., usually from 1 in 100 to 1 in 1,000 for setting occupational guidelines) as presenting an insignificant or de minimis level of risk. By identifying these de minimis levels as virtually safe doses, regulatory agencies do not give the impression that there is an absolutely "safe" level of exposure or that there is a threshold below which no response would be expected. This has historically been considered prudent $(115,118)$.

Often the use of these statistical models to help assess risks of exposure to carcinogens has been erroneously called "risk assessment" $(39,118)$. In practice, modeling is only one part of the risk assessment process. A good dose-response assessment whose purpose is to help identify safe levels of occupational exposure requires exhaustive analysis of all of the information obtained from studies of mutagenicity, acute toxicity, subchronic toxicity, chronic studies in animals and metabolism data, human epidemiology data, and an understanding of the role of dermal uptake (118).

At this time in the evolution of our understanding of the cancer process, most scientists would support using the results of quantitative risk modeling only as providing an additional piece of information to consider when setting an OEL. Because there are dozens of shortcomings associated with the models, especially their inability to consider complex biological events that undoubtedly occur at low doses, they have not been used as the sole basis for deriving occupational exposure limits.

Several papers have compared the model predicted upper bound cancer risk for workers exposed to TLV concentrations of several chemicals with risks often deemed acceptable by the EPA and FDA $(48,113)$. One example of these analysis are presented in Table 20.5. As shown, the theoretical cancer risk for exposure to many, if not most, occupational carcinogens at the current OSHA PELs is about 1 in 1000 rather than 1 in $1,000,000$ (the goal of many environmental regulations). Some TLVs for carcinogens have model predicted risks as high as 1 in 100. The degree of acceptable exposure to carcinogens in the workplace considered "safe or acceptable" is even more interesting when one considers the estimated steady-state tissue concentration in humans 
TABLE 20.5 Model Derived Estimates of Lifetime Risks of Death from Cancer per 1000 Exposed Persons Associated with Occupational Exposure at Pre-1986 and Post-1987 OSHA PELs for Selected Substances ${ }^{a}$

\begin{tabular}{lcc}
\hline Substance & $\begin{array}{c}\text { Cases/1000 at } \\
\text { Previous PEL }\end{array}$ & $\begin{array}{c}\text { Cases/1000 at } \\
\text { Revised PEL }\end{array}$ \\
\hline Inorganic arsenic & $148-767$ & 8 \\
Ethylene oxide & $63-109$ & $1-2$ \\
Ethylene dibromide (proposal) & $70-110$ & $0.2-6$ \\
Benzene (proposal) & $44-152$ & $5-16$ \\
Acrylonitrile & 390 & 39 \\
Dibromochloropropane (DBCP) & - & 2 \\
Asbestos & 64 & 6.7 \\
\hline
\end{tabular}

${ }^{a}$ Table reprinted from Rodricks et al. (42), reprinted with permission of Regulatory Toxicology and Pharmacology.

following chronic exposure to the TLV versus that due to background exposure to that chemical in our diet (Table 20.4).

The principal reason for the wide disparity between the ambient air guidelines recommended by the U.S. EPA (which attempts to limit the model-predicted cancer risk to 1 in 10,000 to 1 in 1,000,000) and the workplace values recommended by the TLV Committee can be explained primarily by the underlying philosophical principles governing the two organizations and the differences in the exposed populations, rather than the technical differences between the two methods for identifying "safe doses." The TLV Committee is governed by the precept that "Threshold Limit Values refer to airborne concentrations of chemical substances and represent conditions under which it is believed that nearly all workers may be repeatedly exposed, day after day, over a working lifetime, without adverse effect" (4). Occupational exposure involves $40 \mathrm{~h} /$ week for about 40 years. In contrast, the U.S. EPA's Clean Air Act (CAA) and other environmental regulations are intended to ensure that virtually all members of the public are exposed to virtually insignificant risks. For example, the CAA states that air standards must protect the public health with an adequate margin of safety. The requirement for an "adequate margin of safety" is intended both to account for inconclusive scientific and technical information and to provide a reasonable degree of protection against hazards that research has not yet identified. The TLVs define "adequate margin of safety" differently from EPA since healthy workers allegedly make up the bulk of the workforce, for example, those who report to work each day must be healthier than the general population. Rather than $40 \mathrm{hr} / \mathrm{week}$, for 40 years, environmental exposure is assumed to occur continuously for $168 \mathrm{~h}$ /week for 70 years.

With respect to setting environmental standards, the use of conservative low-dose extrapolation models and the adoption of a 1 in 100,000 or 1 in 1,000,000 risk criterion have been justified because of a strong desire to protect virtually everyone in the public (e.g., the aged, young, and infirm), and to account for the fact that the public can be continually exposed for 70 years rather than a 40 year working lifetime. Due to the very 
different populations at risk and the fact that workers are sometimes compensated for accepting certain risks, it has been considered reasonable that the approaches used to set various limits (as well as the risk criteria) are different.

\subsection{Setting Limits for Mixtures}

The whole topic of setting OELs for mixtures began to be re-evaluated by the toxicology community in the mid-1990s and it can be expected that it will receive a good deal of discussion over the next 10 years (119). Indeed, the topic has drawn the attention of a larger segment of the occupational health and toxicology communities in recent times (120). Historically, the ACGIH TLV Committee approach has been to consider chemicals that act on the same target organ or act through the same mechanism of action as being additive with respect to their hazard. A number of meetings of experts were held in the 1970s through the 1990s to reassess this approach and, in the main, it was concluded that the methodology described in the TLV booklet was adequate (if not amply health protective) (121). Interestingly, when an EU committee reviewed the various approaches for dealing with mixtures in 2008, it basically embraced the historical TLV methodology (122).

The approach currently recommended by the TLV Committee is as follows (taken from the recent TLV booklet) (4):

When two or more hazardous substances have a similar toxicological effect on the same target organ or system, their combined effect, rather than that of either individually, should be given primary consideration. In the absence of information to the contrary, different substances should be considered as additive where the health effect and target organ or system is the same. That is, if the sum of

$$
\frac{C_{1}}{T_{1}}+\frac{C_{2}}{T_{2}}+\ldots \frac{C_{n}}{T_{n}}
$$

exceeds unity, the threshold limit of the mixture should be considered as being exceeded (where $C_{1}$ indicates the observed atmospheric concentration and $T_{1}$ is the corresponding threshold limit; see Examples A.1 and B.1 in the TLV Booklet). It is essential that the atmosphere is analyzed both qualitatively and quantitatively for each component present in order to evaluate the threshold limit of the mixture.

The additive formula applies to simultaneous exposure for hazardous agents with TWA, STEL, and ceiling values. The threshold limit value time interval base (TWA, STEL, and ceiling) should be consistent where possible. When agents with the same toxicological effect do not have a corresponding TLV type, use of mixed threshold limit value types may be warranted. Table 20.6 lists possible combinations of threshold limits for the additive mixture formula. Multiple calculations may be necessary.

Where a substance with a STEL or ceiling limit is mixed with a substance with a TLV-TWA but no STEL, comparison of the short-term limit with the applicable excursion limit may be appropriate. Excursion limits are defined as a value five times the TLV-TWA limit. The amended formula would be 
TABLE 20.6 Possible Combinations of Threshold Limits When Applying the Additive Mixture Formula

\begin{tabular}{lll}
\hline Full Shift or Short Term & \multicolumn{1}{c}{ Agent A } & \multicolumn{1}{c}{ Agent B } \\
\hline Full shift & TLV-TWA & TLV-TWA \\
Full shift & TLV-TWA & TLV-Ceiling \\
Short term & TLV-STEL & TLV-STEL \\
Short term & TLV-Ceiling & TLV-Ceiling \\
Short term & Excursion limits where & TLV-Ceiling or \\
& there is no STEL & TLV-STEL \\
& (five times TLV-TWA value) & \\
Short term & TLV-STEL & TLV-Ceiling \\
\hline
\end{tabular}

$$
\frac{C_{1}}{T_{1 \mathrm{STEL}}}+\frac{C_{2}}{\left(T_{2}\right)(5)} \leq 1
$$

where $T_{1 \mathrm{STEL}}$ is the TLV-STEL and $T_{2}$ is the TLV-TWA of the agent with no STEL.

The additive model also applies to consecutive exposures of agents that occur during a single work shift. Those substances that have TLV-TWAs (and STELs or excursion limits) should generally be handled the same as if they were the same substance, including attention to the recovery periods for STELs and excursion limits as indicated in the Introduction to Chemical Substances. The formula does not apply to consecutive exposures of TLV-ceilings.

Exceptions to the above rule may be made when there is a good reason to believe that the chief effects of the different harmful agents are not additive. This can occur when neither the toxicological effect is similar nor the target organ is the same for the components. This can also occur when the mixture interaction causes inhibition of the toxic effect. In such cases, the threshold limit ordinarily is exceeded only when at least one member of the series $\left(C_{1} / T_{1}+\right.$ or $+C_{2} / T_{2}$, etc. $)$ itself has a value exceeding unity.

Another exception occurs when mixtures are suspected to have a synergistic effect. The use of the general additive formula may not provide sufficient protection. Such cases at present must be determined individually. Potentiating effects of exposure to such agents by routes other than that of inhalation are possible. Potentiation is characteristically exhibited in high concentrations, less probable for low. For situations involving synergistic effects, it may be possible to use a modified additive formula that provides additional protection by incorporating a synergy factor. Such treatment of the TLV should be used with caution, as the quantitative information concerning synergistic effects is sparse.

Care must be considered for mixtures containing carcinogens in categories A1, A2, or A3. Regardless of application of the mixture formula, exposure to mixtures containing carcinogens should be avoided or maintained as low as possible. 
The additive formula applies to complex mixtures with a reasonable number of agents. It is not applicable to complex mixtures with many components (e.g., gasoline, diesel exhaust, thermal decomposition products, fly ash, etc.).

As described in the ACGIH TLV booklet, the formula applies only when the components in a mixture have similar toxicologic effects. The only exceptions involve sensory irritants or chemicals that are esthetically displeasing since additivity of adverse effects should not occur. They should not be used for mixtures with widely differing reactivities or mechanisms of toxic action, for example, hydrogen cyanide and sulfur dioxide. In such case, the formula for independent effects should be used. It is essential that the atmosphere be analyzed both qualitatively and quantitatively for each component present in order to evaluate compliance or noncompliance with this calculated TLV.

This approach to dealing with mixtures was questioned by the German MAK committee. Specifically, in 1997 the MAK committee reiterated their view that this simple approach may not be appropriate in some situations. They stated that it was advisable to conduct toxicology tests on the mixture of chemicals to which workers would be exposed rather than rely on equations that attempt to consider only the target organ. In particular, they believed it was essential to evaluate common commercial mixtures, like gasoline or certain other mixtures, in separate toxicology tests and not to rely on the above-mentioned formula. Although any group responsible for setting OELs would not take issue with such an approach, most would probably agree that until such data are available, the method recommended by the ACGIH appears to be reasonable. As noted by Perkins $(61,121)$, there are several possible scientific shortcomings in the approach but it will take many years before these can be improved upon.

Recently, the Interdepartmental Group on Health Risks from Chemicals (IGHRC) (2009) published a framework for assessing risks to human health associated with chemical mixtures. The IGHRC concluded that:

Chemical mixtures are best considered as a series of discrete, precisely defined problems for which clear boundaries can be set. Each discrete, precisely defined risk assessment can then be compared to other, similar risk assessments to enable the larger picture to be assembled over time. A key factor in risk assessments for chemical mixtures is the availability, or absence, of reliable data for the whole mixture or its components. Where mixture risk assessments follow component-based approaches it is particularly important to have reliable data on the identity, toxicokinetics, metabolic pathways, mechanisms of action and levels of exposure for the key components in order to make expert judgments about the potential for interactions between components to affect the overall toxicity of the mixture. Where this information is lacking, regulators may need to make precautionary default assumptions. Where there is no clear information on the potential for interactions to occur, there is no scientific basis from which to consider interactions in either a quantitative or a qualitative sense. Hence, it is most appropriate to use a default approach assuming no interactions as the starting point for a preliminary (Tier 1) risk assessment. It is acknowledged that the "no-interaction" hypothesis may appear to be a less precautionary approach. The picture that is emerging from robust mixture studies suggests that interactions are not observed at dose levels below thresholds of effect. 
If there is evidence to suggest that interactions may occur, the risk assessor should use all available data to make, as far as is possible, a quantitative assessment of the effects of the interaction. For the situation where chemical-chemical reactions are considered important, the document recommends that potential reaction product(s) should be included in the assessment as additional component(s). For the situation where toxicokinetic interactions may increase overall toxicity, in the absence of information to allow the effects of the interaction to be quantified, the document recommends the use of assessment factors to take account of potential increases in the levels of a toxicant at its target site or prolonged exposure if clearance of the toxicant is delayed. The rationale for the selection of assessment factors must be clearly described. Where there is a potential for toxicodynamic interactions, evidence from robust mixture studies suggests that these are only likely to occur where exposures are around and above thresholds of effect. Therefore, providing the exposure level for each component (or group of components producing functionally similar effects) is below its threshold of effect (noting the need to consider the potential for toxicokinetic interactions to influence the relationship between an external dose and the level of the toxicant at its target site), there should be no toxicodynamic interactions (122).

\subsection{Dermal Exposure Limits}

There has been discussion within the industrial hygiene community that perhaps a new category of occupational exposure limit was needed to protect against excessive uptake of chemicals via the skin. Indeed, it was first mentioned by Paustenbach et al. (1992) (225) that inherent in the original TLVs was some assumption that there was dermal intake since, by definition, it had to be occurring between the 1930s and the 1960s and that the epidemiology data would have incorporated that route of intake. Many OELs has been based on epidemiology data. They tried to consider this factor in their exposure analyses of the Pliofilm cohort. Later, they concluded that these initial attempts to quantify exposure were often unrealistically high and they adopted a Monte Carlo approach in the subsequent analyses (223).

Generally accepted quantitative dermal exposure limits are not presently available, although safe dermal exposure levels may serve as valuable risk assessment and management tools. Characterization of dermal exposures range from qualitative skin notations or exposure banding to proposed quantitative dermal standards and various methods for the latter have been proposed in the literature. One can also attempt to estimate the contribution of dermal intake using classic exposure assessment techniques $(225,230)$.

Proposed methods for developing quantitative dermal occupational exposure levels include (1) biological measures of exposure or internal dose, (2) the use of levels of deposition on clothes or contaminated skin, or surfaces in the occupational setting through the application of conceptual models like the one suggested by Schneider and colleagues $(123,124),(3)$ methods that assume complete absorption of chemicals that have been deposited on the skin, (4) flux-based methods for determining allowable absorption, and (5) the skin absorption time method (125).

A skin notation (SN), when attached to a TLV, represents a hazard identification tool for occupational health professionals to identify chemicals that are subject to 
percutaneous absorption and which may cause adverse health effects $(77,78)$. However, the transparency and rigor of the traditional SN assignment process and the adequacy of qualitative hazard indicators have been questioned $(126,127)$. Further, there has been some confusion about the practical definition for assignment of a SN among both practicing industrial hygienists and regulators. Historically, the SN has been assigned by the ACGIH in circumstances where "the potential significant contribution to the overall exposure by cutaneous route, including mucous membranes and the eyes, either by contact with vapors or, of probable greater significance, by direct skin contact with a substance" (4). SNs were not originally designed to identify chemicals inducing localized skin injuries or where the skin is the target organ. Furthermore, a key criticism of the original SN has been that they merely list the ability of a chemical to be absorbed through the skin and do not allow for determination of the severity of health impact.

A strategy for assigning new expanded skin notations was recently proposed by NIOSH where is suggests an REL. This strategy was designed "to preserve the conventional wisdom about [SNs] and also to address the issues associated with their historic misuse-including their assignment to nonsystemic effects" $(77,78)$. The new NIOSH strategy involves the assignment of multiple SNs for distinguishing systemic, direct, and sensitizing effects caused by chemical exposure $(77,78)$. According to NIOSH, the new system of labeling of chemicals with single or multiple hazard-specific SNs will greatly enhance the quality of hazard communication and the associated risk management process $(77,78)$. The new designations include notations for the traditional systemic absorption (SYS) indication, but also for direct effects on the skin (DIR), including corrosion (COR) and irritation (IRR); and also sensitization (SEN). Additionally, NIOSH will assign a notation to indicate that a chemical has been reviewed, but no notation has been assigned, and will also assign a notation if there are insufficient data available to assign a specific notation(s) at the time of review. During development of expanded SNs, NIOSH is collecting detailed amounts of chemical specific information associated with dermal risk factors, which in the future may allow for improvements in the development of quantitative dermal occupational exposure limits.

Banding of dermal exposures has also been suggested as a means for categorizing chemicals into bands of acceptable exposures as an alternative to deriving a dermal OEL (236). In the European Union, an approach has been recommended for control banding that employs the risk phases (or R phases) required on MSDSs in the EU. This method uses the same health criteria for the dermal route as for the inhalation route, and because of its simplicity must also assure $100 \%$ absorption of chemicals deposited on the skin. For these reasons, this method currently has limited usefulness as a meaningful exposure assessment criterion.

An example of the use of biological monitoring and skin surface contamination measurements to validate a DOEL was presented by Brouwer et al. (128). In this paper, the authors evaluate the effectiveness of both surrogate skin sampling and handwashing techniques to measure dermal deposition. They subsequently compare these measurements to biological monitoring results to establish a relationship between the skin deposition and the ultimate dermal uptake. 
The results were used to test the applicability of a recently proposed quantitative dermal occupational exposure limit (DOEL) for [4, 4'-methylene dianiline] MDA in a workplace scenario. For two consecutive weeks, six workers were monitored for exposure to MDA in a factory that made glass fiber reinforced resin pipes. Dermal exposure of the hands and forearms was assessed during week 1 by a surrogate skin technique (cotton monitoring gloves) and during week 2 by a removal technique (handwash). As well as the dermal exposure sampling, biological monitoring, measurement of MDA excretion in urine over $24 \mathrm{~h}$, occurred during week 2 . Surface contamination of the workplace and equipment was monitored qualitatively by colorimetric wipe samples. Geometric means of daily exposure ranged from 81-1762 micrograms MDA for glove monitoring and from 84-1783 $\mathrm{gg}$ MDA for handwashes. No significant differences, except for one worker, were found between exposure of the hands in weeks 1 and 2. Significant differences between the mean daily exposure of the hands (for both weeks and sampling methods) were found for all workers. Excretion of MDA in $24 \mathrm{~h}$ urine samples ranged from 8 to $249 \mu \mathrm{g}$ MDA, whereas cumulative MDA excretion over a week ranged from 82 to $717 \mu \mathrm{g}$ MDA. Cumulative handwash and MDA excretion results over a week showed a high correlation $\left(r^{2}=0.94\right)$. The highest actual daily dermal exposure found seemed to be about $4 \mathrm{mg}$ (handwash worker A on day 4 ), about $25 \%$ of the external DOEL.

The authors concluded that both dermal exposure monitoring methods were applicable, where the exposure relevant to dermal absorption is considered mainly restricted to hands. They concluded that setting a DOEL of $16 \mathrm{mg} / \mathrm{day}$ seemed to be relevant and applicable for compliance testing and health surveillance. Although the DOEL provides a quantitative estimate of acceptable dermal exposure levels and considers the impact of exposure frequency, duration, and surface area, it is not possible to set a DOEL for all exposure scenarios (237).

A proposal to establish quantitative DOEL in the absence of dermal flux data (i.e., assuming complete absorption through skin) was described and it warrants further evaluation $(61,121,128,129)$. Conceptually, the proposal is not complex. The approach assumes that the dose absorbed following $8 \mathrm{~h}$ of inhalation exposure to a particular OEL is acceptable. For example, if the OEL is $5 \mu \mathrm{g} / \mathrm{m}^{3}$, it is inferred that a dose of $50 \mu \mathrm{g} /$ day $\left(5 \mu \mathrm{g} / \mathrm{m}^{3} \times 10 \mathrm{~m}^{3} /\right.$ day $)$ poses no significant risk. Clearly, the driver of the calculations is the dermal penetration rate, while surface area of exposed skin and time of contact are the secondary factors.

Bos and colleagues (1998) present an example that involves a pharmaceutical agent. They assumed that during preparation of cyclophosphamide, it is expected that dermal exposure is limited to the hands and lower arms, an area of about $2000 \mathrm{~cm}^{2}$.

Starting from an absorption percentage of $30 \%$, a daily internal dose of $0.75 \mathrm{mg}$ equals a $D_{A}$ of $(750 \times 100 / 30) / 2000 \approx 1 \mu \mathrm{g} / \mathrm{cm}^{2}$. However, the absorption percentage of $30 \%$ was estimated based on a dermal area dose $\left(D_{A}\right)$ of $100 \mu \mathrm{g} / \mathrm{cm}^{2}$. Considering the fact that absorption percentage may increase with decreasing $D_{A}$, an absorption percentage of $100 \%$ was assumed at a dermal dose/unit area of about $1 \mu \mathrm{g} / \mathrm{cm}^{2}$. Therefore, the DOEL interpreted as $D_{A}$ times area was set at $0.75 \mathrm{mg} /$ day. For an estimated maximum value for $A$ of $2000 \mathrm{~cm}^{2}$ the $D_{A}$ will be $750 / 2000 \approx 0.4 \mu \mathrm{g} / \mathrm{cm}^{2}$. 
Similarly, the cyclophosphamide dose of $7.5 \mu \mathrm{g}$ associated with the lower reference value equals a $D_{A}$ of $4 \mathrm{ng} / \mathrm{cm}^{2}$.

A flux-based method for establishing quantitative dermal exposure limits has been described by McDougal and Boeniger (2002) and others. In this method, the experimentally determined maximum flux (mass absorbed/area-time) is used to derive the DOEL. The maximum flux $\left(J_{\max }\right)$ represents the worst case penetration from a case where "excess chemical" is applied to the skin. The maximum dermal internal dose $(M)$ from a specific chemical exposure can be calculated from $J_{\max }$, an exposed surface area $(A)$ and exposure time $(t)$ :

$$
M=J_{\mathrm{M}} \times A \times t
$$

In order for the maximum internal dose to be equivalent to the $\mathrm{OEL}_{\text {int }}$, they can be set to equal each other:

$$
\mathrm{OEL}_{\mathrm{int}}=J_{\mathrm{M}} \times A \times t
$$

Rearranging, we get

$$
A(\mathrm{DOEL})=\frac{\mathrm{OEL}_{\mathrm{int}}}{J_{\mathrm{M}} \times t}
$$

In this case, the DOEL has units of area $\left(\mathrm{cm}^{2}\right)$ and can be interpreted as the maximum skin area that can safely be exposed limit the internal dose to the equivalent of the derived internal OEL $\left(\mathrm{OEL}_{\text {int }}\right)$ over the chosen exposure time. Maximum flux will be applicable when the skin loading is large (i.e., an infinite dose situation) and it will apply primarily to pure chemicals, not solutions (237). However, dermal flux must be experimentally determined and this data is not always readily available.

Another method employing maximum flux was suggested by Walker et al. (125), which uses flux data for pure chemicals and permeability coefficients of solutions and mixtures to provide an allowable exposure time as a quantitative way to assess the hazards of dermal exposures (237). By calculating the skin absorption time (SAT), this method determines the equivalent time duration that yields the same internal dose as the existing inhalation PEL or TLV for the same chemical on a daily basis.

$$
\mathrm{SAT}_{\text {pure chemicals }}=\frac{\text { total absorption at PEL }}{\text { flux } \times \text { hand area }}
$$

or

$$
\mathrm{SAT}_{\text {solutions and mixtures }}=\frac{\text { total absorption at PEL }}{K_{p} \times \text { concentration } \times \text { hand area }}
$$


where SAT is exposure time in hours, total absorption is in milligram flux is in units of $\mathrm{mg} / \mathrm{cm}^{2}-\mathrm{h}$, hand area has units of $\mathrm{cm}^{2}, K_{\mathrm{p}}$ is the permeability coefficient with units of $\mathrm{cm} / \mathrm{h}$, concentration is surface concentration in $\mathrm{mg} / \mathrm{mL}$.

Although significant advances have been made in the area of dermal exposure assessment and the potential for setting quantitative dermal exposure limits, additional research is likely needed before a consensus regarding the most effective way to quantitatively control dermal exposures.

\section{DO THE TLVS PROTECT ENOUGH WORKERS?}

Beginning about 1988, concerns were raised by numerous persons regarding the adequacy or health protectiveness of the Threshold Limit Values $(86,130,131)$. The key question raised in these papers was "what percent of the working population is truly protected from adverse health effects when exposed to the TLV?"

In the first of their papers, Castleman and Ziem (130) claimed that the TLVs were excessively influenced by corporations and, as a result, suggested that they lacked adequate objectivity. In addition, they indicated that the scientific documentation for many, if not most, of the TLVs was woefully inadequate. They concluded by suggesting that "an ongoing international effort is needed to develop scientifically based guidelines to replace the TLVs in a climate of openness and without manipulation by vested interests."

In their second paper, Ziem and Castleman (131) further discussed their views about the inadequacies of the TLVs. To a large extent, this paper was a modification and expansion of their 1988 paper. They once again concluded that the TLVs were not derived with sufficient input from physicians and that many TLVs were simply not low enough to protect most workers. They believed that there was more than circumstantial evidence to show that there had been an excessive amount of industrial influence on the TLV Committee and that this resulted in TLVs that were not sufficiently low to protect workers.

The response to these two papers by occupational physicians and industrial hygienists was significant $(31,118,131,132)$. Over the 12 months that followed, more than a dozen letters to the editor were published and editorials appeared in Journal of Occupational Medicine, American Journal of Industrial Medicine, and the American Industrial Hygiene Association Journal (AIHAJ). One editorial, written by Tarlau (133) of the New Jersey Department of Environmental Protection, suggested that industrial hygienists would be better off not relying on the TLVs. This prompted a rather lengthy response that discussed the historical benefits of the TLVs and suggested that the papers criticizing the TLVs had some merit but that the critics, to a large degree, were applying the social expectations and scientific standards of 1990 on risk decisions that were often performed more than 30-40 years ago (30).

During 1988-1990, the claims that the TLVs were not well based in science were, to a large extent, subjective or anecdotal. Although Castleman and Ziem (121) identified 
inconsistencies in the margin of safety inherent in various TLVs, alleged that companies had undue influence on the TLV Committee, and claimed that objective analysis had not been conducted, the significance of these claims with respect to whether employees were sufficiently protected at the TLV remained unclear. The situation changed when two professors, one from the University of California at Berkeley and the other from England, published a rather lengthy paper that analyzed the scientific basis for a large fraction of the TLVs (86). In this paper, they showed that for many of the irritants and systemic toxicants, the TLVs were at or near a concentration where $10-50 \%$ of the population could be expected to experience some adverse effect. Although for many chemicals the adverse effect might be transient or not very significant, for example, temporary eye, nose or throat irritation, these authors did offer adequate evidence that there was only a small margin of safety between the TLV concentration for some chemicals and those concentrations that had been shown to cause some adverse effect in exposed persons.

Roach and Rappaport summarized their work in the following manner:

Threshold Limit Values (TLVs) represent conditions under which the TLV Committee of the American Conference of Governmental Industrial Hygienists (ACGIH) believes that nearly all workers may be repeatedly exposed without adverse effect. A detailed research was made of the references in the 1976 Documentation to data on "industrial experience" and "experimental human studies." The references, sorted for those including both the incidence of adverse effects and the corresponding exposure, yielded 158 paired sets of data. Upon analysis it was found that, where the exposure was at or below the TLV, only a minority of studies showed no adverse effects (11 instances) and the remainder indicated that up to $100 \%$ of those exposed had been affected (eight instances of $100 \%$ ). Although, the TLVs were poorly correlated with the incidence of adverse effects, a surprisingly strong correlation was found between the TLVs and the exposures reported in the corresponding studies cited in the Documentation. Upon repeating the search of references to human experience, at or below the TLVs, listed in the more recent 1986 edition of the Documentation, a very similar picture has emerged from the 72 sets of clear data which were found. Again, only a minority of studies showed no adverse effects and the TLVs were poorly correlated with the incidence of adverse effect and well correlated with the measured exposure. Finally, a careful analysis revealed that authors conclusions in the references (cited in the 1976 Documentation) regarding exposure-response relationships at or below the TLVs were generally found to be at odds with the conclusions of the TLV Committee. These findings suggest that those TLVs which are justified on the basis of "industrial experience" are not based purely upon health considerations. Rather, those TLVs appear to reflect the levels of exposure which were perceived at the time to be achievable in industry. Thus, ACGIH TLVs may represent guides or levels which have been achieved, but they are certainly not thresholds" (134).

The authors reported the following as their key findings:

Three striking results emerged from this work, namely, that the TLVs were poorly correlated with the incidence of adverse effects, that the TLVs were well correlated with the exposure levels which has been reported at the time limits were adopted and 
that interpretations of exposure-response relationships were inconsistent between the authors of studies cited in the 1976 Documentation and the TLV Committee. Taken together these observations suggest that the TLVs could not have been based purely on consideration of health.

While factors other than health appear to have influenced assignments of particular TLVs, the precise nature of such considerations is a matter of conjecture. However, we note that one interpretation is consistent with the above results, namely, that the TLVs represent levels of exposure which were perceived by the Committee to be realistic and attainable at the time (134).

A number of scientists published comments on the Roach and Rappaport analysis. One of the more thorough discussion papers was written by the past chairs of the ACGIH (31). In their letter to the editor, they claimed that the Roach and Rappaport paper was flawed and that it did not assess the validity of the bulk of the TLVs. The essence of their criticism was that the

... conclusions which they draw concerning the protection afforded by TLVs are based on incomplete consideration of all of the data relative to a given substance. The authors present information in their tables as though the effects and exposures are valid and generally accepted by the occupational health community. No single epidemiologic study normally stands by itself. Requirements for inferring a causal relationship between disease and exposure in epidemiological studies are well established and include criteria for temporality, biological gradient with exposure, strength of the association, consistency with other studies, and biological plausibility of the observed effect. Roach and Rappaport present an uncritical analysis of various reports which would lead the uninformed reader to conclude that these criteria have been satisfied. In developing exposure recommendations, the TLV Committee and most other scientific organizations consider all of the relevant data before drawing conclusions. This includes judgments as to the validity and quality of individual studies in addition to the overall weight of the scientific evidence.

Another set of comments on the Ziem and Castleman articles that contained a good deal of historical perspective was written by the ACGIH Board of Directors (135). In that paper, the Board stated that

While some criticisms may be valid, these articles do not fairly present the facts concerning historical development of TLVs nor do they accurately portray procedures followed by the TLV Committee in developing and reviewing TLV recommendations. Both articles contain a substantial number of errors and omissions and freely exercise selective quotation and quotation out of context in an effort to make their points. The section of Ziem and Castleman's article which discusses "Origins of TLVs" is a masterpiece of selective quotation and quotation out of context. This begins with their quoting a statement made by L. T. Fairhall concerning the role of industrial hygienists in setting health standards: "He [industrial hygienist] is in contact with the individuals exposed and therefore soon learns whether the concentrations measured are causing any injury or complaint." The authors use this quote to imply that physicians were 
excluded from the process of developing exposure guidelines. Taken in context, Fairhall's statement is as follows: "The industrial hygienist is in contact with not one, but a number of plants, using a given toxic substance. He knows, as no one else knows, the actual aerial concentration of contaminant encountered in practice. And he is in contact with the individuals exposed and therefore soon learns whether the concentrations measured are causing any injury or complaint. His judgement and the combined judgement of this entire Conference group is therefore most valuable in helping formulate maximum allowable concentration values." Contrary to Ziem and Castleman's comments, Fairhall advocated a multi disciplinary approach, including physicians, to making exposure recommendations. This has continued to be the operating philosophy of the TLV Committee. The conference in its first ten meetings was chaired by five physicians in six of the ten years.

In 1993, Rappaport published a follow-up analysis regarding the adequacy of the TLVs. He noted that given the continuing importance of the ACGIH limits, it was useful to compare the basis of the TLVs with that employed by OSHA de novo in its 12 new PELs. Using benzene as an example, he showed that OSHA's new PELs had been established following a rigorous assessment of the inherent risks and the feasibility of instituting the limit. He concluded that the TLVs, on the other hand, had been developed by ad hoc procedures and appeared to have traditionally reflected levels thought to be achievable at the time. However, Rappaport noted that this might be changing. Specifically, he said, "Analysis of the historical reductions of TLVs, for 27 substances on the 1991-1992 list of intended changes, indicates smaller reductions in the past (median reduction of 2.0-2.5-fold between 1946 and 1988) compared to those currently being observed (median reduction of 7.5-fold between 1989 and 1991). Further analysis suggests a more aggressive policy of the ACGIH regarding TLVs for carcinogens but not for substances that produce effects other than cancer." He also noted that "Regardless of whether the basis of the TLVs has changed recently, it would take a relatively long time for the impact of any change to be felt, since the median age of the 1991-1992 TLVs is 16.5 years, and $75 \%$ of these limits are more than 10 years old" (136).

One of the more thought-provoking proposals offered by Rappaport was whether the TLV Committee should consider redefining the definition of the protectiveness of these limits (136). Specifically, he suggested, among other things, that the ACGIH "define TLVs officially as levels that represent guides for purposes of control but that do not necessarily protect 'nearly all' workers. Such a move would be in keeping with what appears to be the traditional basis of TLVs. This direction could, in time, lead to explicit rules for establishing 'feasibility' and could allow for the direct participation of industry through the submission of data related to levels of exposure in facilities of various types and ages."

A related opinion paper, or commentary, that criticized Rappaport's 1993 analysis was published in 1994 by Castlemen and Ziem (137). The authors claimed that the TLV setting process continued to lack objectivity and that there was too much opportunity for conflicts of interest to occur. In support of their claims, they presented two tables that listed the names of certain chemicals where the primary authors were 
from various chemical companies or the chemicals for which their TLVs had been criticized. Since this paper, additional debate has occurred and the ACGIH continues to work to improve the process to help satisfy its critics. In Europe, the TLVs received considerable scrutiny in recent years, (213).

Although the merits of the Roach and Rappaport analysis, or for that matter, the opinions of Ziem and Castleman, have been debated over the past 20 years, it is clear that the process by which TLVs and other OELs will be set will never again be as it was between 1945 and 1990. In the future, it can be expected that the rationale, as well as the degree of "risk" inherent in a TLV, will be more explicitly described in its documentation. This degree of transparency in the documentation is necessary since the definition of "virtually safe" or "insignificant risk" with respect to workplace exposure will change as the values of society evolve regarding the definition of "safe" $(138,139)$.

It seems clear to most industrial hygienists and toxicologists who have reflected on this issue that, given our increased awareness of the differences in susceptibility of various persons in the workplace, there is a growing lack of confidence that "nearly all workers" are protected against some of the adverse effects at the current TLVs (such as irritation) unless "nearly all workers" is defined as 80-95\% (140). Whether it is necessary for the ACGIH to ask the TLV Committee to reduce these values in an attempt to protect an even greater percentage of workers continues to be a topic of discussion within ACGIH and a number of other OEL setting organizations.

The issue of transparency was discussed by Haber and Maier (141) in their discussion of the methods used for setting OELs for metals.

\section{CORPORATE OELS}

Although exposure limits or guides like TLVs or WEELs for most large volume chemicals have been established, and the vast majority of workers are exposed to processes for which these guidance values are applicable, the majority of the 3000 chemicals to which workers are routinely exposed in industry do not have PELs, RELs, HSEs, SCOELs, WEELs, or MAKs. As a result, at least 50 companies in the United States have chosen to establish a number of internal or corporate limits to protect their employees, as well as the persons who purchase those chemicals.

The need for internal limits is generally identified by the manufacturing divisions within large companies, although the Health, Safety and Environmental Affairs department may also initiate the process (54). A panel of toxicologists, industrial hygienists, physicians and epidemiologists usually gather the scientific data and make the technical assessment much like the ACGIH TLV Committee. The process used is depicted in Figure 20.4 (54). The data considered by the group are similar to those considered by other OEL setting bodies (Table 20.7). Their deliberations are often reviewed by an oversight group, which integrates the scientific input with information provided by the manufacturing, legal, law, regulatory and other groups in the company 


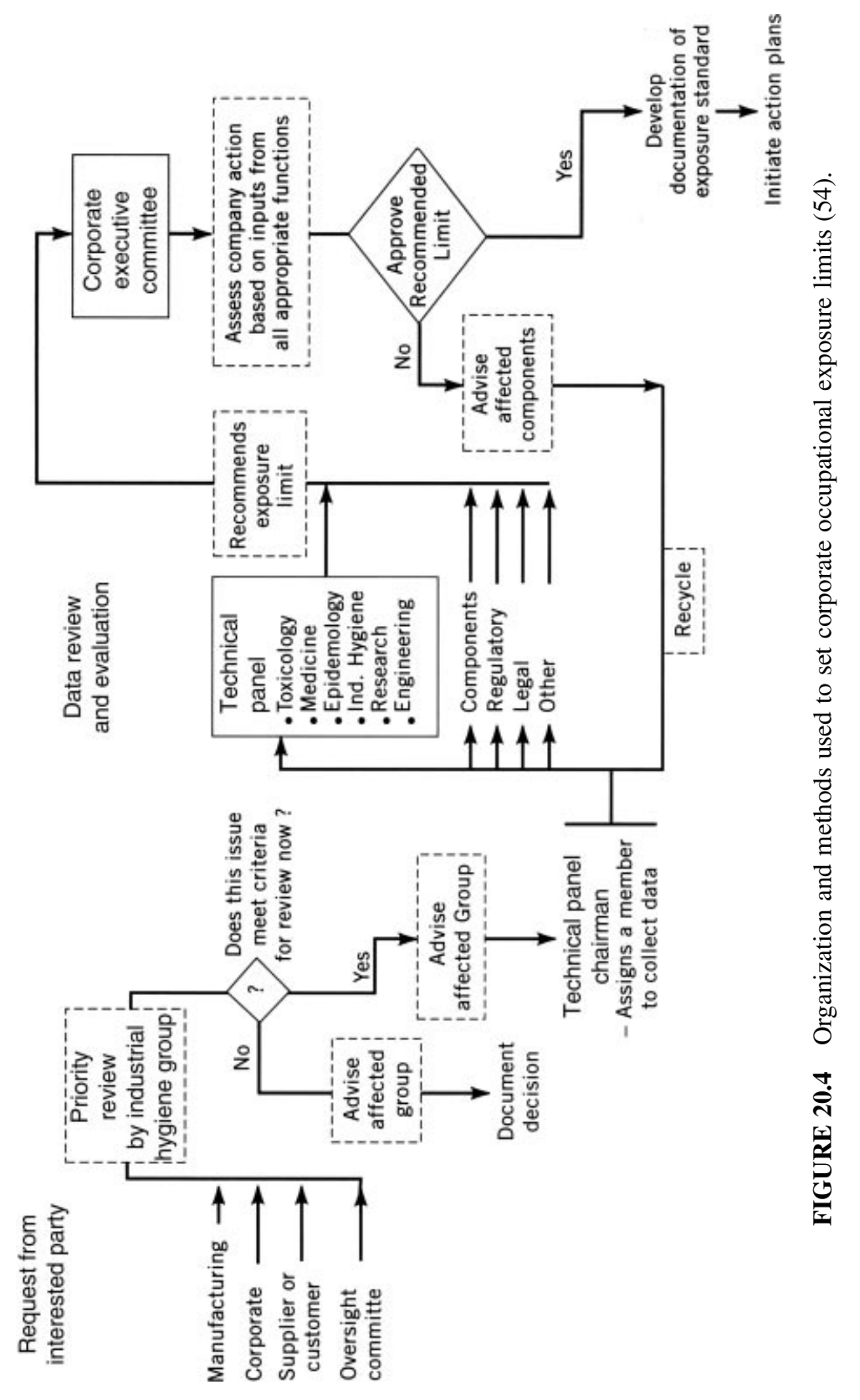


TABLE 20.7 Data often Used in Developing an Occupational Exposure Limit ${ }^{a}$

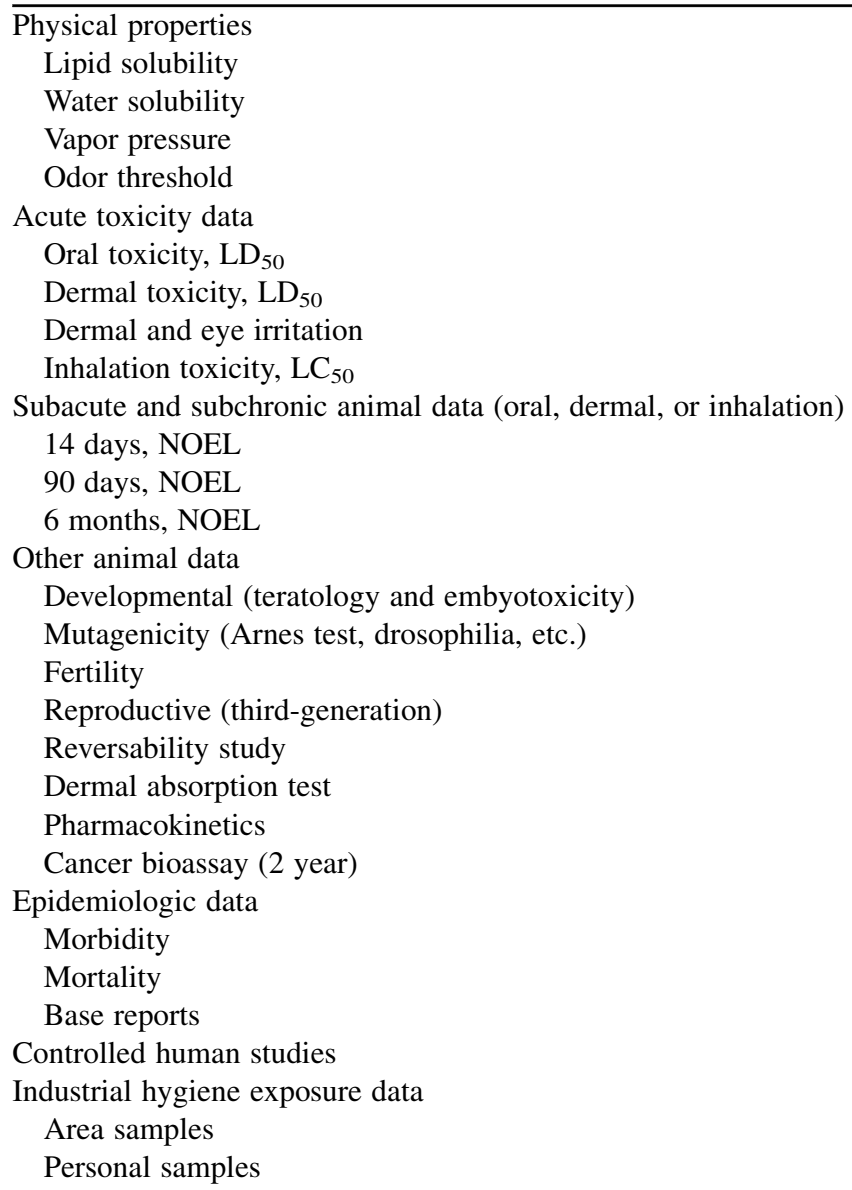

${ }^{a}$ Paustenbach and Langner (54).

to establish, as appropriate, internal exposure levels, including in some instances maximum exposure levels and short-term exposure levels.

Most firms who have established OELs believe that the management of occupational exposure requires limits or criteria much like a manufacturing group needs quality control criteria. Some companies have found that manufacturing groups use OELs to define acceptable versus unacceptable manufacturing conditions. Without these limits as guides, operations managers claim that they would not know when conditions are unhealthy, when personnel need to be protected and, if monitoring is performed, how the results should be interpreted. In short, the experience of the past 30 years indicates that corporate or internal OELs serve a useful purpose (54).

Many firms who have set their own OELs acknowledge that they have done so because they believe in several principles. Foremost is the concept that guidelines are 
needed whenever employees are being exposed. Second, it is imperative that the health of the worker be protected. Third, firms should document the rationale for establishing their guides and share these with the TLV Committee and others. Fourth, if adequate toxicology data are not available, it is still valuable to set tentative exposure limits for a chemical based on exposure levels that have been measured and found to be acceptable. Since scientific data are generally lacking for establishing "exact" exposure levels, this kind of approach seems reasonable and more prudent than simply waiting to see if adverse effects are observed.

The question could be asked "If internal OELs are so beneficial, why do not all companies set them?" The answer to the question is complex. First, the cost of establishing limits through committees is substantial. Based on the author's experience, to establish and document a corporate OEL, about 80-240 professional hours are invested in

1. identifying the proper studies,

2. reading and interpreting them,

3. selecting a preliminary OEL,

4. writing the documentation,

5. having committee meetings,

6. revising the documentation and OEL based on the committee's suggestions, and

7. obtaining reviews of corporate management and the legal department.

At a cost of about $\$ 250$ per hour, this equates to an investment of about $\$ 40,000$ 80,000 per OEL. Second, many firms believe that setting an internal OEL establishes a legal responsibility to meet this limit at all times and that it generates a liability that is otherwise unnecessary. Although these are the two most important issues, others have been mentioned (54).

Nearly all the firms who set OELs have found that perhaps the most difficult and controversial aspects are the legal ramifications. For example, lawyers have noted that if a company develops internal standards on its chemicals or chooses to adopt values for a chemical that are more conservative than those of a regulatory agency, the firm had best plan to comply with them. On the other hand, many lawyers believe that perhaps an equal legal exposure exists with those firms who know a great deal about the potential hazards of a chemical yet do not set internal limits. Admittedly, such a scenario puts manufacturers between a rock and a hard place. For example, some firms may feel that the workmen's compensation immunity does not encourage them to set internal limits on their own chemicals. It is, however, worth bearing in mind that as the manufacturer of a chemical they could be sued by someone else's employee who, if injured, could claim that they did not supply enough data. Although internal limits have been set for nearly 40 years by various firms, there remains controversy about these complex legal issues. 


\section{MODELS FOR ADJUSTING OELS}

Several researchers have proposed mathematical formula or models for adjusting OELs (PELs, TLVs, etc.) for use during unusual work schedules and these have received a good deal of interest in the industrial and regulatory arenas $(34,72$, 142-147). Although OSHA has not officially promulgated specific exposure limits applicable to unusual work shifts, at various times over the years they have published guidelines for use by OSHA compliance officers for adjusting exposure limits (148). These generally apply to work shifts longer than $8 \mathrm{~h}$ per day. Chapter 20 in this volume is devoted to describing how to adjust OELs. Only a couple of methods are described here.

\subsection{Brief and Scala Model}

In the early 1970s, due to the increasingly large number of workers who had begun working unusual schedules, the Exxon Corporation began investigating approaches to modifying the OELs for their employees on $12 \mathrm{~h}$ shifts. In 1975, the first recommendations for modifying TLVs and OSHA PELs were published by Brief and Scala (149), wherein they suggested that TLVs and PELs should be modified for individuals exposed to chemicals during novel or unusual work schedules.

They called attention to the fact that, for example, in a $12 \mathrm{~h}$ workday the period of exposure to toxicants was $50 \%$ greater than in the $8 \mathrm{~h}$ workday, and that the period of recovery between exposures was shortened by $25 \%$, from 16 to $12 \mathrm{~h}$. Brief and Scala noted that repeated exposure during longer workdays might, in some cases, stress the detoxication mechanisms to a point that a toxicant might accumulate in target tissues, and that alternate pathways of metabolism might be initiated. It has generally been held that given the margin of safety in most of the TLVs, there was little potential for frank toxicity to occur due to unusually long work schedules. Based on recent evaluations of the TLVs, the margins of safety are probably not as great as was believed prior to 1990 (86).

Brief and Scala's (149) approach was simple but important since it emphasized that unless worker exposure to systemic toxicants was lowered, the daily dose would be greater, and due to the lesser time for recovery between exposures, peak tissue levels might be higher during unusual shifts than during normal shifts. This concept is illustrated in Figure 20.5. The following formulas for adjusting limits are intended to ensure that this will not occur during unusual work shifts. The following equation was recommended for a 5-day workweek:

$$
\text { TLV Reduction Factor }(\mathrm{RF})=\frac{8}{h} \times \frac{24 h}{16}
$$

where $h$ is the number of hours worked per day 


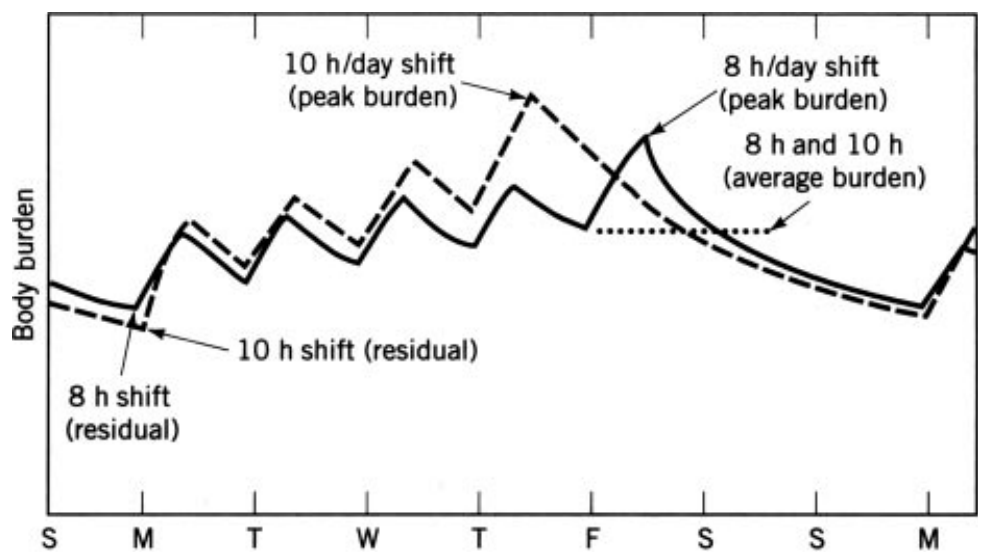

FIGURE 20.5 Comparison of the peak average and residual body burdens of an air contaminant following exposure during a standard $(8 \mathrm{~h} /$ day $)$ and unusual $(10 \mathrm{~h} /$ day $)$ workweek. In this case, the weekly average body burdens are the same for both schedules since each involved $40 \mathrm{~h} /$ week. The residual (Monday morning) body burden of the $8 \mathrm{~h}$ shift worker, however, is greater than the $10 \mathrm{~h}$ shift worker and the peak body burden of the person who worked the $10 \mathrm{~h}$ shift is higher than the $8 \mathrm{~h}$ worker. Based on Ref. 145.

For a 7-day workweek, they suggested that the formula be driven by the $40 \mathrm{~h}$ exposure period; consequently, they developed the following formula, which accounts for both the period of exposure and the period of recovery:

$$
\text { TLV Reduction Factor }(\mathrm{RF})=\frac{40}{h} \times \frac{168 h}{128}
$$

where $h$ is the number of hours exposed per week.

One advantage of these formulas is that the biologic half-life of the chemical and the mechanism of action are not needed in order to calculate a modified TLV. Such a simplification has shortcomings since the reduction factor for a given work schedule is the same for all chemicals even though the biologic half-lives of different chemicals vary widely. Consequently, the Brief and Scala approach should overestimate the degree to which the limit should be lowered.

Brief and Scala (149) were cautious in describing the strength of their proposal and offered the following guidelines for its use. Their caveats should be considered when applying this model and also other approaches:

1. Where the TLV is based on systemic effect (acute or chronic), the TLV reduction factor will be applied and the reduced TLV will be considered as a TWA. Acute responses are viewed as falling into two categories: (a) rapid with immediate onset and (b) manifest with time during a single exposure. The former is guarded by the $C$ notation and the latter are presumed time and concentration dependent, and hence, are amenable to the modifications 
proposed. Number of days worked per week is not considered, except for a 7day workweek discussed later.

2. Excursion factors for TWA limits (Appendix D of the 1974 TLV publication) will be reduced according to the following equation:

$$
\mathrm{EF}=\left(\mathrm{EF}_{8}-1\right) \mathrm{RF}+1
$$

where $\mathrm{EF}$ if the desired excursion, $\mathrm{EF}_{8}$ is the value in Appendix $\mathrm{D}$ for $8 \mathrm{~h}$ TWA, $\mathrm{TW}=\mathrm{TLV}$ reduction factor

3. Special case of 7-day workweek. Determine the TLV reduction factor based on exposure hours per week and exposure-free hours per week.

4. When the novel work schedule involves $24 \mathrm{~h}$ continuous exposure, such as in a submissive or other totally enclosed environment designed for living and working, the TLV reduction technique cannot be used. In such cases, the 90-day continuous exposure limits of the National Academy of Science should be considered, where applicable limits apply.

5. The techniques are not applicable to work schedules less than $7-8 \mathrm{~h}$ per day or $\leq 40 \mathrm{~h}$ per week.

Brief and Scala (149) also correctly noted as follows:

The RF value should be applied (a) to TLVs expressed as time-weighted average with respect to the mean and permissible excursion and (b) to TLVs which have a $\mathrm{C}$ (ceiling) notation except where the $\mathrm{C}$ notation is based solely on sensory irritation. In this case the irritation response threshold is not likely to be altered downward by an increase in number of hours worked and modification of the TLV is not needed.

In short, the Brief and Scala approach is dependent solely on the number of hours worked per day and the period of time between exposures. For example, for any systemic toxicant, this approach recommends that persons who are employed on a $12 \mathrm{~h}$ per day, three or four day workweek, should not be exposed to an air concentration of a toxicant greater than one-half that of workers who work on an $8 \mathrm{~h}$ per day, 5-day schedule.

In their publication, Brief and Scala acknowledged the importance of a chemical's biologic half-life when adjusting exposure limits, but because they believed this information was rarely available, they were comfortable with their proposal. They noted that a reduction in an occupational exposure limit is probably not necessary for chemicals whose primary untoward effect is irritation since the threshold for irritation response is not likely to be altered downward by an increase in the number of hours worked each day (149); that is, irritation is concentration rather than time dependent. Although this appears to be a reasonable assumption, some researchers believe that it may not be entirely justified since duration of exposure could possibly be a factor in causing irritation in susceptible individuals who are not otherwise irritated during normal $8 \mathrm{~h}$ per day exposure periods (95). 
5.1.1 Illustrative Example 1 (Brief and Scala Model) Refinery operators often work a 6-week schedule of three $12 \mathrm{~h}$ workdays for 3 weeks, followed by four $12 \mathrm{~h}$ workdays for three weeks. What is the adjusted TLV for methanol (1998 TLV= $200 \mathrm{ppm}$ ) for these workers? Note that the weekly average exposure is only slightly greater than that of a normal work schedule.

$$
\mathrm{RF}=\frac{8}{12} \times \frac{24-12}{16}=0.5
$$

Solution.

$$
\begin{aligned}
\text { Adjusted TLV } & =\mathrm{RF} \times \mathrm{TLV} \\
& =0.5 \times 200 \mathrm{ppm} \\
& =100 \mathrm{ppm}
\end{aligned}
$$

Note: The TLV reduction factor of 0.5 applies to the $12 \mathrm{~h}$ workday, whether exposure is for 3,4 , or 5 days per week.

5.1.2 Illustrative Example 2 (Brief and Scala Model) What is the modified TLV for tetrachloroethylene $(1998 \mathrm{TLV}=25 \mathrm{ppm})$ for a $10 \mathrm{~h}$ per day, 4 days per week work schedule if the biologic half-life in humans is $144 \mathrm{~h}$ ?

Solution.

$$
\begin{aligned}
& \mathrm{RF}=\frac{8}{10} \times \frac{24-10}{16}=0.7 \\
& \text { Adjusted TLV }=0.7 \times 25=15 \mathrm{ppm}
\end{aligned}
$$

Note: This model and the one used by OSHA do not consider the pharmacokinetics (biologic half-life) of the chemical when deriving a modified TLV. Other models to be discussed later do take this into account.

\subsection{Haber's Law Model}

Most toxicologists believe that, in general, the intensity and likelihood of a toxic response is a function of the mass that reaches the site of action per unit time (150152). This "delivered dose" is usually exposed as the concentration of the chemical in the blood for systemic agents. This principle is simplistic and, while it may not apply to irritants and sensitizers, it is clearly true for the systemic toxins. This assumption is the basis for the OSHA model for modifying PELs for unusual shifts (148), which is based on Haber's Law. The originators of the model assumed that for chemicals that cause an acute response, if the daily uptake (concentration $\times$ time) during a long workday was limited to the amount that would be absorbed during a standard workday, then the same degree of protection would be given to workers on the longer shifts. For 
chemicals with cumulative effects (i.e., those with a long half-life), the adjustment model was based on the dose imparted through exposure during the normal workweek $(40 \mathrm{~h})$ rather than the normal workday $(8 \mathrm{~h})$.

OSHA recognized that the rationale for the OELs for the various chemicals was based on different types of toxic effects. After OSHA adopted the 500 TLVs of 1968 (53) as PEL (29 CFR 1910.1000), and attempted to do the same in 1989 (88), they placed each of the chemicals into different toxicity categories to ensure that an appropriate adjustment model would be used by their hygienists. As can be seen in Examples 3 and 4, the degree to which an exposure limit is to be adjusted, if at all, is based to a large degree on the primary toxic effect of the chemical. The ACGIH TLV Handbook now lists the primary adverse effect associated with each chemical that is most helpful for knowing how to evaluate mixtures and unusually long work schedules (4).

Irrespective of the model that will be used to make the adjustments, including the pharmacokinetic models to be discussed, the table in the Federal Register (88) should be consulted before the hygienist begins the task of modifying an exposure limit. The use of the OSHA tables or the designations of primary adverse effect shown in the most recent ACGIH TLV booklet (4) combined with some professional judgment will prevent hygienists from requiring control measures when they are unnecessarily restrictive as well as minimize the risk of injury or discomfort from overexposure during an unusual exposure schedule.

The objective of OSHA's approach for acute toxicants is to modify the limit for the unusually long shift to a level that would produce a dose $(\mathrm{mg})$ that would be no greater than that obtained during $8 \mathrm{~h}$ of exposure at the PEL. Examples of chemicals with exclusively acute effects include carbon monoxide or phosphine. The following equation is recommended by OSHA for calculating an adjustment limit (equivalent PEL) for these types of chemicals:

$$
\text { Equivalent PEL }=8 \mathrm{~h} \text { PEL } \times \frac{8 \mathrm{~h}}{\text { Hours of exposure per day }}
$$

The other formula recommended by OSHA applies to chemicals for which the PEL is intended to prevent the cumulative effects of repeated exposure, for example, the chronic toxicants. For example, PCBs, PBBs, mercury, lead, and DDT are considered cumulative toxins because repeated exposure is usually required to cause an adverse effect and the overall biologic half-life is clearly in excess of $10 \mathrm{~h}$. The goal of PELs in this category is to prevent excessive accumulation in the body following many days or even years of exposure. Accordingly, the next equation is offered to OSHA compliance officers as a viable approach for calculating a modified limit for chemicals whose half-life would suggest that not all of the chemical will be eliminated before returning to work the following day. Its intent is to ensure that workers exposed more than $40 \mathrm{~h}$ per week will not eventually develop a body burden of that substance in excess of persons who work on normal $8 \mathrm{~h}$ per day, $40 \mathrm{~h}$ per week schedules. 


$$
\text { Equivalent PEL }=8 \mathrm{~h} \text { PEL } \times \frac{40 \mathrm{~h}}{\text { Hours of exposure per week }}
$$

The OSHA models, although less rigorous than the pharmacokinetic models that will be discussed, have certain advantages since they do account for the kind of toxic effect to be avoided, require no pharmacokinetic data, and tend to be more conservative than the pharmacokinetic models.

5.2.1 Illustrative Example 3 (OSHA Model) An occupational exposure limit of $1 \mu \mathrm{g} / \mathrm{m}^{3}$ has been suggested by NIOSH for polychlorinated biphenyls (PCBs). In studies of humans, it has been found that the biologic half-life of PCBs is several years. Animal studies have shown that some can cause cancer at certain doses. What adjustment to the occupational exposure limit might be suggested by NIOSH for workers on the standard $12 \mathrm{~h}$ work shift involving four days of work per week if they adopted the simple OSHA formula?

Solution.

$$
\begin{aligned}
& \text { Recommended limit }=8 \mathrm{~h} \text { PEL } \times 40 \mathrm{~h} / 48 \mathrm{~h} \\
& \text { Recommended limit }=1 \mu \mathrm{g} / \mathrm{m}^{3} \times 0.667=0.833 \mu \mathrm{g} / \mathrm{m}^{3}
\end{aligned}
$$

5.2.2 Illustrative Example 4 (OSHA Model) Many industries such as boat manufacturing are seasonal in their workload. During the months of January, February, March and April, the builders of boats work 5 days per week, $14 \mathrm{~h}$ per day and could be exposed to concentrations of toluene diisocyanate (TDI) at the TLV of $0.005 \mathrm{ppm}$. What occupational exposure limit is recommended for TDI for a person who works 14 h per day for 5 days per week but only works 8 weeks per year?

Solution. No adjustment is necessary.

Note: TDI is categorized as a sensitizer and irritant. Substances in this category have limits that should never be exceeded and consequently the limits are independent of the length or frequency of exposure.

Exposure limits for chemical irritants such as these are currently thought not to require adjustment. Until more is known about human response to irritants during unusually long durations of exposure, the physician, nurse, and hygienist should make note of the employee tolerance to the presence of irritants at levels at or near the TLV. Eventually, human experience will provide information that will help identify those classes of chemicals for which irritation could be a time dependent phenomenon.

\subsection{Pharmacokinetic Models}

Pharmacokinetic models for adjusting occupational limits have been proposed by several researchers $(142-150,153,154)$. These models acknowledge that the maximum body burden arising from a particular work schedule is a function of the 
biological half-life of the substance. Pharmacokinetic models, like the other models, generate a correction factor that is based on the elimination half-life of the substance as well as the number of hours worked each day and week and this is applied to the standard limit in order to determine a modified limit. Unlike the OSHA, as well as the Brief and Scala approaches, by accounting for a chemical's pharmacokinetics, these models can also identify those exposure schedules where a reduction in the limit is not necessary.

The rationale for a pharmacokinetic approach to modifying limits is that during exposure to the TLV for a normal workweek, the body burden rises and falls by amounts governed by the biological half-life of the substance (see Fig. 20.6). A general formula provides a modified limit for exposure during unusual work shifts so that the peak body burden accumulated during the unusual schedule is no greater than the body burden accumulated during the normal schedule. This is the goal of all of the pharmacokinetic models that have thus far been developed.

It is worthwhile to note that the maximum body burden arising from continuous uniform exposure under the standard $8 \mathrm{~h}$ per day work schedule nearly always occurs at the end of the last work shift before the 2-day weekend. The only exception is for some

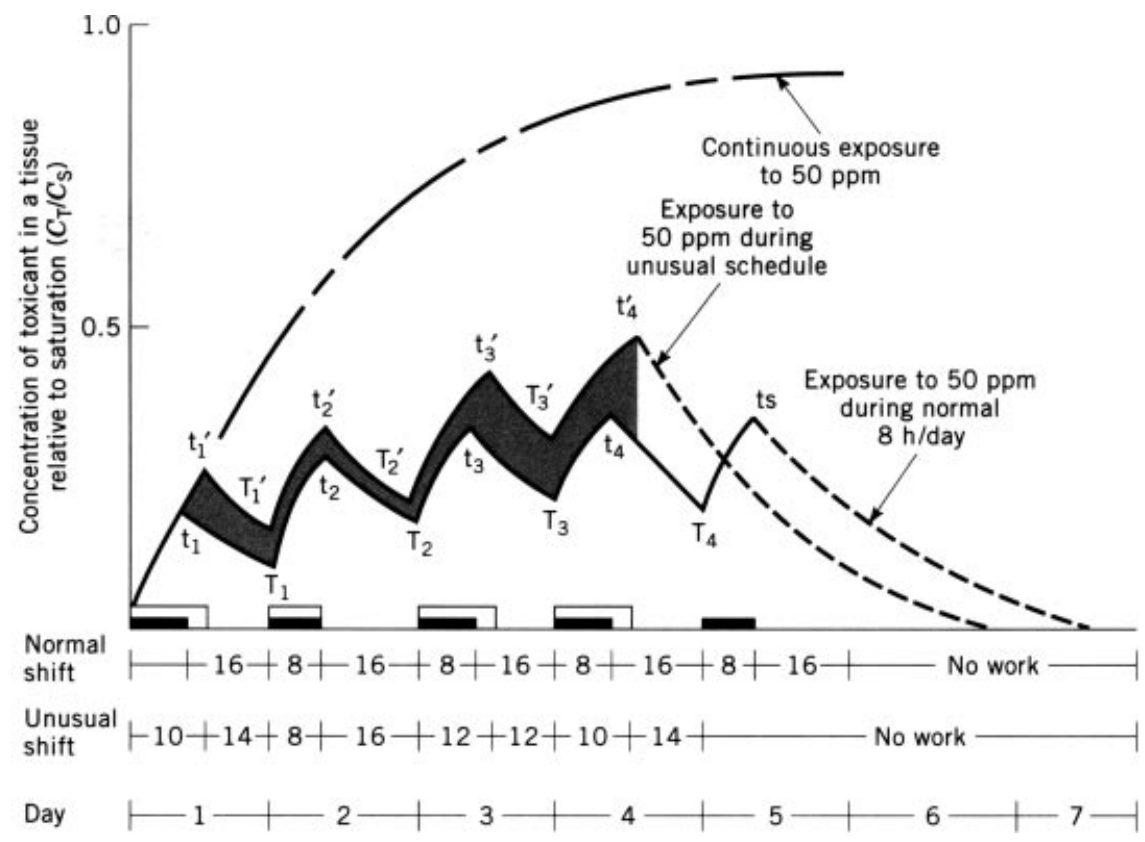

FIGURE 20.6 The accumulation of a substance during irregular periods of intermittent exposure that could occur during unusual work shifts and overtime. This plot illustrates that even when the total weekly dose $(40 \mathrm{~h} \times 50 \mathrm{ppm})$ is unchanged, the peak body burden for two different shift schedules may not be equivalent. To help ensure that the peak tissue concentration for the unusual exposure schedule does not exceed the presumably "safe" level of the normal schedule, the air concentration of toxicant in the workplace may have to be reduced. $K_{\text {elim }}$ has a value of $0.03 \mathrm{~h}^{-1}$ in this illustration. (Courtesy of Dr. J. Walter Mason.) 
of the agents whose biologic half-life is quite long (greater than $16 \mathrm{~h}$ ). On the other hand, the maximum body burden under an extraordinary work schedule may not occur at the end of the last shift of that schedule (Fig. 20.6). This is especially true when the duration and spacing of work shifts that precede the last shift differ markedly from the standard week. Because unusual work schedules can be based on a 2-week, 3-week, 4-week, or even 11-week cycle and the work shift may be $10,12,16$, or even $24 \mathrm{~h}$ in duration, no generalization regarding the time of peak body burden can be offered. The time of peak tissue burden for unusual schedules must therefore be calculated for each specific schedule.

In 1977, Hickey and Reist (144) published a paper describing a general formula approach to modifying exposure limits that was fundamentally equivalent to that of Mason and Dershin (146). The benefits of their work were manifold. First, they validated their approach to some extent by comparing the results with published biological data. Second, they proposed broader uses of the pharmacokinetic approach to modifying limits and presented a number of graphs that could be used to adjust exposure limits for a wide number of exposure schedules. The graphs were based on ( 1 ) the biologic half-life of the material, (3) hours worked each day, and (3) the number of hours worked per week.

Over the next 3 years they wrote publications that illustrated how their model could be used to set limits for persons on overtime (145) and for seasonal workers (142). Hickey's treatment of the topic of adjusting exposure limits is quite thorough and his publications are primarily responsible for most of the interest and research activity in this area. In recent years, other researchers have continued to assess the conditions under which OELs should be adjusted (153).

\subsection{A Physiologically Based Pharmacokinetic (PB-PK) Approach to Adjusting OELs}

As noted previously, the rationale for adjusting OELs for unusual work schedules is to ensure, as much as possible, that persons on these schedules are placed at no greater risk of injury or discomfort than persons who work a standard $8 \mathrm{~h}$ per day, $40 \mathrm{~h}$ per week schedule. For most systemic toxicants, the risk index upon which the adjustments are made will be either peak blood concentration or integrated tissue dose, depending on that chemical's presumed mechanism of toxicity.

The previous section described how one can adjust the OEL using mathematics to ensure that peak tissue levels are not exceeded during long shifts. Unfortunately, these models cannot account for biological factors like enzyme induction or approximate target tissue concentrations. The optimal method for adjusting exposure limits to account for peak blood levels for long workdays, or even continuous exposure, is to base it on a pharmacokinetic approach that accounts for the differences between animals and humans, as well as other biologic factors that are not dealt with through the use of a single term such as biologic half-life. The most sophisticated approach for incorporating these factors involves the use of a PB-PK model. At this time, about 40 papers describing evaluations of at least that many chemicals have been published (Table 20.8) (151). 
TABLE 20.8 Some examples of PB-PK Models for Toxic Substances ${ }^{a}$ that are available

\begin{tabular}{ll}
\hline Benzene & Methanol \\
Benzo $(a)$ pyrene & Methoxyethanol \\
Butoxyethanol & Methyl ethyl ketone \\
Carbon tetrachloride & Nickel \\
Chlorfenvinphos & Nicotine \\
Chloralkanes & Parathion \\
Chloroform & Physostigmine \\
Chloropentafluorobenzene & PBB \\
cis-Dichlorodiamine platinum & PCBs \\
Dichloroethane & Styrene \\
Dichloroethylene & Toluene \\
Dichloromethane & TCDF \\
Dieldrin & TCDD \\
Diisopropylfluorophosphate & Tetrachloroethylene \\
Dimethyloxazolidine dione & Trichloroethane \\
Dioxane & Trichloroethylene \\
Ethylene oxide & Trichlorotribluoroethane \\
Glycol ethers & Vinylidene fluoride \\
Hexane & Xylene \\
Kepone & \\
Lead & \\
\hline
\end{tabular}

${ }^{a}$ This table was presented in a paper by Leung and Paustenbach (151).

At present, the PB-PK approach is recommended only for adjusting OELs for exposure periods of 4-16 h per day.

At present, the PB-PK approach is recommended only for exposure periods of 4-16 h per day. Pharmacokinetic approaches alone should not be relied on for exposure periods greater than $16 \mathrm{~h}$ per day or less than $4 \mathrm{~h}$ per day because the mechanisms of toxicity for some chemicals may vary for very short- or very long-term exposure. For these altered schedules, biological information on recovery, rest periods and mechanisms of toxicity should be considered before any adjustment should be attempted. As noted by Andersen et al. (150), when pharmacokinetic data are not available, a simple inverse formula may be sufficient for adjustment in most instances. Their paper illustrated the use of the PB-PK approach on two industrially important chemicals: styrene and methylene chloride.

\section{OELS OUTSIDE THE UNITED STATES}

OELs have been adopted or established in a number of countries outside the United States. Some information about these various limits is presented in this section. Much of the following information on various countries was obtained from Cook (3) and it represents only a fraction of the information on OELs used in other countries. A compilation of virtually all of the OELs used by various countries is routinely 
published by the World Health Organization (49). The number of substances for select countries that have OELs is shown in Table 20.9 (167).

Recently, a fairly comprehensive analysis of the process for setting OELs was published by Neilsen and Ovrebo (1). A prior review discussed how other countries set limits (51). Vincent offered the following general observations, which provides insight that is necessary to properly interpret OELs set in other countries:

Even for OELs set on the basis of the same scientific data, there are differences in how the OEL is set. The first may derive from divergent opinions about which health endpoint should drive the OEL or about what level or prevalence of ill-health is considered acceptable. Such differences are value-driven, dependent on variations in emotional response to certain types of ill-health, and variations in attitude to risk associated with certain substances. These in turn depend on local cultures and perceptions and cannot be quantified.

If the scientific discussion leading to even a health-based OEL is subject to considerable differences at a number of levels, then opening up the process to consideration of questions beyond health effects leads to further amplification of the differences. Now a completely different set of criteria and values comes into play. They are driven by the

TABLE 20.9 Number of Regulated Substances in Each Individual List and Number of Substances Regulated Uniquely in Those Lists (167)

\begin{tabular}{|c|c|c|c|}
\hline Country/Organisation & $\begin{array}{c}\text { Total Number } \\
\text { of OELs }\end{array}$ & $\begin{array}{c}\text { Number of } \\
\text { CAS-Designated OELs }{ }^{a}\end{array}$ & $\begin{array}{c}\text { Number of } \\
\text { Unique OELS }\end{array}$ \\
\hline $\mathrm{ACG} 1 \mathrm{H}^{c}$ & 763 & 714 & 2 \\
\hline Alberta, Canada & 765 & 664 & 5 \\
\hline Australia & 696 & 616 & 1 \\
\hline British Columbia, Canada & 795 & 685 & 24 \\
\hline California, USA & 732 & 659 & 24 \\
\hline Estonia & 436 & 352 & 5 \\
\hline EU & 105 & 102 & 0 \\
\hline Finland & 760 & 742 & 189 \\
\hline France & 556 & 514 & 5 \\
\hline Germany & 325 & 313 & 30 \\
\hline $\mathrm{JSOH}^{d}$ & 196 & 192 & 13 \\
\hline New Zealand & 660 & 636 & 17 \\
\hline Ontario, Canada & 750 & 677 & 34 \\
\hline OSHA $^{e}$, USA & 543 & 455 & 4 \\
\hline Poland & 541 & 490 & 51 \\
\hline Quebec, Canada & 686 & 628 & 18 \\
\hline Sweden & 436 & 385 & 28 \\
\hline United Kingdom & 414 & 358 & 10 \\
\hline
\end{tabular}

${ }^{a}$ Number of different CAS designations.

${ }^{b}$ Number of substances specified with CAS designations that are only regulated in that list.

${ }^{c}$ American Conference of Governmental and Industrial Hygienists.

${ }^{d}$ Japan Society for Occupational Health.

${ }^{e}$ Occupational Safety and Health Administration. 
question of feasibility. Although feasibility relates to whether a given OEL is practically achievable using known or available technology, there is the underlying rationale related to the cost of achieving a given OEL versus the cost of loss of life or quality of life, and to the local and national need for a given industry to continue to operate and be profitable (and the resultant cost to society were it not to do so).

At the societal or cultural level, it relates to individuals' and society's perceptions of the relative value of risk versus the need for employment and their attitudes toward the role of government in regulating industry and work, and to the ability of the government to set and enforce OELs within the machinery of the given regulatory framework and ethical climate. The issue then becomes part of the wider political discussion. Comparison of the British and U.S. approaches to occupational exposure standards illustrates how such issues can lead to differences. As noted in the SMA report, (7) the British process, based on consensus among industry, workers' unions, and independent experts and backed up by a strong, respected, and demonstrably impartial civil service, develops standards that are recommended to Parliament, which in turn can incorporate them into an existing regulatory framework. The goodwill engendered by this consensus-based process means that the possibility of legal actions to challenge occupational health standards is largely deflected. The same approach would not be possible in the United States because Congress does not have power of final approval over regulatory actions by an executive agency such as OSHA. In addition, culturally, the U.S. approach is greatly influenced by adversarial legal processes.

"Although there are considerable differences in the types of OEL that are set by individual bodies, and the ways in which they are set, there does appear to be some common ground. Perhaps the most striking part is the fact that so many bodies depended strongly on the TLVs in the early years, and that the influence still remains strong today. The role of ACGIH was particularly important at the beginning in establishing a process by which (a) published - and sometimes unpublished — data on health effects and exposures, in humans and in animals, could be documented, evaluated, and discussed in a multidisciplinary peer group; (b) dose-response relationships identified; and (c) health-based OELs arrived at. Although many of the individual national bodies have striven over the years to reexamine the old data (and to include new data) to develop their own OELs independently, progress has been relatively slow. So progress in developing completely home-grown OELs has been slow in most countries and, in view of the effort required to carry out the full process for any given substance, it is likely to remain so. As a result, most of the OELs listed by many individual bodies remain numerically the same as the corresponding ones listed by ACGIH. The differences, where they occur, are for the relatively small number of "difficult" substances that have continued to generate interest by virtue of ongoing public concerns about associated occupational ill-health (e.g., crystalline silica, asbestos and other fibrous dusts, benzene and other solvents, etc.)."

It is suggested that those who wish to better understand some of the differences in philosophy used to set OELs in other countries read not only Vincent (51) but also several other papers on the topic $(1,87,167)$. See also the General References in this chapter. Web sites for various OEL setting groups in Europe are presented in Table 20.10 (1). 
TABLE 20.10 Web Sites with Access to Occupational Exposure Limits in Several European Countries

\begin{tabular}{ll}
\hline Country & Web address \\
\hline Denmark & http://www.at.dk/graphics/at/04-Regler/05-At-vejledininger/ \\
& C-vejledninge/C-0-1-Graensevaerdilisten -2007.pdf \\
Finland & http://www.ketsu.net/htp/index.htm \\
Norway & http://www.arbeidstilsynet.no/c26983/artikkel/vis.html?tid=28880 \\
Sweden & http://www.gr.nl/wgd.php \\
The Netherlands, & \\
DECOS & http://ec.europa.eu/employment_social/health_safety/ \\
The SCOEL & recommendations_en.htm \\
United Kingtom & http://www.hse.gov.uk/coshh/table1.pdf \\
\hline
\end{tabular}

\subsection{Argentina}

Under ANNEX III, Article 60 of the regulation approved for Decree No. 351/79 lists OELs for Argentina that are essentially the same as those of the 1978 ACGIH TLVs. These OELs continue in force. The principal difference from the ACGIH list is that, for the 144 substances (of the total of 630) for which no STELs are listed by ACGIH, the values used for the Argentina TWAs are entered also under this heading.

\subsection{Commonwealth of Australia}

The National Health and Medical Research Council (NHMRC) of the Commonwealth of Australia adopted a revised edition of the Occupational Health Guide Threshold Limit Values (1990-91) in 1992. The OELs have no legal status in Australia, except where specifically incorporated into law by reference. The ACGIH TLVs are published in Australia as an appendix to the occupational health guides, revised with the ACGIH revisions in odd-numbered years. Vincent (51) provides a current analysis of the procedures used in this country.

\subsection{Austria}

The acronym MAC or maximal acceptable (or allowable) concentration was a term used in the USA during the years before the ACGIH introduced the expression TLV. The MAC was translated by both Austria and Germany to MAK for Maximale Arbeitsplatzkonzentration with the same pronunciation.

The Austrian list of values recommended by the Expert Committee of the Worker Protection Commission for Appraisal of MAC Values in cooperation with the General Accident Prevention Institute of the Chemical Workers Trade Union is used by the Federal Ministry for Social Administration. The MAC values were declared obligatory by the Federal Ministry on December 23, 1982, Number 61,710/24-4/82. They are 
applied by the Labor Inspectorate under the authority of the Labor Protection Law, Section 6, Abstract 2 (3).

\subsection{Belgium}

The Administration of Hygiene and Occupational Medicine of the Ministry of Employment and of Labor uses the TLVs of the ACGIH as a guideline in control of occupational health hazards. As of July 13, 1983, the periodically issued Belgian TLV publication was being brought up-to-date with the 1982 ACGIH TLVs (3).

\subsection{Brazil}

The TLVs of the ACGIH have been used as the basis for the occupational health legislation of Brazil since June 8, 1978, through the 3214/78 Edict published by the Ministry of Labor. As the Brazilian workweek is usually $48 \mathrm{~h}$, the values of the ACGIH (1977 TLVs with changes recommended for 1978) were adjusted in conformity with a formula developed for this purpose. The ACGIH list was not adopted in its entirety but only for those air contaminants that at the time had nationwide application. The Ministry of Labor has brought the limits up to date with establishment of values for additional contaminants in accordance with recommendations from the Fundacentro Foundation of Occupational Safety and Medicine (3).

\subsection{Canada}

For each of the various Provinces in Canada, there can be different OELs. In the Province of Alberta, OELs are under the direction of Alberta Regulation 8/82 of the Occupational Health and Safety Act, Chemical Hazard Regulation with amendments up to and including Regulation 242/83. Section 2 of this Act requires the employer to ensure that workers are not exposed above the limits. They are under the direction of the Standards \& Projects Section, Occupational Hygiene Branch, Occupational Health and Safety Division of the Workers' Health, Safety, and Compensation Department (3).

In the Province of British Columbia, the Industrial Hygiene Department, Industrial Health and Safety Division of the Workers' Compensation Board, administers the Industrial Health and Safety Regulations that are legal requirements with which most of British Columbia industry must comply. These requirements refer to the current schedule of threshold limit values for atmospheric contaminants published by the ACGIH (3).

In the province of Manitoba, the Department of Environment and Workplace Safety and Health is responsible for legislation and its administration concerning the OELs. Manitoba relies on the provisions of the Workplace Safety and Health Act (Chapter W210), ("assented to" June 11, 1976) for protection of workers. Section 4 provides that "every employer shall provide and maintain a workplace that is safe and without the risks of health, as far as is reasonably practicable" together with other sections on 
enforcement by the Department of Safety and Health Officer. The guidelines currently used to interpret risk to health are the ACGIH TLVs with the exception that carcinogens are given a zero exposure level "so far as is reasonably practicable" (3).

The New Brunswick Occupational Health and Safety Commission is the authority responsible for the health and safety of workers in this province. Under the Occupational Health and Safety Act, New Brunswick has adopted the ACGIH TLVs. The applicable standards are those published in the latest ACGIH issue and, in case of an infraction, it is the issue in publication at the time of infraction that dictates compliance.

The Northwest Territories Safety Division of the Justice and Service Department regulates workplace safety for nonfederal employees in the Northwest Territories. The latest edition of the ACGIH TLVs has been adopted by the division and these values have the force of law (3).

The Department of Labour and Manpower administers the Public Health Act of Nova Scotia, under which the list of OELs is a legal requirement. This list is the same as that of the ACGIH as published in 1976 and its subsequent amendments and revisions. These permissible exposure levels have been adopted and constituted as regulations under both the Industrial Safety Act and Regulations and the Construction Safety Act and Regulations (3).

In the Province of Ontario, regulations for a number of hazardous substances are enforced under the Occupational Health and Safety Act, Revised Statutes of Ontario, 1980, Chapter 321. These regulations are administered by the Occupational Hygiene Services, Occupational Health Branch, Ministry of Labour. Regulations are published each in a separate booklet that includes the permissible exposure level and codes for respiratory equipment, techniques for measuring airborne concentrations and medical surveillance approaches.

In the Province of Quebec, the Act is administered by the Commission of Occupational Health and Safety. Permissible exposure levels are similar to the ACGIH TLVs and compliance with the permissible exposure levels for workplace air contaminants is a legal requirement in Quebec (3).

\subsection{Chile}

The term "Concentraciones Ambientalis Maximas Permissibles" with the acronym "CAMP" is used for maximum permissible atmospheric concentrations in Chile. This refers to an average exposure during $8 \mathrm{~h}$ daily with a weekly exposure of $48 \mathrm{~h}$ that can be exceeded only momentarily. In the list of permissible exposure limits for Chile, the concentrations of eleven of the substances, indicated by an asterisk, cannot be exceeded for even a moment, these having the capacity of causing acute, severe, or fatal effects.

The CAMP Standards are legally enforceable under Title III on environmental contamination of workplaces of Decreto No. 78 in conformity with the "Sanitary Code." The administration of the Regulation is by the Department of Occupational Health and Environmental Contamination, Institute of Public Health of Chile, 
Ministry of Health. The values in the Chile standard are those of the ACGIH TLVs, to which a factor of 0.8 is applied in view of the $48 \mathrm{~h}$ week (3).

\subsection{Denmark}

The Danish OELs of April 1984 include values for 542 chemical substances and 20 particulates. It is legally required that these not be exceeded as time-weighted averages. Data from the ACGIH are used in the preparation of the Danish standards. About one-fourth of the values are different from those of ACGIH, with nearly all of these being somewhat more stringent (3). A useful review of practices in the Nordic countries was published in 1993 (155).

\subsection{Ecuador}

The Division of Occupational Hazards of the Ecuadorian Institute of Social Security is responsible for control of occupational health hazards, but at this time Ecuador does not have a list of permissible exposure levels incorporated in its legislation. The TLVs of the ACGIH are used as a guide for good industrial hygiene practice (3).

\subsection{European Union}

The evolution of OELs within the European Union began in 1978 when the European Community announced its first Action Programme on Health and safety at work, which first defined a European legal framework for chemicals in the workplace (Walters and Grodski, 2006; 50). Since 1990, an informal advisory board has given recommendations and in 1995 the Scientific Committee on Occupational Exposure Limits (SCOEL) began recommending health-based OELs to the European Commission (50). As noted by Schenk and coauthors (50):

When the SCOEL finds it impossible on the basis of current knowledge to identify threshold doses below which no harm to human health can be guaranteed, the SCOEL recommends a pragmatic OEL that is deemed to carry a sufficiently low risk. The feasibility of the OELs recommended by the SCOEL is evaluated by a separate committee, the Advisory Committee for Safety, Hygiene and Health at Work. It is an assembly of representatives from governments, employers' organizations and trade unions. Indicative OELs are established by the EC when it is concluded that there is a clear threshold dose below which there are no adverse effects on human health. The indicative exposure limits are to be taken into consideration by each member state, but the national OEL is allowed to be higher or lower than the EC indicative OEL. Binding OELs are, as the name implies, mandatory and each member state must either implement the limit set by the EC or a lower limit (Feron, 2003). Up to date decisions have been made on 105 substances resulting in 100 indicative OELs and $1 / 4$ ve binding OELs. These are listed in 91/322/EEC (indicative OELs), 00/39/EC (indicative OELs), 98/24/EC (binding OEL for lead), 03/18/EC (binding OEL asbestos), 04/37/EC (binding OELs for wood dusts, vinyl chloride and benzene) and 06/15/EC (indicative OELs). 
The EU is not a pioneering agency concerning coverage of substances or the level of the OELs; rather, the Commission chooses to set exposure limits for substances already regulated by several European countries. A harmonization of national exposure limits can be expected, since the EU sets both binding and indicative OELs for each member state to consider in its national regulations. However as noted by Vincent (51), a full international harmonization of OELs is unlikely and may not even be the most efficient means to improve the working environment. Vincent proposes an intermediate harmonization' with national lists of exposure limits based on national considerations but with common international criteria and methods.

\subsection{Finland}

The OELs for Finland are defined as concentrations that are deemed to be hazardous to at least some workers on long-term exposure. In the establishment of these values, possible effects to especially sensitive persons such as those with allergies are not taken into consideration, nor are those exposures where the possibility of deleterious effect is very improbable.

It is stated that whereas the ACGIH has as their philosophy that nearly all workers may be reportedly exposed to substances below the threshold limit value without adverse effect, the viewpoint in Finland is just the opposite in considering that where exposures are above the limiting value, deleterious effects on health may occur.

\subsection{Germany}

The definition of the MAC value is "the maximum permissible concentration of a chemical compound present in the air within a working area (as gas, vapor, particulate matter) which, according to current knowledge, generally does not impair the health of the employee nor cause undue annoyance. Under these conditions, exposure can be repeated and of long duration over a daily period of $8 \mathrm{~h}$, constituting an average workweek of $40 \mathrm{~h}$ ( $42 \mathrm{~h}$ per week as averaged over four successive weeks for firms having four work shifts). Scientifically based criteria for health protection, rather than their technical or economical feasibility, are employed."

\subsection{Ireland}

Workplace air contaminants are regulated by Section 20 of the Safety in Industry Act of 1980 under the direction of the Industrial Inspectorate of the Ministry of Labor. For the purpose of enforcing and interpreting this Section, the latest TLVs of the ACGIH are normally used. However, the ACGIH list is not incorporated in the national laws or regulations.

\subsection{Japan}

The process for setting limits in Japan has been described by Cook (3). It is not significantly different from that used in most other countries. In recent years, the 
process for setting limits for certain classes of chemicals has changed from the traditional approach that relied on safety factors to a greater emphasis on more complex approaches. For example, when setting OELs for carcinogens, low-dose extrapolation models and risk criterion like 1 in 1000 or 1 in 10,000 have been adopted (156). Examples of how this approach has been applied were recently described by Kaneko et al. and the Japan Society for Occupational Health (157).

\subsection{Korea}

The process of setting OELS in Korea has evolved over time. As described by Park and Park (158), the Industrial Safety and Health Act (ISHA) of 1981 has been the basis for the regulation of hazardous chemicals in the workplace in Korea.

The Ministry of Labor can establish and notify OELs based on the ISHA and often these are identical to the ACGIH TLVs. There is currently no statutory or centralized process for setting up OELs in Korea. They can, as they see fit, establish their own OELs as they did with 2-bromopropane in 1995.

Currently, Korea evaluates the various OELs established by different organizations and chooses the one that they deem appropriate.

\subsection{The Netherlands}

The OELs are used as a guide by the Labour Inspectorate administered by the Director General of Labour. The levels listed for the Netherlands in Table VII are those published as the "National MAC-list 1985 Arbeidsinspectie P no 145." Most desirably, the substances in this list include the Chemical Abstracts Service (CAS) numbers. These values are a revision of the 1981 and 1982/83 lists based on the advice of the National MAC Commission.

These MAC values are taken largely from the list of the ACGIH. A number of values are based on those of the Federal Republic of Germany's Senate Commission for the Investigation of Health Hazards of Work Materials; others are taken from the recommendations of the United States National Institute of Occupational Safety and Health.

The "Maximal Accepted Concentration" is the term used in Netherlands with emphasis on the word "accepted" rather than acceptable to point to the fact that the MAC value has been accepted by the authorities. The MAC of a gas, vapor, fume or dust of a substance is defined as "that concentration in the workplace air which, according to present knowledge, after repeated long-term exposure even up to a whole working life, in general does not harm the health of workers or their offspring." It is to be noted that the words "or their offspring" in this definition are not included in the definition of the ACGIH, on which the Dutch TLVs are based. In the MAC list, two types of values are used:

1. Maximum Aanaarde Concentratie-tijdgewogen gemiddelde (MAC-TGG). This is the maximal accepted concentration averaged over an exposure period up to $8 \mathrm{~h}$ per day and $40 \mathrm{~h}$ per week. 
2. Maximale Aanvaarde Concentratie-ceiling (MAC-C). This concentration may not be exceeded in any case. A MAC-C is based on short-term toxic action.

\subsection{Philippines}

The Bureau of Working Conditions has adopted the entire list of the 1970 TLVs of the ACGIH. This list was incorporated in the Occupational Safety and Health Standards promulgated in 1978. In 1986, the only deviations from the 1970 list were $50 \mathrm{ppm}$ for vinyl chloride and $0.15 \mathrm{mg} / \mathrm{m}^{3}$ for lead, inorganic compounds, fume and dust (3).

\subsection{Russia (Former USSR)}

The former USSR established many of its limits with the goal of eliminating any possibility for even reversible effects, such as those involving subtle changes in behavioral response, irritation or discomfort. The philosophical differences between limits set in the USSR and in the United States have been discussed by Letavet (159), a Russian toxicologist, who stated the following:

The method of conditioned reflexes, provided it is used with due care and patience, is highly sensitive and therefore it is a highly valuable method for the determination of threshold concentrations of toxic substances.

At times disagreement is voiced with Soviet MAC's for toxic substances, and the argument is that these standards are founded on a method which is excessively sensitive, namely the method of conditioned reflexes. Unfortunately, science suffers not a surplus of excessively sensitive methods, but their lack. This is particularly true with regard to medicine and biology (159).

Although the methods of examination of the higher nervous activity are very sensitive, they cannot be considered to always be the most sensitive indicator of an adverse response and to enable us always to discover the harmful after-effects of being exposed to a poison at the earliest time.

Such subclinical and fully reversible responses to workplace exposures have thus far been considered too restrictive to be useful in the United States and in most other countries. In fact, due to the economic and engineering difficulties in achieving such low levels of air contaminants in the workplace, there is little indication that these limits have actually been achieved in countries that have adopted them. Instead, the limits appear to serve more as idealized goals rather than limits manufacturers are legally bound or morally committed to achieve (58-60).

Vincent (51) provides a recent analysis of the process used in Russia. One of the most informative portions of his report summarizes the Russian MAC setting process:

The MAC development process is entirely toxicological, without reference to occupational hygiene or epidemiology. It is carried out under the auspices of 
the Ministry of Health, acting through the Russian Federation Department of Sanitary and Epidemiological Surveillance (DSES).

In preparing the MACs, the material considered is derived mostly from Russian sources. There is no discussion about prevailing exposure levels in industry, technical feasibility, or economical implications. The development of an MAC for a given substance is based entirely on its potential impact on the health of the worker, to the exclusion of all other considerations. But, even at the level of basic health effects, the criterion for setting an MAC is generally much more stringent than that adopted by other standards-setting bodies.

Of all countries, the OELs used by Russia or the other countries formerly part of the USSR are the most difficult to interpret due to the factors mentioned here. Their applicability to other countries is therefore limited. Shenk et al. (167) recently discussed OELs in the European Union which are now applied to some former republics (203).

\subsection{United Kingdom}

The Control of Hazardous Substances Hazardous to Health Regulations (COSHH) was passed in the United Kingdom in 2005. It represented a major change in the U.K. approach to OELs and the comprehensiveness of application of IH principles to all workplaces. It introduced eight principles, including the following, which apply regardless of whether a substance had an OEL: (1) Assess the risks to health from chemicals and decide what controls are needed, (2) Use those controls and make sure workers use them, (3) Make sure the controls are working properly, (4) Inform workers about the risks to health, (5) Train workers (IOHA, 2009).

Furthermore, the COSHH also introduced a new type of limit, workplace exposure limits (WELs) that are not to be exceeded, replacing the maximum exposure limits (MELs) and occupational exposure standards (OESs). Furthermore, COSHH required assurance that exposure to substances that could cause occupational asthma, cancer, or damage to genes passed down from one generation to the next were reduced as low as reasonably practicable. Since WELs did not exist for a great many substances, the process of control banding (and a focus on prescriptive risk control measures as opposed to exposure monitoring and comparison with an existing OEL) became paramount in the U.K. occupational health system (IOHA, 2009). The U.K. approach, as administered by the Health and Safety Executive considers the concept of tolerable, unacceptable, and generally acceptable (safe) in its selection of an appropriate OEL (Fig. 20.7).

\section{THE FUTURE OF OCCUPATIONAL EXPOSURE LIMITS}

It appears likely that the OEL-setting process will become an increasingly international issue and countries in the future may rely on global limits or consensus standards rather than national standards or national organizations that establish guidance limits. With the advent of REACH, the Globally Harmonized System, and other 


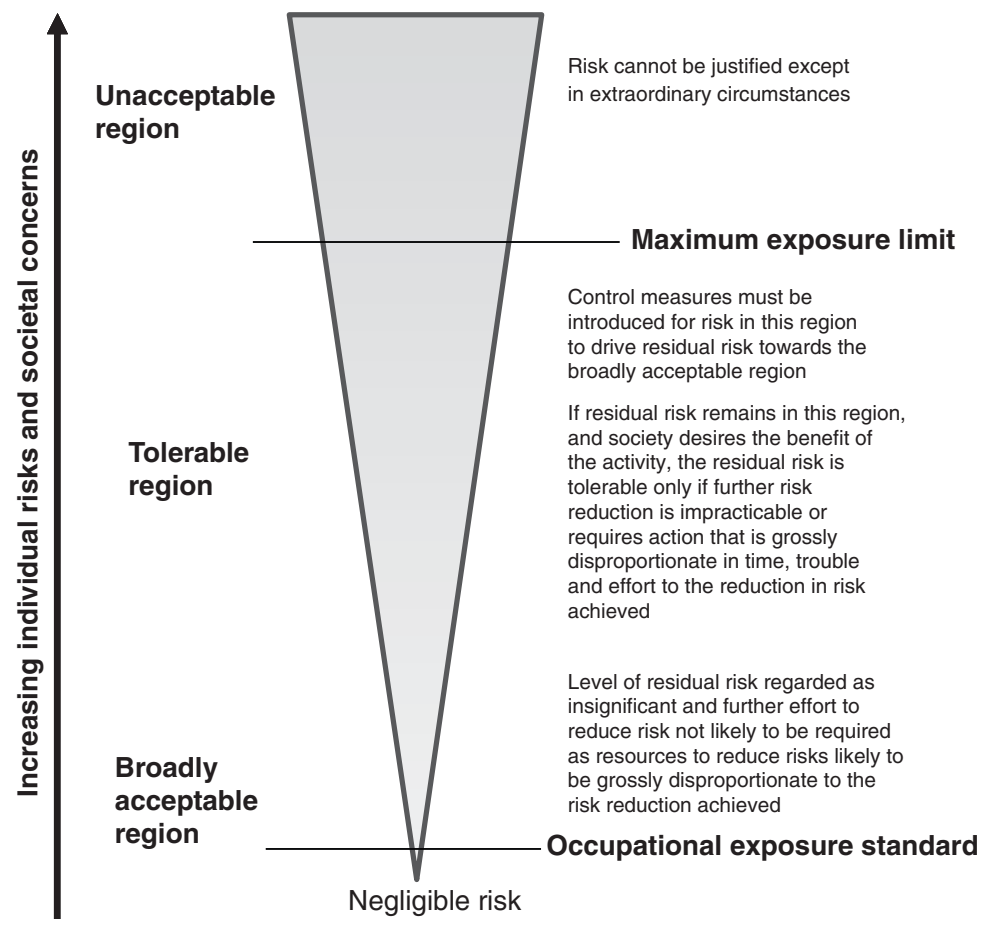

FIGURE 20.7 How OELs fit into the HSE's tolerability of risk framework. (From: Topping, 2001).

developments to streamline the OEL process such as control banding, the OEL setting process of the future may look very different in the years post-2010 $(79,160,161,238)$.

\subsection{Globally Harmonized System}

The Globally Harmonized System of Classification and Labeling of Chemicals (GHS) is an international classification and labeling system for chemicals adopted by the United Nations in 2003 to ensure their safe use, transport, and disposal. These criteria for the classification of chemicals are based on health (toxicological), physical (flammability), and environmental hazards and specify what information should be included on labels of hazardous chemicals and material safety data sheets. The GHS criteria outlines a similar strategy as presented in the Current Intelligence Bulletin 61 for the classification and labeling of chemicals to warn against the health risks of skin exposures, including systemic toxicity, skin irritation or corrosivity, and sensitization $(77,78)$. The GHS risk communication system has been suggested and may represent a strategy for bringing together risk assessment and risk management, and hazard communication in a globally consistent strategy for chemicals, and may provide a context for the use of newer exposure control tools without the need for the same level of technically intensive risk assessment. Although GHS represents a harmonized system, it should not be thought of as a substitute for OELs, rather it is a qualitative 
strategy for determining and communicating risk. For example, if a chemical is classified as a respiratory irritant, the severity of or level at which adverse health effects cannot be determined. However, its critical link to OELs should not be ignored as it presents an opportunity for improving and standardizing the ways in which OELs are used.

\subsection{Control Banding}

Conducting extensive air sampling campaigns and comparing the results to established occupational exposure limits is not always feasible for small- to medium-sized employers (SMEs). Furthermore, not all individual chemicals or mixtures have established OELs. control banding (CB) represents a qualitative technique for the assessment and management of occupational risks. This technique determines a control measure (for example, dilution ventilation, engineering controls, containment, etc.) based on a range or "band" of hazards and controls. The high potency of some pharmaceutical compounds required the use of alternatives to setting numerical OELs, for example, performance-based exposure control limits (PB-ECLs) or occupational exposure bands (OEBs), especially for early development compounds with limited information (Naumann).

Control banding uses the control methodologies that other experts have previously developed to address occupational chemical exposures $(77,78)$. The least complex form of CB involves four levels of risk management options: (1) good occupational hygiene practices, which may be supplemented by use of appropriate PPE; (2) engineering controls, including local exhaust ventilation (LEV); (3) containment; and (4) seeking specialty advice $(77,78)$. In the absence of an established OEL, CB techniques provide guidance to small firms in implementing control options and provide recommendations based on a qualitative assessment of the chemical exposure. $\mathrm{CB}$ techniques do not replace the need for an on-site expert, rather they provide guidance for occupational health issues that have been previously evaluated.

Internationally, a comprehensive control banding model has been adopted by the United Kingdom Health and Safety Executive (HSE) known as the control of substances hazardous to health $(\mathrm{COSHH})$ essentials toolkit. This technique provides guidance specifically for SMEs on controlling the use of chemicals for a range of common industrial tasks (162). Other qualitative CB programs have been developed in the last 10 years including the International Labour Organization Toolkit, BelgiumREGETOX, Norway-KjemiRisk, and Netherlands Stoffenmanager (79, 163). The margins of safety afforded by qualitative $\mathrm{CB}$ programs have been questioned and the authors stated the following:

We believe that by shifting the focus away from meeting health-based exposure levels in favor of installing specified control technologies, without making target exposure levels explicit, COSHH Essentials and the Toolkit may not adequately protect worker health. By not including the target exposure bands in COSHH Essentials and the Toolkit, users are forced to look elsewhere to identify appropriate exposure limits with which to demonstrate adequate exposure control, effectively undermining the goals of the 
systems: to make occupational safety and health more accessible to small businesses, and to provide exposure limit guidance when formal occupational exposure limits are lacking. In our view, introducing such systems without providing end users sufficient information to gauge the level of control permits a false sense of health protection in the workplace (164).

The formal adoption of CB programs as an alternative to OELs by other countries outside of the United Kingdom is unclear at this time, but interest in the method has been high. Other methods have focused on the banding of exposures rather than controls. One example is Bayesian Decision Analysis (BDA), which represents a method for formally integrating professional judgment and monitoring data into a single decision output (210).

\subsection{REACH-Derived No-Effect Levels}

The promulgation of the European Union's Registration Evaluation Authorization and Restriction of Chemical substances (REACH) has forced all manufacturers to classify chemicals as posing "insignificant risk" or to establish a level of exposure that is believed not to represent a risk to human health. In the absence of sufficient data, it has been suggested that rigorous derived no-effect levels (DNELs) be established. $\mathrm{REACH}$ and the associated guidance require the DNEL for each route of exposure to be based on the study that gives rise to the highest observed degree of concern, following the precautionary principle (165).

DNELs are established through a stepwise process where all available toxicology data are compiled and reviewed. Dose descriptors such as no-observable-adverseeffect levels (NOAELs), lowest-observed-adverse-effect levels (LOAELs), benchmark doses (BMDs), $\mathrm{LD}_{50}$ levels, and others are corrected and modified to establish an allowable level of exposure (239). The first step of the DNEL process is to gather all available information, with an emphasis on studies of highest quality. This enables the risk assessor to establish a database of dose descriptors for appropriate routes of exposure, addressing a variety of human health endpoints. These dose descriptors will then be corrected for differences in absorption, route of entry, experimental conditions, and in exposure parameters. The use of chemical-specific information is encouraged if available, but default factors are provided in most cases. This series of steps gives rise to a corrected dose descriptor (DDcorr). If necessary, assessment factors (AFs, analogous to safety factors) are then applied to the corrected dose descriptor. Default factors are provided in some cases for inter- and intraspecies differences, exposure duration, uncertainty in dose-response relationships, and to account for quality of the database of dose descriptors (Table 20.4). Assessment factors can be modified if appropriate scientific justification can be provided.

Williams and colleagues (165) opined that a series DNELs will be generated for multiple human health endpoints in workers and consumers via the environment, and also possibly sensitive subpopulations. DNELs will also be derived for relevant routes of exposure, and for acute versus chronic exposures. These will be prioritized to the most critical DNEL for each subcategory. DNELs will be included in safety data 
sheets, and also as part of classification and labeling procedures under REACH. It is possible that the importance and impact of the REACH process will compliment or even possibly replace the OEL setting process in the future.

\subsection{Where the TLV Process is Going}

The degree of reduction in TLVs or other OELs that will undoubtedly occur in the coming years will vary depending on the type of adverse health effect to be prevented, for example, central nervous system depression, acute toxicity, odor, irritation, cancer, developmental effects, or others $(50,139)$. It is unclear to what degree the TLV Committee will rely on various predictive cancer models or the risk criteria (e.g., 1 in 1000 cancer risk) after 2010. Currently, there is a significant change in philosophy occurring within ACGIH regarding TLVs. However, one thing is clear-transparency in the approach used to set any OEL will be expected by those who are going to apply these guidance values.

During the past 15 years, the ACGIH TLV Committee has worked diligently to make their work more transparent. The benefits of this effort are generally evident in the documentation for the various TLVs that have been published over the past 3-10 years. For example, the 1996 Documentation of the TLV for formaldehyde is 24 pages in length and cites more than 200 references. The version published in 1990 was two pages long and cited about 20 papers. Over the past 10 years, the documentations have continude to increase in quality. Regrettably, the fact that the documentations are much more thorough than in the past does not necessarily mean that all of the key papers have been carefully read and thoroughly understood. Often, the truly important or definitive papers have been weighed equally with those of lesser quality. Also, many documentations still lack a clear and concise explanation of how the limit was identified. That is, the critical study or studies upon which the NOEL was based are not always identified and the rationale for the size of the UF is rarely described. These shortcomings are simply a reflection of the time constraints placed on persons who serve on voluntary committees.

A question that might be raised is "Why hasn't the TLV Committee been able to carefully read each and every published paper on a chemical, understand the subtleties of the experimental method, document the entire process, then select the ideal occupational exposure limit?" Although in some or many cases the committee may have had the time to understand all published data regarding a chemical, there are a number of cases where it did not. Perhaps the primary reason the derivation for many of the TLVs is not well described and, in some cases, the ideal value was not selected, is that a marginally adequate number of human and financial resources have been dedicated to the task of setting these values. One must remember that those on the committee have always been unpaid volunteers. Each of these professionals allocates more than $200 \mathrm{~h}$ each year to the business of setting TLVs simply because they believe these values have helped prevent disease in millions of workers. However, the time these professors or senior researchers can devote to conducting detailed analyses is quite limited. In the past, at various times, the burden of finding the published papers, carefully comparing and contrasting the different experimental methods, and 
resolving differences in results, was done as a labor of love by government employees, professors, and industry consultants to the TLV committee. In some cases, many years ago, these professionals were given support by their employers and some spent as much as 50\% of their workweek performing TLV Committee work. During the 1960s and 1970s, this was more commonplace because industrial hygiene groups in the government and in industry had much larger staffs and more generous budgets than have been seen in recent years. Based on discussions with those who have served, it appears that the industry consultants and the regular members of the TLV Committee now try to limit their time commitment to 3-5 days a month.

This level of historical employer support (both government and private sectors) lessened in the 1980s and 1990s as it was assumed that professionals within NIOSH and OSHA, using tax money, should begin displacing the TLVs with OSHA PELs and NIOSH RELs. In fact, the NIOSH criteria documents of the 1970s and 1980s were often more than 100 pages in length with dozens of references, and they rapidly became "the standard" by which future documentations of the TLVs would be compared. About 100 criteria documents were written between 1975 and 1985 and each provided a reasonably complete story of all toxicological and analytical chemistry issues related to a particular chemical. During the same time, the legal liabilities of setting and not meeting TLVs and other OELs (citable under Section 5A1 of OSHA) took on greater significance so corporations were less anxious to devote their resources to a program that might pose some incremental legal exposure and increase what was already considered a heavy regulatory burden. Thus, a serious chasm occurred about 1985 between the amount of effort expected to go into the development of the TLVs and the resources available to perform the work. To make matters worse by 1990, the consultants to the TLV Committee from industry who had for many years performed much of the literature searches, copying, and preliminary analyses were discouraged from being as active due to complaints that industry had had undue influence on the TLV setting process (131).

The availability of funds or professional resources is not the only reason that many current TLVs are not sufficiently well documented to satisfy every health professional. The other reason is that "the bar has been set much higher than its historical placement." In short, the quality of analysis that health professionals, lawyers, and the courts have come to expect since about 1990 has frequently gone beyond what can be provided by volunteers. The compilation of information and the analyses that were invested in the NIOSH criteria documents and the proposed OSHA standards of the 1980s and early 1990s were much more comprehensive than that envisioned as necessary by those who originally established the TLV setting process. One reason the TLV documentation fell short of these other efforts with respect to documentation was that it was not the original intent of the ACGIH to publish "permanent" values that would be "cast in stone." Rather, the goal was to disseminate information to health professionals to assist them in helping to protect workers from harm or discomfort. To perform this service, more than 50 years ago the ACGIH asked the most reputable and knowledgeable persons in the field to analyze what was known about a chemical and to suggest a value that was expected to be protective. After the value was proposed, then various parties could submit comments and documentation for the next two years 
so that a new TLV could be proposed, if appropriate. In short, the TLVs did not have to be scientifically "bulletproof" since they were to be dynamic values that could be changed in rather short periods of time.

The ACGIH anticipated that those who worked with the chemical each day would have an interest in providing the best possible guidance to fellow health professionals, so they expected any shortcomings in the documentation to be brought to their attention by their colleagues. One must remember that the TLVs came about as a direct result of a concern by health professionals that insufficient information was being shared within the occupational health community to help hygienists protect workers. They were never intended to be dissertation quality analyses. The committee has always encouraged those who were truly expert, including professionals in the firms who used various chemicals, to submit information that would help identify the best possible limits.

Does this discussion suggest that the TLV setting process needs to change? The answer is yes. As was recently discussed by the out going President of the ACGIH, Dr. Jimmy Perkins (166), in his document entitled "TLV/BEI sustainability," it is necessary for permanent funding to be available to support the TLVs or this activity may need to end. The past 10 years of litigation involving the TLV process has been too costly with respect to time and money for an organization like the ACGIH to handle. For it to be truly sustainable, that is, have a long and productive future, a fairly substantial fund needs to be established in order to insure that the quality of future TLVs are sufficient to whether the scrutiny of so many interested parties, maybe as much as \$10-20 million.

In order to satisfy the scrutiny of the global occupational health community, as well as weather the challenges of the United States court system, ACGIH will have to significantly revamp their process, as well as the intent, of the OEL process. There is simply too much information, and the scientific expertise needed to interpret many of these studies is so specialized, that unassailable work products (e.g., Documentations of TLVs) cannot be reasonably provided by a group of volunteers who have a very limited support staff.

If, however, the ACGIH continues to make their "Documentation of the TLVs" more transparent, and if it encourages interested parties to perform the vast amount of the tedious work needed to understand a chemical and to document the rationale for the suggested OEL, and if it is willing to provide modest stipends to the committee members to support graduate students who can do much of the background work, and add several permanent staff at ACGIH, then the TLV setting process could survive. In our view, this will require at least a $\$ 20 \mathrm{M}$ fund (which is much more than Dr. Perkins has recommended).

Based on the numerous scholarly evaluations of the historical OEL setting process that were performed over the past 10 years, both domestically and internationally, and the number of new chemicals that deserve to be evaluated, it is likely that the ACGIH TLVs will in the coming years will not be the primary source of occupational exposure limits $(1,167)$. The enormous gathering of toxicology data that is occurring within the U.S. EPA computational toxicology program, coupled with the rigorous examination of the data that is being gathered under the REACH initiative (165), as well as the dedication of resources by various organizations in Great Britain and the EU, will 
almost certainly dwarf the efforts that any small nongovernmental organization like ACGIH can assemble.

If this occurs, it will not be a sad ending but rather the beginning of a new and better process that will protect literally billions (rather than hundreds of millions) of workers around the world. It is the natural evolution of the scientific and social process. Instead of having 5-10 studies to consider, these OEL setting groups will often have nearly 100 studies for each chemical. Instead of devoting a few hours to discussing the OEL, the process could involve days of discussion and the production of a 30-50 page document. We believe the methodology used to set the OEL will ultimately be very similar to what has been used for more than 60 years. The critical toxicologic effect will be identified, a NOEL for that effect will be selected based on some type of "weight of evidence" analyses, and some safety factor will be applied in an attempt to protect all or virtually all of the exposed workers. The difference going forward is that the endpoints will surely be more subtle and a larger fraction of the population will be protected. That is, the OELs will continue to get lower and lower over time. This has been true since 1960 and it will continue as the economy improves in the industrialized nations. By any standard, this is good and surely Warren Cook, Herb Stokinger, and John Doull, and others who have served as chairman of the TLVs would be pleased with the journey.

During this period of introspection about how to improve the TLV setting process, we should not forget that thousands of lives have been saved as a result of these values and that, to the best of our knowledge, as stated by Stokinger more than 20 years ago, few if any workers "have been shown to have sustained serious adverse effects on his health as a result of exposure to these concentrations of an industrial chemical" (7).

\section{CONCLUSIONS}

Although it is not possible for any single book chapter to discuss how each of the various biological issues should be evaluated when establishing an OEL, many of them have at least been generally addressed here. It should be clear from the discussion that the process for setting OELs remains remarkably similar to those that were used in the late 1940s but that the quality and quantity of data used to set these limits, as well as the methodology, has evolved with our increased level of scientific understanding and funding. It is also clear that as occupational health professionals develop a better understanding of toxicology and medicine, techniques for quantitatively accounting for pharmacokinetic differences among chemicals and more refined approaches for identifying safe levels of exposure will be developed.

\section{BIBLIOGRAPHY}

1. G. D. Nielsen and S. Ovrebo, "Background, Approaches and Recent Trends for Setting Health-Based Occupational Exposure Limits: A Minireview," Regul. Toxicol. Pharmacol. 51, 253-269 (2008). 
2. M. E. LaNier, Threshold Limit Values: Discussion and 35 year index with recommendations (TLVs: 1946-81), American Conference of Governmental Industrial Hygienists Cincinnati, OH, 1984.

3. W. A. Cook, Occupational Exposure Limits-Worldwide, American Industrial Hygienists Association, Akron, OH, 1987.

4. ACGIH (American Conference of Governmental Industrial Hygienists), 2010 Threshold Limit Values for Chemical Substances and Physical Agents and Biological Exposure Indices, American Conference of Governmental Industrial Hygienists, Cinncinnati, $\mathrm{OH}$ (2009a).

5. J. Doull, "ACGIH Approach and Practice," Appl. Occup. Environ. Hyg. 9, 23-24 (1994).

6. H. E. Stokinger, Criteria and Procedures for Assessing the Toxic Responses to Industrial Chemicals, Permissible Levels of Toxic Substances in the Working Environment, ILO, World Health Organization, Geneva, 1970.

7. H. E. Stokinger, Threshold Limit Values: Part 1, Dangerous Properties of Industrial Materials Report, 1981, pp. 8-13.

8. B. Ramazinni, De Morbis Atrificum Diatriba (Diseases of Workers), The University of Chicago Press, Chicago, IL, 1700.

9. W. A. Cook, "Maximum Allowable Concentrations of Industrial Contaminants," Ind. Med. 14, 936-946 (1945).

10. H. F. Smyth, "Improved Communication; Hygienic Standard for Daily Inhalation," Am. Ind. Hyg. Assoc. Q. 17, 129-185 (1956).

11. A. M. Baetjer, "The Early Days of Industrial Hygiene. "Their Contribution to Current Problems," Am. Ind. Hyg. Assoc. J. 41, 773-777 (1980).

12. B. Sicherman, Alice Hamilton: A life in letters, Harvard University Press, Cambridge, 1984, pp. 476.

13. K. B. Lehmann, "Experimentelle Studien uber den Einfluss Technisch und Hygienisch Wichtiger Gase und Dampfe auf Organismus: Ammoniak und Salzsauregas," Arch. Hyg. 5, 1-12 (1886).

14. K. B. Lehmann and L. Schmidt-Kehl, "Die 13 Wichtigsten Chlorkohlenwasserstoffe der Fettreihe vom Standpunkt der Gewerbehygiene," Arch. Hyg. Barkt. 116, 131-268 (1936).

15. R. Kobert, "The Smallest Amounts of Noxious Industrial Gases Which are Toxic and the Amounts Which May Perhaps Be Endured," Compendium of Practical Toxicology, 545 (1912).

16. H. H. Schrenk, "Interpretation of Permissible Limits," Am. Ind. Hyg. Assoc. Q. 8, 55-60 (1947).

17. A. C. Fieldner, S. H. Katz, and S. P. Kenney, Gas Masks for Gases Met in Fighting Fires, in: U.S. Department of the Interior, Bureau of Mines, Pittsburgh, PA, 1921.

18. NSC (National Safety Council), Final Report of the Committee of the Chemical and Rubber Sector on Benzene, National Bureau of Casualty and Surety Underwriters, 1926.

19. PPC (Pretoria Portland Cement Company Limited), Report of Miners', Johannesburg, Union of South Africa, 1916.

20. R. R Sayers, Toxicology of Gases and Vapors, International Critical Tables of Numerical Data, Chemistry and Toxicology, McGraw-Hill, New York, 1927.

21. R. R. Sayers and J. M. Dalle Valle, "Prevention of Occupational Diseases other Than Those That Are Caused by Toxic Dust," Mech. Eng. 57, 230-234 (1935). 
22. K. B. Lehmann and F. Flury, Toxikologie und Hygiene der technischen Losungsmittel Julius, Springer Verlag, Berlin, 1938.

23. M. Bowditch, D. K. Drinker, P. Drinker, H. H. Haggard, and A. Hamilton, "Code for Safe Concentrations of Certain Common Toxic Substances Used in Industry," J. Ind. Hyg. Tox. 22, 251 (1940).

24. Y. Henderson and H. H. Haggard, Noxious Gases and the Principles of Respiration Influencing their Action, Reinhold Publishing Corp., New York, 1943.

25. F. Flury and F. Zernik, Schadliche Gase, Dampfe, Nebel, Rauch-und Staubarten Julius, Springer Verlag, Berlin, 1931.

26. Chemical manufacturers ASSN. An International Review of processes for establishing occupational exposure limits. American Industrial Hygiene, Assn. Press Fairfax, VA, (1996).

27. WHO (World Health Organization), Occupational Exposure Limits for Airborne Toxic Substances, International Labor Office, Geneva, 1995.

28. M. L. Dourson and J. F. Stara, "Regulatory History and Experimental Support of Uncertainty (Safety) Factors," Regul. Toxicol. Pharm. 3, 224-238 (1983).

29. A. Lehman and O. G. Fitzhugh, "100-Fold Margin of Safety," Assoc. Food Drug Off. Q. Bull. 18, 33-35 (1954).

30. D. J. Paustenbach, "Occupational Exposure Limits: Their Critical Role in Preventive Medicine and Risk Management," Am. Ind. Hyg. Assoc. J. 51, A332-A336, (1990). Editorial.

31. L. E. Adkins, et al., "Letter to the Editor," Appl. Occup. Environ. Hyg. 5, 748-750 (1990).

32. C. W. Cooper, "Indicators of Susceptibility to Industrial Chemicals," J. Occ. Med. 15, 355-359 (1973).

33. R. G. Smith and J. B. Olishifski. "Industrial Toxicology," in J. B. Olishifski, Ed., Fundamentals of Industrial Hygiene, National Safety Council, Chicago, IL, 1988, pp. 359-386.

34. ACGIH (American Conference of Governmental Industrial Hygienists), Documentation of Threshold Limit Values (TLVs), ACGIH, Cincinnati, OH, 45240 (2009b).

35. D. J. Paustenbach, "Unusual Workshifts and Pharmacokinetics," in Patty's Industrial Hygiene and Toxicology, Chapter 21, John Wiley and Sons, New York, NY, 2010.

36. BEIR (Committee on the Biological Effects of Ionizing Radiation). BEIR VII Phase 2 Report, "Health Risks from Exposure to Low Levels of Ionizing Radiation," Committee to Assess Health Risks from Exposure to Low Levels of Ionizing Rediation; Board on Radiation Effects Research; Division on Earth and Life Studies; National Research Council of the National Academies the National Academies Press; Washington, D.C. (2006).

37. J. C. Bailer, E. A. C. Crouch, R. Shaikh, and D. Spiegelman, "One-Hit Models of Carcinogenesis: Conservative or Not?" Risk Anal. 8, 485-497 (1988).

38. B. E. Butterworth, R. B. Connolly, and I. J. Morgan, "A Strategy for Establishing Mode of Action of Chemical Carcinogens as a Guide for Approaches to Risk Assessment," Cancer Lett. 93, 129-146 (1995).

39. C. N. Park and N. C. Hawkins. "Cancer Risk Assessment," in L. J. Cralley, et al. Eds., Patty's Industrial Hygiene and Toxicology, John Wiley \& Sons, New York, 1995, pp. 275-318. 
40. L. G. Hernandez, H. van Steeg, and J. van Benthem, "Mechanisms of Non-Genotoxic Carcinogents and the Importance of a Weight of Evidence Approach," Mutat. Res. 682, 94-109 (2009).

41. J. Bus and J. E. Gibson. "Body Defense Mechanisms to Toxicant Exposure," in L. J. Cralley, et al. Eds., Patty's Industrial Hygiene and Toxicology, John Wiley \& Sons, New York, 1995.

42. K. Crump, "Calculation of Benchmark Doses from Continuous Data," Risk Anal. 15, 79-85 (1995).

43. J. P. Seiler, “Apparent and Real Thresholds: A Study of Two Mutagens," in D. Scott, et al. Eds., Progress in Genetic Toxicology, Elsevier Biomedical Press, New York, 1977.

44. C. F. Wilkinson, "Being More Realistic About Chemical Carcinongenesis," Environ. Sci. Technol. 9, 843-848 (1988).

45. J. V. Rodricks, S. Brett, and G. Wrenn, "Significant Risk Decisions in Federal Regulatory Agencies," Regul. Toxicol. Pharm. 7, 307-320 (1987).

46. P. Hewitt, "Interpretation and Use of Occupational Exposure Limits for Chronic Disease Agents," Occup. Med. 11, 561-590 (1996).

47. OSHA (Occupational Safety and Health Association), "Occupational Exposure to Asbestos: Final Rule,” Fed. Regist. 59(153), 40964-41162, 1994.

48. C. C. Travis, S. A. Richter, E. A. C. Crouch, R. Wilson, and E. Wilson, "Cancer Risk Management: a Review of 132 Federal Regulatory Decisions," Environ. Sci. Technol. 21, 415-420 (1987).

49. H.B. Elkins, "Maximum Acceptable Concentration, A Comparison in Russia and the United States," AMA Arch. Environ. Health 2, 729-742, (1961).

50. L. Schenk, C. Ruden, S. Ove Hansson, and M. Gilek, "Abstract R49- Risk Assessment and Occupational Exposure Limits," Toxicol. Lett. 180S, S74 (2008a).

51. J. H. Vincent, "International Occupational Exposure Standards: A Review and Commentary," Am. Ind. Hyg. Assoc. J. 59, 729-742 (1998).

52. APHA (American Public Health Association), Health Based Exposure Limits and Lowest National Occupational Exposure Limits, APHA, Washington, DC, 1991.

53. OSHA (Occupational Safety and Health Association), U. S. Congress (91st) S.2193, P. Law, OSHA, Washington, DC, 1970, pp. 91-596.

54. D. J. Paustenbach and R. R. Langner, "Setting Corporate Exposure Limits: State of the Art," Am. Ind. Hyg. Assoc. J. 47, 809-818 (1986).

55. E. V. Sargent, B. D. Naumann, D. G. Dolan, E. C. Faria, and L. Schulman, "The Importance of Human Data in the Establishment of Occupational Exposure Limits," Human and Ecol. Risk Assess. 8, 805-822 (2002).

56. E. I. Lyublina, Some Methods Used in Establishing the Maximum Allowable Concentrations. MAC of Toxic Substances in Industry, Volume 1, 109-112 (1962).

57. J. M. Manson and Y. J. Kang. "Test methods for Assessing Female Reproductive and Development Toxicology," in A. W. Hayes, Ed., Principles and Methods in Toxicology, Raven Press, New York, 1994, pp. 989-1038.

58. H. L. Magnusson, "Industrial Toxicology in the Soviet Union Theoretical and Applied," Am. Ind. Hyg. Assoc. J. 25, 185-190 (1964).

59. H. E. Stokinger, "International Threshold Limit Values," Am. Ind. Hyg. Assoc. J. 24, 469 (1963). 
60. C. C. Willhite and N. N. Oseas, "Reconciliation of American TLVs and German MAKs," Occup. Hyg. 4, 1-16 (1997).

61. J. Perkins, The Practice of Industrial Hygiene, (a 3 volume text), American Conference of Government Industrial Hygienists, Cincinnati, OH, 2000.

62. WHO (World Health Organization), Methods Used in Establishing Permissible Levels in Occupational Exposure to Harmful Agents, International Labor Office, World Health Organization, Geneva, 1977.

63. H. E. Stokinger, "The Case for Carcinogen TLVs Continues Strong," Occup. Health Saf. 46, 54-58 (1977).

64. B. Clayton, R. Kroes, J. C. Larsen, and G. Pascal, "Applicability of the ADI to Infants and Children," Food Addit. Contam. 15, 1-90 (1998).

65. E. J. Calabrese, Methodological Approaches to Deriving Environmental and Occupational Health Standards, John Wiley \& Sons, New York, 1978.

66. E. J. Calabrese, Principles of Animal Extrapolation, John Wiley \& Sons, New York, 1983.

67. H.P. Illing, "Extrapolating from Toxicity Data to Occupational Exposure Limits: Some Considerations," Am. Occup. Hyg. 35, 569-580 (1991).

68. H. W. Leung and D. J. Paustenbach, "Setting Occupational Exposure Limits for Irritant Organic Acids and Bases Based on their Equilibrium Dissociation Constants," Appl. Occup. Environ. Hyg. 3, 115-118 (1988a).

69. H. W. Leung and D. J. Paustenbach, "Application of Pharmacokinetics to Derive Biological Exposure Indexes from Threshold Limit Values," Am. Ind. Hyg. Assoc. J. 49, 445-450 (1988b).

70. C. S. Weil, "Statistics Versus Safety Factors and Scientific Judgment in the Evaluation of Safety," Man. Toxicol. Appl. Pharmicol. 21, 454-463 (1972).

71. R. L. Zielhuis and F. W. Van Der Kreek, "Calculations of a Safety Factor in Setting Health Based Permissible Levels for Occupational Exposure. A Proposal II. Comparison of Extrapolated and Published Permissible Levels," Int. Arch. Occup. Environ. Health 42, 203-215 (1979a).

72. R. L. Zielhuis and F. W. Van Der Kreek, "Calculations of a Safety Factor in Setting Health Based Permissible Levels for Occupational Exposure. A Proposal I," Int. Arch. Occup. Environ. Health 42, 191-201 (1979b).

73. AIHA (American Industrial Hygiene Association), An International Review of Procedures for Establishing Occupational Exposure Limits AIHA, Fairfax, VA, 1996.

74. D. J. Paustenbach, Y. Alarie, T. Kulle, R. G. Smith, J. Swenberg, M. Witschi, S. Horowitz, and N. Schachter, "A Recommended Occupational Exposure Limit for Formaldehyde Based On Irritation,” J. Toxicol. Environ. Health 50, 217-263 (1997).

75. D. A. Neumann and C. A. Kimmel, Human Variability in Response to Chemical Exposure, I.L.S. Institute, Washington, DC, 1998a.

76. L. Schenk, S. O. Hansson, C. Ruden, and M. Gilek, "Are Occupational Exposure Limits Becoming More Alike with the European Union?" J. Appl. Toxicol. 28, 858-866 (2008c).

77. NIOSH (National Institute for Occupational Safety and Health), A Strategy for Assigning New NIOSH Skin Notations, Current Intelligence Bull. 61, Dept. of Health and Human Services, NIOSH. Publication No. 2009-147, Cincinnati, OH, 2009. 
78. NIOSH, Qualitative Risk Characterization and Management of Occupational Hazards: Control Banding. Retrieved on 10/14/2009 from www.cdc.gov/niosh/topics/ctrlbanding.

79. D. M. Zalk and D. I. Nelson, "History and Evaluation of Control Banding: A Review," J. Occup. Environ. Hyg. 5, 330-346 (2008).

80. D. G. Barnes and M. L. Dourson, "Reference Dose (RfD): Description and Use in Health Risk Assessments," Regul. Toxicol. Pharm. 8, 471-486 (1988).

81. A. M. Jarabek, M. G. Menache, et al, "The U. S. Environmental Protection Agency's Inhalation RfD Methodology: Risk Assessment for Air Toxics," Toxicol. Ind. Health 6, 279-301 (1990).

82. EPA (Environmental Protection Agency), Integrated Risk Information Systems Database, Washington, DC, 1996.

83. M. L. Dourson, "Methods for Establishing Oral Reference Doses (RfD)," in W. Mertz, et al. Eds., Risk Assessment of Essential Elements, ILSI Press, Washington, DC. 1994, pp. 51-61.

84. A. G. Renwick and N. R. Lazarus, "Human Variability and Non-Cancer Risk Assessment: An Analysis of Default Uncertainty Factor," Regul. Toxicol. Pharm. 27, 3-120 (1998).

85. M. L. Dourson, S.P. Felter, and D. Robinson, "Evolution of Science-Based Uncertainty Factors for Noncancer Risk Assessment," Regul. Toxicol. Pharm. 24, 108-120 (1996).

86. S. A. Roach and S. M. Rappaport, "But They are not Thresholds: A Critical Analysis of the Documentation of Threshold Limit Values," Am. Ind. Hyg. Assoc. J. 17, 727-753 (1990).

87. M. Meldrum, "Setting Occupational Exposure Limits for Sensory Irritants: The Approach in the European Union," Am. Ind. Hyg. Assoc. 62, 730-732 (2001).

88. OSHA (Occupational Safety and Health Association), "Air Contaminants: Final Rule," Fed. Regist. 54, 2332-2983, 1989.

89. S. H. Gaffney and D.J. Paustenbach, "A Proposed Approach for Setting Occupational Exposure Limits for Sensory Irritants Based on Chemosensory Models," Ann Occup. Hyg. 51, 345-356 (2007).

90. M. H. Abraham, G. S. Whiting, Y. Alarie, et al., "Hydrogen Bonding 12. A New QSAR for Upper Respiratory Tract Irritation by Airborn Chemicals in Mice," Quant. Struct. Relat. 9, 6-10 (1990).

91. Y. Alarie, "Dose Response Analysis in Animal Studies: Prediction of Human Responses," Environ. Health Perspect. 42, 9-13 (1981).

92. Y. Alarie and G. D. Nielsen, "Sensory Irritation, Pulmonary Irritation, and Respiratory Stimulation by Airborne Benzene and Alkylbenzenes: Prediction of Safe Industrial Exposure Levels and Correlation with their Thermodynamic Properties," Toxicol. Appl. Pharmacol. 65, 459-477 (1982).

93. L. E. Kane and Y. Alarie, "Sensory Irritation to Formaldehyde and Acrolein during Single and Repeated Exposures in Mills," Am. Ind. Hyg. Assoc. J. 38, 509-522 (1977).

94. G. D. Nielsen, "Mechanisms of Activation of the Sensory Irritant Receptor by Airborne Chemicals," Crit. Rev. Toxicol. 21, 183-208 (1991).

95. M. Schaper, "Development of a Database for Sensory Irritants and Its Use in Establishing Occupational Exposure Limits," Am. Ind. Hyg. Assoc. J. 54, 488-544 (1993).

96. D. J. Paustenbach, "Approaches and Considerations for Setting Occupational Exposure Limits (OELs) for Sensory Irritants: Report of a Recent Symposia," Am. Ind. Hyg. Assoc. J. 62, 697-704, (2001). 
97. E. M. Johnson, "Cross-Species Extrapolations and Biologic Basis for Safety Factor Determinations in Developmental Toxicology," Regul. Toxicol. Pharm. 8, 22-36 (1988).

98. J. L. Schardein, Chemically Induced Birth Defects, 2nd ed., Marcel Dekker, New York, 1993.

99. EPA (Environmental Protection Agency), Proposed Guidlines for Health Assessment of Suspect Developmental Toxicants, Federal Regulations, Washington, DC, 1986.

100. D. W. Gaylor, "Quantitative Risk Analysis for Quantal Reproductive and Developmental Effects," Environ. Health Perspect. 79, 243-246 (1989).

101. E. M. Johnson, "A Case Study of Developmental Toxicity Risk Estimation Based on Animal Data. The Drug Bendectin," in D. J. Paustenbach, Ed., The Risk Assessment of Environmental Hazard: A Textbook of Case Studies, John Wiley \& Sons, New York, 1989, pp. 724-771.

102. C. A. Kimmel, R. J. Kavlock, B. C. Allen, and E. M. Faustman, "Benchmark Does Concept Applied to Data from Conventional Development Toxicity Studies," Toxicol. Lett. 82(88), 549-554 (1995).

103. D. A. Karnovsky,in J. G. Wilson and J. Warrany, Eds., Teratology: Principle and Techniques, University of Chicago Press, Chicago, IL, 1965.

104. D. J. Paustenbach, "Assessment of Developmental Risks Resulting form Occupational Exposure to Select Glycol Ethers within the Semi-Conductor Industry," J. Toxicol. Environ. Health 23, 53-96 (1988).

105. H. Zenick, E. D. Clegg, S. D. Perreault, G. R. Klinefelder, and L. Earl Gray, "Assessment of Male Reproductive Toxicity: a Risk Assessment Approach," in A. W. Hays, Ed., Principle and Methods of Toxicology, Raven Press, New York, 1994, pp. 937-988.

106. J. P. J. Mavrissen and J. L. Mattsson. "Neurotoxicology: An Orientation,” in L. J. Cralley, et al., Eds., Patty's Industrial Hygiene and Toxicology, 3rd ed., John Wiley \& Sons, New York, 1995, pp. 231-254.

107. H. W. Leung, D. J. Paustenbach, and F. J. Murray, "A Proposed Occupational Exposure Limit for 2,3,7,8-TCDD," Am. Ind. Hyg. Assoc. J. 49, 466-474 (1988).

108. G. Briatico-Vangosa, C. L. Braun, G. Cookman, T. Hofmann, I. Kimber, S. E. Lovless, T. Morros, J. Pauluhn, T. Sorensen, and H. J. Niessen, "Respiratory Allergy: Hazard Identification and Risk Assessment," Fundam. Appl. Toxicol. 23, 145-158 (1994).

109. K. Sarlo and M. H. Karol. "Guinea Pig Productive Tests for Respiratory Allergy," in Dean, et al., Eds., Immunotoxicolgy and Immunopharmacology, Raven Press, 1994.

110. C. Graham, H.S. Rosenkranz, and M.H. Karol, "Structure-Activity Model of Chemicals that cause Human Respiratory Sensitization," Regul. Toxicol. Pharm. 26, 296-306 (1997).

111. B. N. Ames, L. S. Gold, and W. C. Willet, "The Causes and Prevention of Cancer," Proc. Natl. Acad. Sci. 92, 5258-5265 (1995).

112. J. E. Klaunig and L. M. Kamendulis. "Chemical Carcinogenesis," in C. Klaassen, et al. Eds., Casarett and Doull's Toxicology: The Basic Science of Poisons, 7th ed., McGraw-Hill, New York, (2008), pp. 201-267.

113. M. C. R. Alavanja, C. Brown, and R. Spirtas, M. Gomez, "Risk Assessment of Carcinogens: A Comparison of the ACGIH and the EPA," Appl. Occup. Environ. Hyg. 5, 510-517 (1990). 
114. D. Krewski, D. Murdoch, and J. Withey, "Recent Developments in Carcinogenic Risk Assessment," Health Phys. 57, 313-325 (1989).

115. ILSI (International Life Sciences Institute), Low-Dose Extrapolation of Cancer Risks, (S. S. Olin, et al. Eds.), Washington, DC, 1995.

116. K. Crump, D. G. Hoel, G. H. Langley, and R. Peto, "Carcionogenic Processes and their Implications for Low Dose Risk Assessment," Cancer Res. 36, 2973-2979 (1976).

117. C. D. Holland and R. L. J. Sielken, Quantitative Cancer Modeling and Risk Assessment, Prentice Hall, Englewood Cliffs, NJ 1993.

118. D. J. Paustenbach, "Health Risk Assessments: Opportunities and Pitfalls," Columbia J. Environ. Law 14, 379-410 (1989).

119. R. S. H. Yang, Toxicology of Chemical Mixtures: Case Studies, Mechanisms, and Novel Approaches, Academic Press, New York, 1994.

120. F. R. Cassee, J. P. Groten, P. J. van Bladeren, and V. J. Feron, “Toxicological Evaluation and Risk Assessment of Chemical Mixtures," Crit. Rev. Toxicol. 28, 73-101 (1998).

121. EPA (Environmental Protection Agency), Approaches to Risk Assessment for Multiple Chemical Exposures, Washington, DC, 1984.

122. IGHRC (Interdepartmental Group on Health Risks from Chemicals), Chemical mixtures: A framework for assessing risk to human health (CR14), Institute of Environment and Health, Cranfield University, Bedfordshire, UK, 2009.

123. T. Schneider, R. Vermeulen, D. H. Brouwer, J. W. Cherri, H. Kromhout, and C. L. Fogh, "Conceptual Model for Assessment of Dermal Exposure," Occup. Environ. Med. 56, 765-773 (1999).

124. T. Schneider, J. W. Cherrie, R. Vermuelen, and H. Kromhouts, "Dermal Exposure Assessment," Am. Occup. Hyg. 44, 493-499 (2000).

125. J. D. Walker, C. Whittaker, and J. N. McDougal, "Role of TSCA Interagency Testing Committee in Meeting the U.S. Government's Data Needs: Designating Chemicals for Percutaneous Absorption Testing," in F. N. Marzulliand H. I. Maibach, Eds., Dermatotoxicology, 5th ed., Hemisphere Publishing Corporation, Washington, DC, 1996, pp. 371-381.

126. J. B. Nielsen, and P. Grandjean, "Criteria for Skin Notation in Different Countries," Am. J. Ind. Med. 45, 275-280 (2004).

127. J. Lavoué, A. Milon, and P. O. Droz, "Comparison of Indices Proposed as Criteria for Assigning Skin Notation,” Ann. Occup. Hyg. 52, 747-756 (2008).

128. D. H. Brouwer, L. Hoogendoorn, P. M. Bos, P. J. Boogaard, W. L. De Kort, and J. J. Van Hemmen, "Proposal for the Assessment of Quantitative Dermal Exposure Limits in Occupational Environments. Part 2. Feasibility Study for Application in an Exposure scenario for MDA by Two Different Dermal Exposure Sampling Methods," Occup. Environ. Med. 55, 805-811 (1998).

129. P. M. Bos, D. H. Brouwer, H. Stevenson, P. J. Boogaard, W. L. de Kort, and J. J. van Hemmen, "Proposal for the Assessment of Quantitative Dermal Exposure Limits in Occupational Environments. Part 1. Development of a Concept to Derive a Quantitative Dermal Occupational Exposure Limit," Occup. Environ. Med. 55, 795-801 (1998).

130. B. I. Castleman and G. E. Ziem, "Corporate Influence on Threshold Limit Values," Am. J. Ind. Med. 13, 531-559 (1988).

131. B. I. Castleman and G. E. Ziem, “Toxic Pollutants, Science, and Corporate Influence," Arch. Environ. Health 44(68), 127 (1989). 
132. J. A. Finklea, (1988) "Threshold Limit Values: A Timely Look," Am. J. Ind. Med. 14, 211-212.

133. E. S. Tarlau, "Industrial Hygiene with No Limits," Am. Ind. Hyg. Assoc. J. 51, A9-A10 (1980). A Guest Editorial.

134. P. S. Guzelian, C. J. Itenry, and S. S. Olin, Similarities and Differences Between Children and Adults, International Life Sciences Institute, Washington, DC, 1992.

135. ACGIH (American Conference of Governmental Industrial Hygienists), "Threshold Limit Values: A More Balanced Appraisal," Appl. Occup. Environ. Hyg. 5, 340-344 (1990).

136. S. M. Rappaport, "Threshold Limit Values, Permissible Exposure Limits, and Feasibility: the Bases for Exposure Limits in the United States," Am. J. Ind. Med. 23, 683-694 (1993).

137. B. I. Castleman and G.E. Ziem, "American Conference of Governmental Industrial Hygienists: Low Threshold Credibility," Am. J. Ind. Med. 26, 133-143 (1994).

138. J. Graham and J. Hartwell, The Greening of American Business, Harvard University Press, Cambirdge, MA (1997).

139. D. J. Paustenbach, "Putting Politics Aside, Updating the PELs," Am. Ind. Hyg. Assoc. J. 58, 845-849 (1997).

140. D. A. Neumann and C. A. Kimmel, Human Variability in Response to Chemical Exposures: Measures, Modeling and Risk Assessment, CRC Press, Boca Raton, 1998b.

141. L. T. Haber and A. Maier, "Scientific Criteria Used for the Development of Occupational Exposure Limits for Metals and Other Mining-Related Chemicals," Regul. Toxicol. Pharm. 36, 262-279 (2002).

142. J. L. S. Hickey, “Adjusting of Occupational Exposure Limits for Seasonal Occupations," Am. Ind. Hyg. Assoc. J. 41, 261-263 (1980).

143. J. L. S. Hickey, "The 'TWAP' in the Lead Standard," Am. Ind. Hyg. Assoc. J. 44, 310-311 (1983).

144. J. L. S. Hickey and P. C. Reist, “Application of Occupational Exposure Limits to Unusual Work-Schedules,” Am. Ind. Hyg. Assoc. J. 38, 613-621 (1977).

145. J. L. S. Hickey and P. C. Reist, "Adjusting Occupational Exposure Limits for Moonlighting, Overtime, and Environmental Exposure," Am. Ind. Hyg. Assoc. J. 40, 727-734 (1979).

146. J. W. Mason and H. Dershin, "Limits to Occupational Exposure in Chemical Environments Under Novel Work Schedules," J. Occ. Med. 18, 603-607 (1976).

147. S. A. Roach, "Threshold Limit Values for Extraordinary Work Schedules," Am. Ind. Hyg. Assoc. J. 39, 345-364 (1978).

148. OSHA (Occupational Safety and Health Association), OSHA Compliance Officers Field Manual, Department of Labor, OSHA, Washington, DC, 1976.

149. R. S. Brief and R. A. Scala, "Occupational Exposure Limits for Novel Work Schedules," Am. Ind. Hyg. Assoc. J. 36, 467-471 (1975).

150. M. E. Andersen, M. G. MacNaughton, H. J. Clewell, and D. J. Paustenbach, “Adjusting Exposure Limits for Long and Short Exposure Periods Using a Physiological Pharmacokinetic Model," Am. Ind. Hyg. Assoc. J. 48, 335-343 (1987).

151. H. W. Leung and D. J. Paustenbach, "Physiologically-Based Pharmacokinetic and Pharmacodynamic Modeling in Health Risk Assessment and Characterization of Hazardous Substances," Toxicol. Lett. 79, 55-65 (1995). 
152. M. A. Ottobani, The Dose Makes the Poison, 2nd ed., Van Nostrand, New York, 1991.

153. R. Goyal, K. Krishnan, R. Tardif, S. Lapare, and J. Brodeur, “Assessment of Occupational Health Risks during Unusual Workshifts: Review of the Needs and Solutions for Modifying Environmental and Biological Limit Values for Organic Solvents," Cancer J. Public Health 83, 109-112 (1992).

154. D. J. Paustenbach, "Occupational Exposure Limits, Pharmacokinetics, and Unusual Work Schedules,” in R. L. Harris, et al. Eds., Patty's Industrial Hygiene and Toxicology, John Wiley \& Sons, New York, 1994, pp. 191-301.

155. B. Beije and P. Lundberg, Occupational Exposure Limits: Health Based Values or Administrative Norms? Proceedings of the First Intercouse on OELs, National Institute of Occupational Health, Visby, Sweden, 1993.

156. K. Takahashi and T. Higashi, "The Development and Regulation of Occupational Exposure Limits in Japan," Regul. Toxicol. Pharm. 46, 120-125 (2006).

157. T. Kaneko, P.Y. Wang, and A. Sato, "Development of Occupational Exposure Limits in Japan," Int. J. Occup. Med. Health 11, 81-98 (1998).

158. D. Park and D. Y. Park, "The Development and Regulation of the Occupational Exposure Limits in Korea," Regul. Toxicol. Pharm. 46, 126-130 (2006).

159. A. A. Letavet, Scientific Principles for the Establishment of the Maximum Allowable Concentrations of Toxic Substances in the USSR, Proceedings of the 13th Annual Congress on Occupational Health, July 25-29, Book Craftsmen Associates, New York, 1961.

160. E. Rutkowski, “Updating PELs: Is Now the Time,” The Synergist 20, 39-42 (2009).

161. R. Skoglund and D. Deeds, "Global Impact: GHS and REACH Will Transform Worker Health Programs," The Synergist 20, 30-33 (2009).

162. M. Topping, "Occupational Exposure Limits for Chemicals," Occup. Environ. Med. 58, 138-144 (2001).

163. A. L. Bracker, T. F. Morse, and N. J. Simcox, "Training Health and Safety Committees to Use Control Banding: Lessons Learned and Opportunities for the United States," J. Occup. and Environ. Hyg. 6, 307-314 (2009).

164. R. M. Jones and M. Nicas, "Margins of Safety Provided by COSHH Essentials and The ILO Chemical Control Toolkit," Ann. Occup. Hyg. 2, 149-156 (2005).

165. E. S. Williams, J. Panko, and D. J. Paustenbach, "The European Union's REACH Regulation: A Review of Its History and Requirements," Crit. Rev. Toxicol. 39, 553-575 (2009).

166. J. Perkins, Developing Sustainable TLVs and BEIs, A proposal to the membership of the ACGIH, Cincinnatti, Ohio, 2010.

167. L. Schenk, S. O. Hansson, C. Ruden, and M. Gilek, "Occupational Exposure Limits: A Comparative Study," Regul. Toxicol. Pharm. 50, 261-270 (2008b).

168. T. W. Armstrong, D. J. Caldwell, and D. K. Verma, "Occupational Exposure Limits: An Approach and Calculation Aid for Extended Work Schedule Adjustments," J. Occup. Environ. Hyg. 2, 600-607 (2005).

169. M. Batke, S. Escher, A. Bitsch, C. Melber, N. Simetska, K. Konieczka, S. Czerczak, and I. Mangelsdorf, "Breath: A database on occupational exposure limits and local irritation," Toxicol. Lett. 180S, S62 (2008). Abstract R06.

170. P. Bigelow, D. Moore, and A. Yassi, “Assessing the Health Implications for Healthcare Workers of Regulatory Changes Eliminating Locally Developed Occupational Exposure 
Limits in Favor of TLVs: An Evidence-based Bipartite Approach,” Int. J. Occup. Med. Heatlh 10, 433-444 (2004).

171. H. M. Bolt and A. Huici-Montagud, "Strategy of the Scientific Committee on Occupational Exposure Limits (SCOEL) in the Derivation of Occupational Limits for Carcinogens and Mutagens," Arch. Toxicol. 82, 61-64 (2007).

172. B. E. Butterworth and T. Slaga, Nongenotoxic Mechanisms in Carcinogenesis: Banbury Report 25, Cold Spring Harbor Laboratory, Cold Spring Harbor, NY, 1987.

173. A. C. Capleton and L. S. Levy, "An overview of occupational benzene exposures and occupational exposure limits in Europe and North America," Chemico-Biological Interactions, 153-154, 43-53 (2005).

174. R. Crebelli, "Threshold-Mediated Mechanisms in Mutagenesis: Implications in the Classification and Regulation of Chemical Mutagens," Mutat. Res. 464, 129-135 (2000).

175. Dalton, "Evaluating the Human Response to Sensory Irritation: Implications for Setting Occupational Exposure Limits," Am. Ind. Hyg. Assoc. 62, 723-729 (2001).

176. J. E. Dennison, P. L. Bigelow, and M. E. Andersen, "Occupational exposure limits in the context of solvent mixtures, consumption of ethanol, and target tissue dose," Toxicol. Ind. Health 20, 165-175 (2004).

177. M. J. Duggan, and B. E. Lambert, "Standards for Environmental, Non-Threshold, Carcinogens: A Comparison of the Approaches Used for Radiation and for Chemicals," Ann. Occup. Hyg. 42, 315-323 (1998).

178. V. J. Feron, J. H. E. Arts, and J. Mojet, "Approach to Setting Occupational Exposure Limits for Sensory Irritants in the Netherlands," Am. Ind. Hygiene Assoc. 62, 733-735 (2001).

179. L. Henderson, S. Albertini, and M. Aardema, "Thresholds in Genotoxicity Responses," Mutat. Res. 464, 123-128 (2000).

180. IARC (International Agency for Research on Cancer), Mechanisms of Carcinogenesis in Risk Identification, World Health Organization, IARC Scientific Publications No. 116, Lyon, France, 1992.

181. M. A. Jayjock, P. G. Lewis, and J. R. Lynch, "Quantitative Level of Protection Offered to Workers by ACGIH Threshold Limit Values Occupation Exposure Limits," Am. Ind. Hyg. Assoc. 62, 4-11 (2001).

182. JSOH (Japan Society for Occupational Health), "Recommendation of Occupational Exposure Limits," J. Occup. Health 47, 354-370 (2005).

183. JSOH (Japan Society for Occupational Health), "Recommendation of Occupational Exposure Limits," J. Occup. Health 50, 426-433 (2008).

184. D. J. Kirkland and L. Muller, "Interpretation of the Biological Relevance of Genotoxicity Test Results: The Importance of Thresholds," Mutat. Res. 464, 137-147 (2000).

185. M. Kirsch-Volders, M. Aardema, and A. Elhajouji, "Concepts of Threshold in Mutagenesis and Carcinogenesis," Mutat. Res. 464, 3-11 (2000).

186. J. H. Lange, U. Fedeli, and G. Mastrangelo, "Letter to the Editor: Is Mushroom Workers' Chronic Cough the Same as Byssinosis and What Should the Occupational Exposure Limit Be for Endotoxin?," Am. Coll. Chest Physicians 123: 2160-2161 (2007).

187. D. P. Lovell, "Dose-Response and Threshold-Mediated Mechanisms in Mutagenesis: Statistical Models and Study Design," Mutat. Res. 464, 87-95 (2000).

188. J. McDougal, "Methods for Assessing Risks of Dermal Exposures in the Workplace," Crit. Rev.Toxicol. 32, 291-327 (2002). 
189. R. H. McKee, A. M. Medeiros, and W. C. Daughtrey, "A Proposed Methodology for Setting Occupational Exposure Limits for Hydrocarbon Solvents," J. Occup. Environ. Hyg. 2, 524-542 (2005).

190. D. Michaels, P. Lurie, and C. Monforton, "Lung Cancer Mortality in the German Chromate Industry, 1958-1998," J. Occup. Environ. Med. 48, 995-997 (2006). Letter to the Editor.

191. E. Moustacchi, "DNA Damage and Repair: Consequences on Dose-Responses," Mutat. Res. 464, 35-40 (2000).

192. B. D. Naumann and E. V. Sargent. Control Banding in the Pharmaceutical Industry, White paper retrieved on October 15, 2009 from Australian Institute of Occupational Hygienists, Available at http://www.aioh.org.au/downloads/documents/ ControlBandingBNaumann.pdf.

193. J. M. Parry, G. J. S. Jenkins, F. Haddad, et al., "In Vitro and In Vivo Extrapolations of Genotoxin Exposures: Consideration of Factors Which Influence Dose-Response Thresholds," Mutat. Res. 464, 53-63 (2000).

194. G. M. Pastino, A. A. Kousba, L. G. Sultatos, and E. J. Flynn, "Derivation of Occupational Exposure Limits Based on Target Blood Concentrations in Humans," Regul. Toxicol. Pharm. 37, 66-72 (2003).

195. J. M. Paull, "The Origin and Basis of Threshold Limit Values," Am. J. Ind. Med. 5, 227-238 (1984).

196. D. J. Paustenbach, "Approaches and Considerations for Setting Occupational Exposure Limits for Sensory Irritants: Report of Recent Symposia," Am. Ind. Hyg. Assoc. 62, 697-704 (2001).

197. C. H. Powell and C. L. Berry. "Non-genotoxic or Epigenetic Carcinogenesis," in B. Ballantyne, et al., Eds., General and Applied Toxicology, 2nd ed., Macmillan Reference Ltd., London, 1994.

198. I. F. H. Purchase and T. R. Auton, "Thresholds in Chemical Carcinogenesis," Regul. Toxicol. Pharmacol. 22, 199-205 (1995).

199. K. G. Rampal and J. M. Nizam, "Developing Regulations for Occupational Exposures to Health Hazards in Malaysia," Regul. Toxicol. Pharm. 46, 131-135 (2005).

200. A. G. Renwick, "The Use of an Additional Safety or Uncertainty Factor for Nature of Toxicity in the Estimation of Acceptable Daily Intake and Tolerable Daily Intake Values," Regul. Toxicol. Pharm. 22, 250-261 (1995).

201. C. Ruden, "Scrutinizing ACGIH Risk Assessments: The Trichloroethylene Case," Am. J. Ind. Med. 44, 207-213 (2003).

202. U.S. Environmental Protection Agency (EPA) Guidelines for Carcinogen Risk Assessment, EPA/630/P-03/001F (2005).

203. L. Schenk, C. Ruden, M. Gilek, and S. Ove Hansson, "Occupational Exposure Limits: A Comparative Study of the Levels Today and Development During the Past 10 Years," Toxicol. Lett. 172S, S123-S124 (2007). Abstract O31.

204. R. Schulte-Hermann, B. Grasl-Kraupp, and W. Bursch, "Dose-Response and Threshold Effects in Cytotoxicity and Apoptosis," Mutat. Res. 464, 13-18 (2000).

205. M. D. Shelby, "The Genetic Toxicity of Human Carcinogens and Its Implications," Mutat. Res. 204, 3-15 (1988).

206. T. S. Shih, K. Y. Wu, H. I. Chen, C. P. Chang, H. Y. Change, Y. S. Huang, and S. H. Liou, "The Development and Regulation of Occupational Exposure Limits in Taiwan," Regul. Toxicol. Pharm. 46, 142-148 (2006). 
207. D. J. Sivulka, B. R. Conard, G. W. Hall, and J. H. Vincent, "Species-Specific Inhalable Exposures in the Nickel Industry: A New Approach for Deriving Inhalation Occupational Exposure Limits," Regul. Toxicol. Pharm. 48, 19-34 (2007).

208. M. A. M. Smeets, J. H. A. Kroeze, and P. H. Dalton, "Setting Occupational Exposure Limits in Humans: Contributions from the Field of Experimental Psychology," Int. Arch. Occup. Environ. Health 79, 299-307 (2006).

209. T. Sofuni, M. Hayashi, T. Nohmi, et al., "Semi-Quantitative Evaluation of Genotoxic Activity of Chemical Substances and Evidence for a Biological Threshold of Genotoxic Activity," Mutat. Res. 464, 97-104 (2000).

210. P. E. Sottas, J. Lavoue, R. Bruzzi, D. Vernez, N. Charriere, and P. O. Droz, “An Empirical Hierarchical Bayesian Unification of Occupational Exposure Assessments Methods," Stat. Med. 28, 75-93 (2008).

211. G. Speit, H. Autrup, R. Crebelli, et al., "Thresholds in Genetic Toxicology: Concluding Remarks," Mutat. Res. 464, 149-153 (2000).

212. M. E. Stelljes and R. R. Wood, "Development of an Occupational Exposure Limit for n-Propylbromide Using Benchmark Does Methods," Regul. Toxicol. Pharm. 40, 136-150 (2004).

213. H. Stouten, H. Ott, C. Bouwman, and P. Wardenbach, "Reassessment of Occupational Exposure Limits," Am. J. Ind. Hyg. 51, 407-418 (2008).

214. T. K. Tang, L. H. Siang, and D. Koh, "The Development of Occupational Exposure Limits in Singapore," Regul. Toxicol. Pharm. 46, 136-141 (2006).

215. T. W. Tsin, "The Development and Implementation of Occupational Exposure Limits in Hong Kong," Regul. Toxicol. Pharm. 46, 114-119 (2006).

216. D. Walters and K. Grodzki, Beyond Limits? Dealing with Chemical Risks at Work in Europe, Elsevier, Oxford, 1996.

217. C. C. Willhite, "Origin and Derivation of TLVs and AEGLs Intended to Prevent Sensory Irritation," Am. Ind. Hyg Assoc. J., (in preparation).

218. J. A. Wiltse and V. L. Dellarco, "U. S. Environmental Protection Agency's Revised Guidelines for Carcinogen Risk Assessment: Evaluating a Postulated Mode of Carcinogenic Action in Guiding Dose-Response Extrapolation," Mutat. Res. 464, 105-115 (2000).

219. O. Wong, "The Development and Regulation of Occupational Exposure Limits in Asia," Regul. Toxicol. Pharm. 46, 105-106 (2006).

220. H. Yanagida, A. Yamasaki, and Y. Yanagisawa, "Methodology for Predicting OEL from Rodent $\mathrm{LD}_{50}$ Values for Metals and Metallic Compounds," Environ. Sci. Technol. 39, 371-376 (2005).

221. R. Zito, "Low Doses and Thresholds in Genotoxicity: From Theories to Experiments," J. Exp. Clin. Cancer Res. 20, 315-325 (2001).

222. Crump, K., and Allen, B. 1984. Quantitative Estimates of Risk of Leukemia from Occupational Exposure to Benzene. OSHA Docket H-059b, Exhibit 152 (Appendix B). Washington, D.C.

223. Williams, P. R. and D. J. Paustenbach. 2003. Reconstruction of benzene exposure for the Pliofilm cohort (1936-1976) using Monte Carlo techniques. J. Toxicol. Environ. Health A. 66(8): 677-781.

224. D. Paustenbach, Methods for setting limits for acute and chronic toxic air contaminants. Appl. Occup. Environ. Hyg. 12: 418-428 (1997). 
225. D. J. Paustenbach, P. E. Price, W. Ollison, C. Blank, J. D. Jernigan, R. D. Bass, and D Peterson. "Re-evaluation of Benzene Exposure for the Pliofilm (rubberworker) Cohort (1936-1976)." J. Toxicol. Environ. Health 36(3): 177-231 (1992).

226. P. Dalton, Evalvating the Human Response to Sensory Irritation: Implications for Setting Occupational Exposure Limits. AIAA Journal 62: 723-729 (2001).

227. V. J. Feron, J. H. E. Arts, and J. Mojet, "Approach to Setting Occupational Exposure Limits for Sensory Irritants in the Netherlands," AIAA Journal 62: 733-735 (2001).

228. Patty, F. A. (ed.): Industrial Hygiene and Toxicology, Vol. II, Interscience Publishers, Inc., New York, NY (1949).

229. R. L. N Brandys and Y. M. Brandys, Global Occupational Exposure Limits for Over 6,000 Specific Chemicals, 2nd Edition: Occupational and Environmental Health Consulting Services 635 Harding Road, Hingdale, ILL 60521-4814 (2008).

230. J. E. Klaunig and L. M. Kamendulis. "Chemical Carcinogenesis," (Chapter 8), pp. 329382, in Casarett and Doull's Toxicology: The Basic Science of Poisons (C. D. Klaassen, ed.), Seventh edition. McGraw-Hill, New York, NY (2008).

231. M. Eisenbud. The standard for control of chronic beryllium disease. Appl. Occup. Environ. Hyg. 13: 25-31 (1998).

232. M. E. Kolanz. Introduction to beryllium: uses, regulatory history, and disease. Appl. Occup. Environ. Hyg. 16: 559-67 (2001).

233. D. J. Paustenbach, A. K. Madl, and J. F. Greee. Identifying and appropriate occupational exposure limit (OEL) for beryllium: data gaps and current research initiatives. Appl. Occup. Environ. Hyg. 16: 527-38 (2001).

234. P. K. Henneberger, D. Cumro, D. D. Deubner, M. S. Kent, M. McCawley, and K. Kreiss. Beryllium sensitization and disease among long-term and short-term workers in a beryllium ceramics plant. Int. Arch. Occup. Environ. Health 74: 167-76 (2001).

235. C. Saltini and M. Amicosante. Beryllium disease. Am. J. Med. Sci. 321: 89-98 (2001).

236. J. Sahmel, and M. Boeninger, "Dermal Exposure Assessment" (Chapter 12) pp. 137-161. In: A Strategy for Assessing and Managing Occupational Exposures. [Bullock, W.H. and Ignacio, J.S., editors]. Amer. Ind, Hygiene Assn. Press Fairfax VA. (2006).

237. J. N. McDougal, M. F. Boeninger. Methods for assessing risks of dermal exposures in the workplace. Crit. Rev. Toxicol. 32: 291-327 (2002).

238. J. Michaels, Control Banding. April issue. Synergist. American Ind. Hygiene Assoc. (2009).

239. ECHA (2008g). Guidance on Information Requirements and Chemical Safety Assessement, Chapter R. 8: Characterization of Dose [Concentration]-Response for Human Health (ECHA). http://guidance.echa.europa.eu/docs/guidance document/ information requirements $\mathrm{r} 8$ en.pdf?vers $=200808$.

240. E. K. Weisburger, History and Background of the TLV Committee of the American Conference of Governmental Industrial Hygienists, Chemical Health and Safety, 2001, p. $10-12$. 
